\title{
Impact of Natural Fracture Induced Elastic Anisotropy on Completion and Hydraulic Fracturing Designs
}

\author{
Emre Can Dundar \\ ecd0003@mix.wvu.edu
}

Follow this and additional works at: https://researchrepository.wvu.edu/etd

Part of the Petroleum Engineering Commons

\section{Recommended Citation}

Dundar, Emre Can, "Impact of Natural Fracture Induced Elastic Anisotropy on Completion and Hydraulic Fracturing Designs" (2019). Graduate Theses, Dissertations, and Problem Reports. 3826.

https://researchrepository.wvu.edu/etd/3826

This Thesis is protected by copyright and/or related rights. It has been brought to you by the The Research Repository @ WVU with permission from the rights-holder(s). You are free to use this Thesis in any way that is permitted by the copyright and related rights legislation that applies to your use. For other uses you must obtain permission from the rights-holder(s) directly, unless additional rights are indicated by a Creative Commons license in the record and/ or on the work itself. This Thesis has been accepted for inclusion in WVU Graduate Theses, Dissertations, and Problem Reports collection by an authorized administrator of The Research Repository @ WVU. For more information, please contact researchrepository@mail.wvu.edu. 
Impact of Natural Fracture Induced Elastic Anisotropy

on

Completion and Hydraulic Fracturing Designs

Emre Can Dundar

Thesis Submitted

to the Benjamin M. Statler College of Engineering and Mineral Resources at West Virginia University

in partial fulfilment of the requirements for the degree of

Master of Science

in

Petroleum and Natural Gas Engineering

Ming Gu, Ph.D., Chair

Ali Takbiri, Ph.D.,

Huseyin Ilkin Bilgesu, Ph.D.

Petroleum and Natural Gas Engineering Department

Morgantown, West Virginia

2019

Keywords: Anisotropy, Natural Fracture, Shale, Sonic Log, Minerology, Orthorhombic Model, Geomechanics, Stress Contrast, Hydraulic Fracturing, Completion

Copyright 2019 Emre Can Dundar 


\section{Abstract}

\section{Impact of Natural Fracture Induced Elastic Anisotropy \\ on \\ Completion/Hydraulic Fracturing Design}

\section{Emre Can Dundar}

Shale has been usually recognized as a transverse isotropic (TI) medium in conventional geomechanical log interpretation due to its laminated nature. However, when natural fractures (NFs) exist in the rock body, additional elastic anisotropy can be introduced, converting Shale to an orthorhombic (OB) medium. Previous study illustrates that treating the naturally fractured shale rock as a TI medium by ignoring the NF-induced anisotropy can cause the erroneous estimation of the geomechanical properties (i.e. Young's modulus, Poisson's ratio, brittleness index, and etc.) and in-situ stress. In this paper, the study is extended to quantify the impact of NF-induced elastic anisotropy on completion and frac designs in different actual shale reservoirs in U.S.

Published acoustic log data from five different shale formations (Bakken, Marcellus, Haynesville, Eagle Ford, and Niobrara) are collected and examined to determine their availability to generate the stiffness tensor of the representative TI background rock of each Shale reservoir. Natural fractures with different intensity values from 0 to 10 per foot, with shear wave splitting ranging from $0-5 \%$, are introduced in the $\mathrm{TI}$ background rock to create the corresponding OB rock stiffness tensor. The OB stiffness tensors of different shale cases are finally converted back to the compressional and shear acoustic signals, which can be interpreted based on the TI or OB assumptions. The final output elastic moduli and in-situ stress results interpreted from different assumptions are compared, and the impact of NF-induced elastic anisotropy on completion and fracturing designs is quantified and fully understood for different shales.

The results show that the higher the natural fracture intensity within the shale rock body, the outcomes interpreted from $\mathrm{TI}$ and $\mathrm{OB}$ models are more deviated from each other. In addition to that, the impact of natural fracture induced anisotropy on geomechanical log interpretation is different in different shale reservoirs. Specifically, the magnitudes of Young's modulus are overestimated for all five shale when ignoring natural fracture induced anisotropy in log interpretation. The overestimation is different for different layers of a single shale formation as well as different shales. Similarly, the magnitudes of the minimum horizontal stress are also overestimated by different extents for different shales. Moreover, ignoring natural fracture induced anisotropy leads to incorrect interpretation of stress contrast. The stress depth profiles of all five shales are identified for upper, middle, and lower zones. The stress difference between upper and middle zones (upper stress contrast) and between middle and lower zones (lower stress contrast) are calculated and compared for $\mathrm{TI}$ and $\mathrm{OB}$ models. It is interesting to observe a complex NF induced anisotropy impact on stress contrast interpretation. For example, both upper and lower stress 
contrasts are overestimated for Bakken and Marcellus Shales, with a higher overestimation for Bakken. In contrast, both upper and lower stress contrasts are underestimated for Eagle Ford and Niobrara Shales, with a slightly higher underestimation for Niobrara. Regarding to Haynesville Shale, there is almost no impact on upper stress contrast, whereas a significant overestimation for lower stress contrast. Such complexity of impacts is believed to be closely associated with the mineralogy of the shale rocks as well as their lithology sequence across the identified upper, middle, and lower zones. Future study is needed to investigate the inherent relation between the NF induced impact and rock mineralogy. Because Young's modulus, minimum horizontal stress, and stress contrast are all critical parameters for completion and hydraulic fracturing designs, ignoring natural fracture induced anisotropy can result in different kinds of erroneous or suboptimal designs for different shale reservoirs, which is also discussed and concluded in the thesis. The current study not only illustrates the importance of taking natural fracture induced anisotropy into account when performing geomehcanical log interpretation, but also provides guidance to the operators of the current five fields to better evaluate their current completion/fracturing design strategies and to determine if the natural fracture induced anisotropy impact should be corrected for their current designs or not, based on the monitored splitting of shear fast and slow wave slowness. 


\section{Dedication}

This thesis is dedicated to my dear parents, Engin and Nurten Dundar; and to my siblings Oguzhan and Merve Nur Dundar. 


\section{TABLE OF CONTENTS}

Abstract flation.

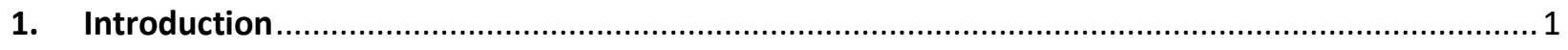

1.1 General Information of the Oil and Gas production in the USA ...................................... 1

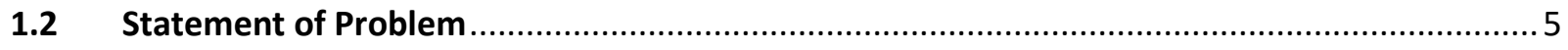

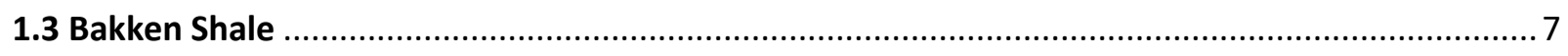

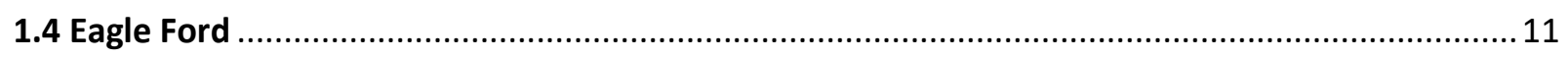

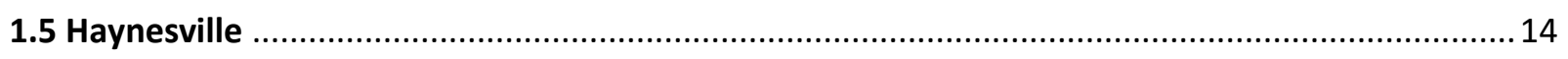

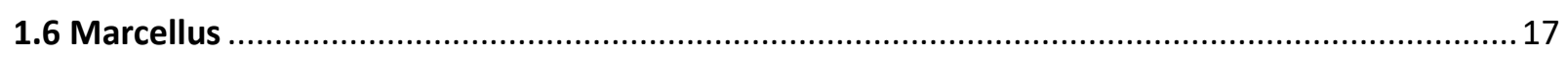

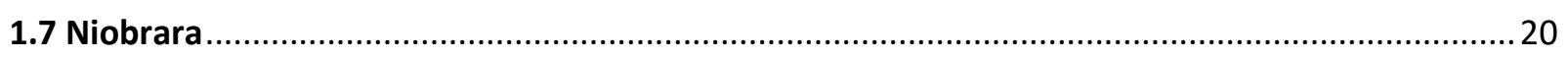

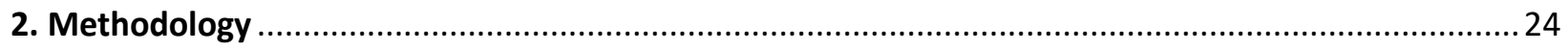

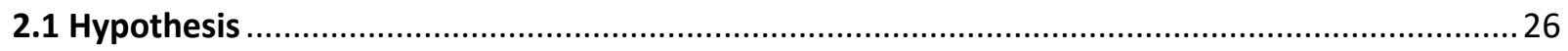

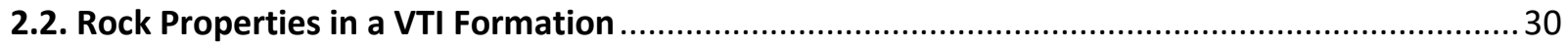

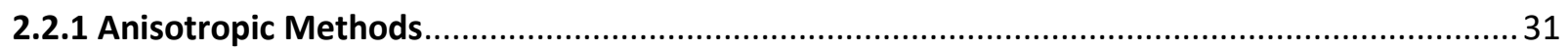

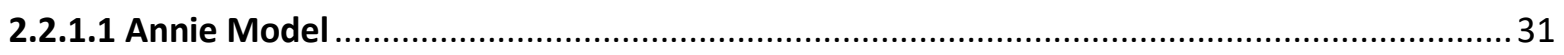

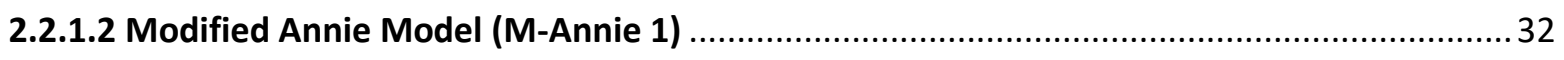

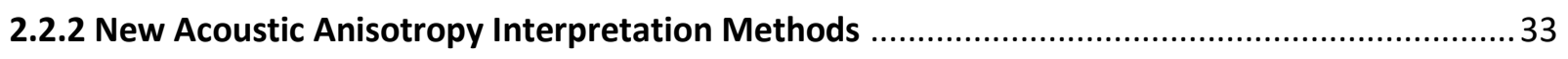

2.2.2.1 Modified Annie-2 Model (Further Modified Annie Method) ........................................... 33

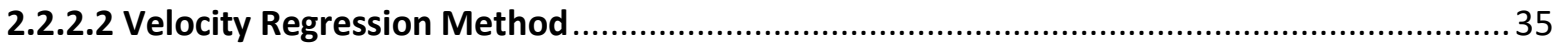

2.2.2.3 Integration Method (Combination of V-reg and M-Annie-2) .......................................... 36

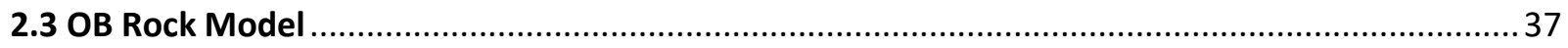

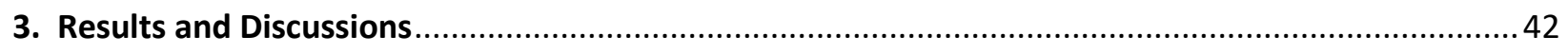

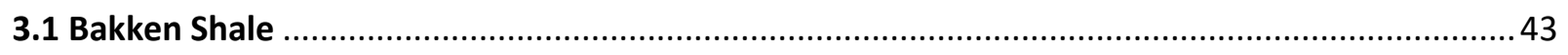

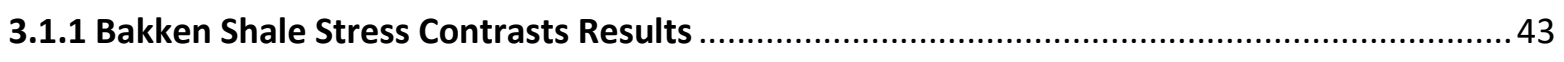

3.1.2 Young's Modulus approach for NFs impact on the Bakken Shale ....................................... 46

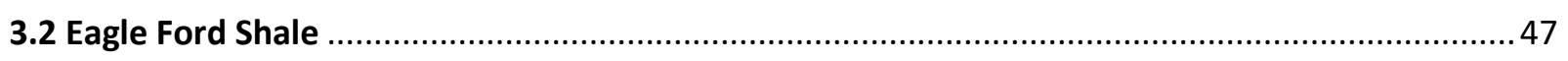

3.2.1 Eagle Ford Shale Stress Contrasts Results ................................................................ 47 
3.2.2 Young's Modulus approach for NFs impact on the Eagle Ford Shale

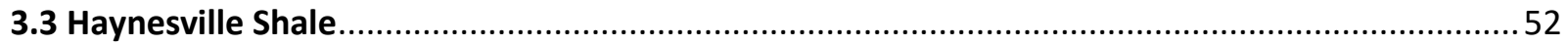

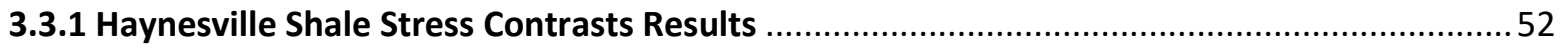

3.3.2 Young's Modulus approach for NFs impact on the Haynesville Shale .................................56

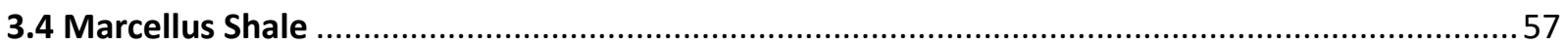

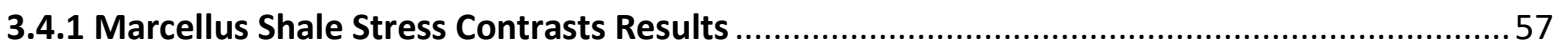

3.4.2 Young's Modulus approach for NFs impact on the Marcellus Shale...................................61

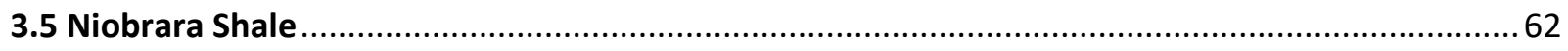

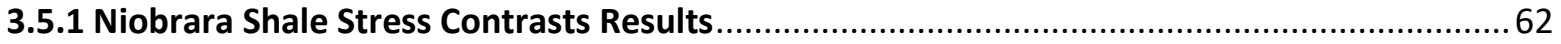

3.5.2 Young's Modulus approach for NFs impact on the Niobrara Shale ...................................66

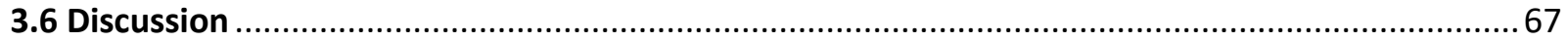

3.6.1 Natural Fracture Induced Anisotropy Impact on Stress Contrast and Young's Modulus .......67

3.6.2 Investigation of Inherent relationship between NF induced anisotropy impact and

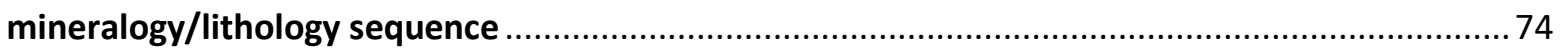

3.6.3 Investigation of NF induced anisotropy impact on operational designs............................. 77

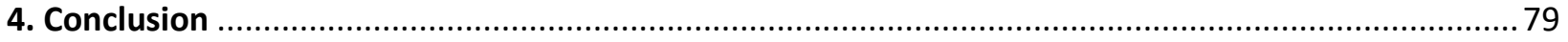

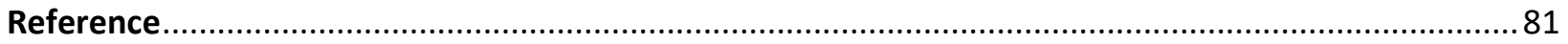




\section{LIST OF FIGURES}

Figure 1: World energy demand prospection. (EIA, International Energy Outlook 2017) ......................... 2

Figure 2: World oil and gas basins. (EIA. Recoverable Shale Oil and Shale Gas Resources 2013) ................ 3

Figure 3: USA current shale plays (EIA, US Shale Oil and Natural Gas Maps 2015) .................................. 3

Figure 4: Five Shale Formation in the U.S. (EIA, drilling productivity report 2019) ................................... 4

Figure 5: Natural Fractures are perpendicular to the direction of the shale lamination in the shale

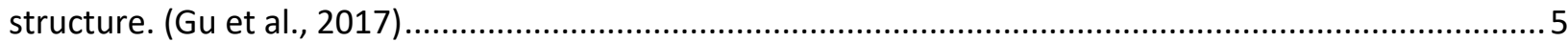

Figure 6: Bakken Shale in Williston Basin (Polzin., 2018) ............................................................... 7

Figure 7: Bakken Shale Depositional Environment (EERC, The Bakken Oil History 2014 ) .........................8

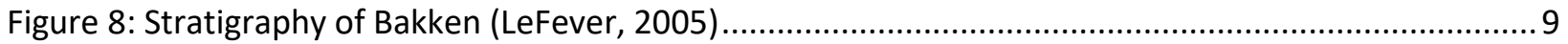

Figure 9: Ternary Diagram of Sandstone distribution in Middle Bakken (Saidian et al., 2016)................10

Figure 10: Bakken Shale field sonic log data (Ramakrishna et al., 2010) ...........................................10

Figure 11: Eagle Ford Shale Play, hydrocarbon types and the location in the South of the Texas. (Mullen

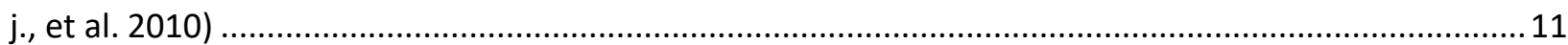

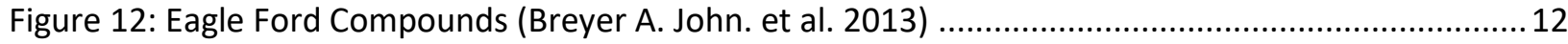

Figure 13: Eagle Ford Shale sonic log data (Brooks et al., 2015) .........................................................13

Figure 14: Late Jurassic Structural Elements and the Haynesville Shale Productive area (red stripped

area, which is the area located in the middle of the Texas and the Louisiana, Hammes et all., 2011)......14

Figure 15: Haynesville minerology analyses (Saidian et al., 2016) .....................................................16

Figure 16: Haynesville Shale Sonic Log Data (Ramirez et al., 2011).....................................................16

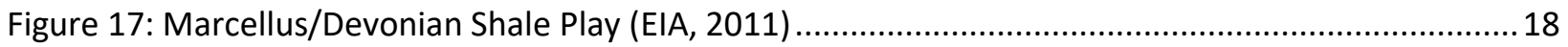

Figure 18: The Marcellus Shale Rock Composition (Wang et al., 2013) ................................................19

Figure 19: Western Interior Cretaceous Seaway's Location (Sonnenberg, 2013) ....................................20

Figure 20: Schematic cross-section of Calcareous Niobrara Shale (modified from Kauffman, 1977;

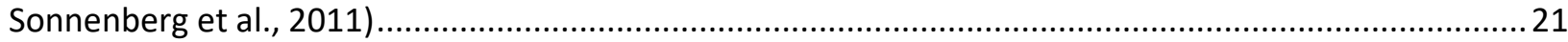

Figure 21: Niobrara Shale rock composition (Saidian et al., 2016) .......................................................22

Figure 22: Niobrara Shale Sonic Log Data (Mc.Clave et al., 2014) .......................................................23

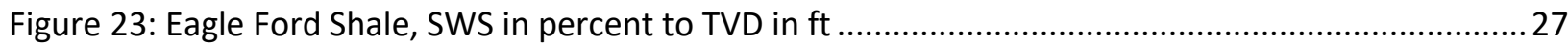

Figure 24: Eagle Ford OB and TI model assumption for SWS in percent to Stress Barriers in psia ...........27

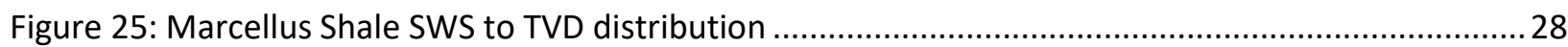

Figure 26: Marcellus OB and TI model assumption for SWS in percent to Stress Barriers in psia .............29

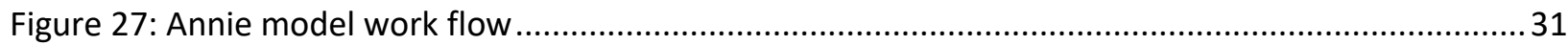

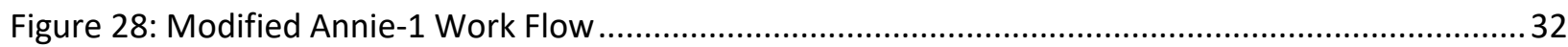

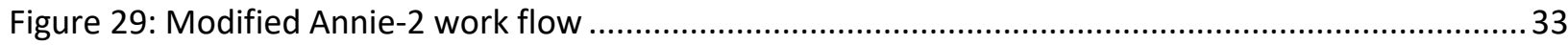

Figure 30: Velocity Regression model work flow (Gu et al., 2016).....................................................35

Figure 31: Fracture compliance as a function of the fracture dimension on field and laboratory data

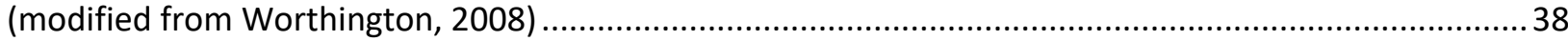

Figure 32: Minimum horizontal stress vs. TVD plot of the Bakken Shale..............................................43

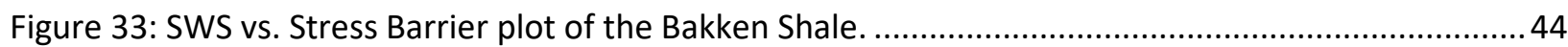

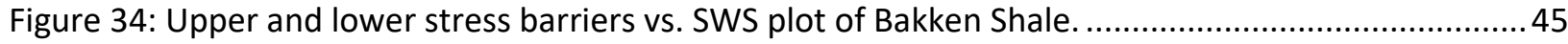

Figure 35: Bakken Shale's Young's Modulus distribution vs. SWS\% ....................................................46

Figure 36: Minimum horizontal stress vs. TVD plot of the Eagle Ford Shale ...........................................47 
Figure 37: SWS vs. Stress Barrier plot of the Eagle Ford Shale

Figure 38: Upper and lower stress barriers vs. SWS plot of Eagle Ford Shale ......................................49

Figure 39: Stress contrasts of OB and TI within the Eagle Ford versus TVD while the SWS is 1 percent ...50

Figure 40: Stress contrasts of OB and TI within the Eagle Ford versus TVD while the SWS is 2 percent ...50

Figure 41: : Eagle Ford Shale's Young's Modulus distribution vs. SWS\% ..............................................5

Figure 42: Minimum horizontal stress vs. TVD plot of the Haynesville Shale. ........................................52

Figure 43: SWS vs. Stress Barrier plot of the Haynesville Shale.......................................................... 53

Figure 44: Upper and lower stress barriers vs. SWS plot of Haynesville Shale.......................................5 54

Figure 46: Stress contrasts of OB and TI within the Haynesville Shale versus TVD while the SWS is 4.23

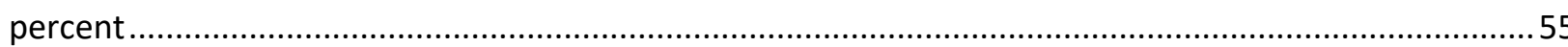

Figure 45: Stress contrasts of OB and TI within the Haynesville Shale versus TVD while the SWS is 1.25

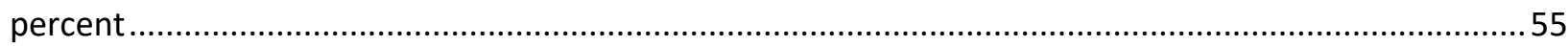

Figure 47: Young's Modulus approach for NFs impact on the Haynesville Shale....................................56

Figure 48: Minimum horizontal stress vs. TVD plot of the Marcellus Shale ...........................................57

Figure 49: SWS vs. Stress Barrier plot of the Marcellus Shale...............................................................58

Figure 50: Upper and lower stress barriers vs. SWS plot of Marcellus Shale........................................59

Figure 52: Stress contrasts of OB and TI within the Marcellus Shale versus TVD while the SWS is 1.37

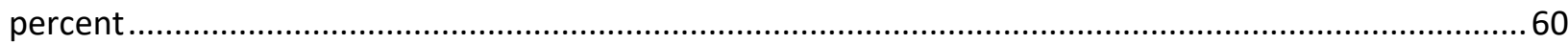

Figure 52: Stress contrasts of $O B$ and TI within the Marcellus Shale versus TVD while the SWS is 4.18

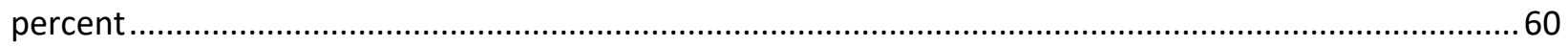

Figure 53: Young's Modulus approach for NFs impact on the Marcellus Shale .....................................61

Figure 54: Minimum horizontal stress vs. TVD plot of the Niobrara Shale. ...........................................62

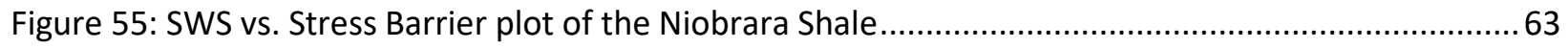

Figure 56: Upper and lower stress barriers vs. SWS plot of Niobrara Shale...........................................64

Figure 57: Stress contrasts of OB and TI within the Niobrara Shale versus TVD while the SWS is 1.37

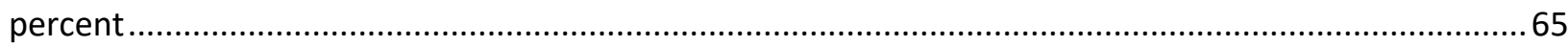

Figure 58: Stress contrasts of OB and TI within the Niobrara Shale versus TVD while the SWS is 4.16

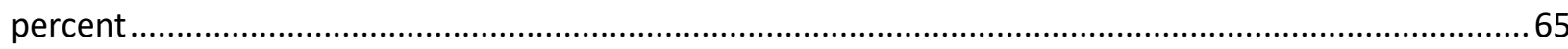

Figure 59: Young's Modulus approach for NFs impact on the Niobrara Shale.......................................66

Figure 60: Difference of Upper Stress Contrasts of the Shales.........................................................68

Figure 61: Deviation of TI treated shales from OB treated correction line -red dashed line-...................68

Figure 62: Mineral-based model results of the Haynesville Shale, provided by two different companies.

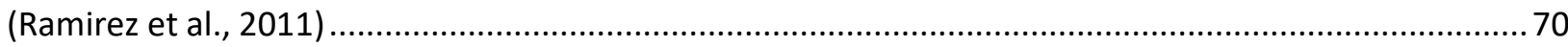

Figure 63: Horizontal Young Modulus differences vs. SWS\% for the upper zones of the five shales ........71

Figure 64: Horizontal Young's modulus vs. SWS\% for the middle zones of the five shales ......................72

Figure 65: Horizontal Young's modulus vs. SWS\% for upper zone of the five shales ...............................73

Figure 66: The mineralogy/lithology logs for Bakken (modified from Ramakrishna et al., 2010),

Haynesville (modified from Ramirez et al., 2011), and Marcellus Shale ................................................ 74 


\section{LIST OF TABLES}

Table 1: Average General Properties of the Bakken Shale (Kocoglu et al., 2013) ................................... 9

Table 2: Average General Properties for the Eagle Ford Shale Play (EIA, 2011)....................................13

Table 3: Average General Properties for the Haynesville Shale Play (EIA, 2011) ....................................15

Table 4: State Distribution of the Marcellus Shale Play (EIA, 2011) .....................................................17

Table 5: Average General Properties for the Marcellus Shale Play (EIA, 2011) ...................................... 18

Table 6: Average General Properties of the Niobrara Shale (CloverGS et al., 2013)...............................21

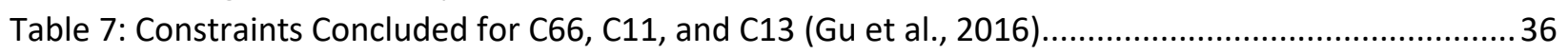

Table 8: Mohs Harness Scale ......................................................................................................69

Table 9: Conclusion of prediction errors of stress contrast and Young's modulus, and

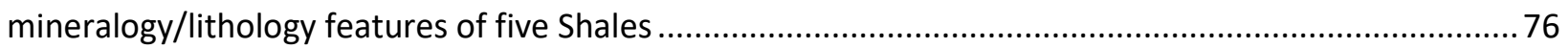

Table 10: Conclusion of prediction errors of stress contrast and Young's modulus, and resulted problematic operational designs of five Shales .................................................................................. 78 


\section{ACKNOWLEDGEMENT}

I would like to acknowledge my advisor, Dr. Ming Gu for his guidance and support throughout my MS study. With his unreserved knowledge and perpetual feedbacks this thesis becomes possible.

I also would like to thank my committee members; Dr. Huseyin Ilkin Bilgesu and Dr. Ali Takbiri for their knowledge which helped me to start and conclude this study.

I want to state my appreciation to National Education Ministry of Turkey and General Directorate of mineral research and exploration (MTA) for their support to my MS study.

The last but not the least, I acknowledge the great contribution of the Department of Energy (DOE) for their sponsorship of MSEEL project. 


\section{Introduction}

This chapter gives a general information of shale reservoirs and a brief history of skyrocketing shale oil and shale gas industry. In addition to that, this chapter will conclude the need of this study and how to apply on the real case shale formations.

Shales are the most widespread sedimentary rocks across the globe. Most US shale plays vary prospects in terms of solid maturity regions. The breakthrough novelties are also shortly mentioned in the following part of the thesis. With the new perspective, source rock richness identification and optimal zone description also changed. (Gupta et al., 2018).

Shale reservoirs and other tight reservoirs have been in the interest of the petroleum, natural gas, coalbed methane and even geothermal industry since its frequent spread around across the world, and its promising reserve potentials. After many attempts, other than a small amount of hydrocarbon producing were not possible in a small number of the shale reservoirs in Kansas, Oklahoma, North Texas, and Arkansas.

\subsection{General Information of the Oil and Gas production in the USA}

Oil and gas industry were expeditiously developed with the increasing demand of energy alongside the technological developments in the last part of the 19th century and 20th century. The first examples of fossil product uses exist in the steam engines and steam-powered factories. The primarily produced petroleum products, like kerosene and natural gas which come with the water and brine in the first type of the salt wells as in the example of the Burning Springs in West Virginia, are used for the basic need of the city people, and pharmaceutics. For example, gas lightening by the roads was one of the first examples of oil and gas use in the cities.

Moreover, petroleum and natural gas production and technology grew parabolically with the technological developments at the end of the 19th and 20th centuries. Until the 21st century, most of the production is made by the conventional reservoirs which were the most known, unrivaled and very cheap to produce since their conventional structure to produce oil and gas.

However, since shale formations have low porosity and low permeability features in general, the production used to be challenging and not economic. Hence, the unconventional methods are developed in the beginning of the 21st. century in the south of the U.S, so in the North Texas, Kansas, Oklahoma, and Arkansas, this first success was recorded, and the application has been developing since then, so the production and the economical return from the shale reservoirs has been increasing day by day. 
Since the production in shale oil and shale gas skyrocketed, the oil and gas prices around the world decreased. Horizontal drilling and hydraulic fracturing have been becoming cheaper day by day with the improvements of the technology, and the widespread use of those new methods in the oil and gas industry. Thus, thanks to hydraulic fracturing, horizontal drilling, and the other improvements in the technology; tight formation hydrocarbons, shale oil and shale gas has become more available than they were before. More locations which were conventionally unable to be produced has become producible for oil and gas industries with the help of unconventional reservoir methods. In addition to the production, the demand for oil and gas also keep growing year to year. (Figure 1).

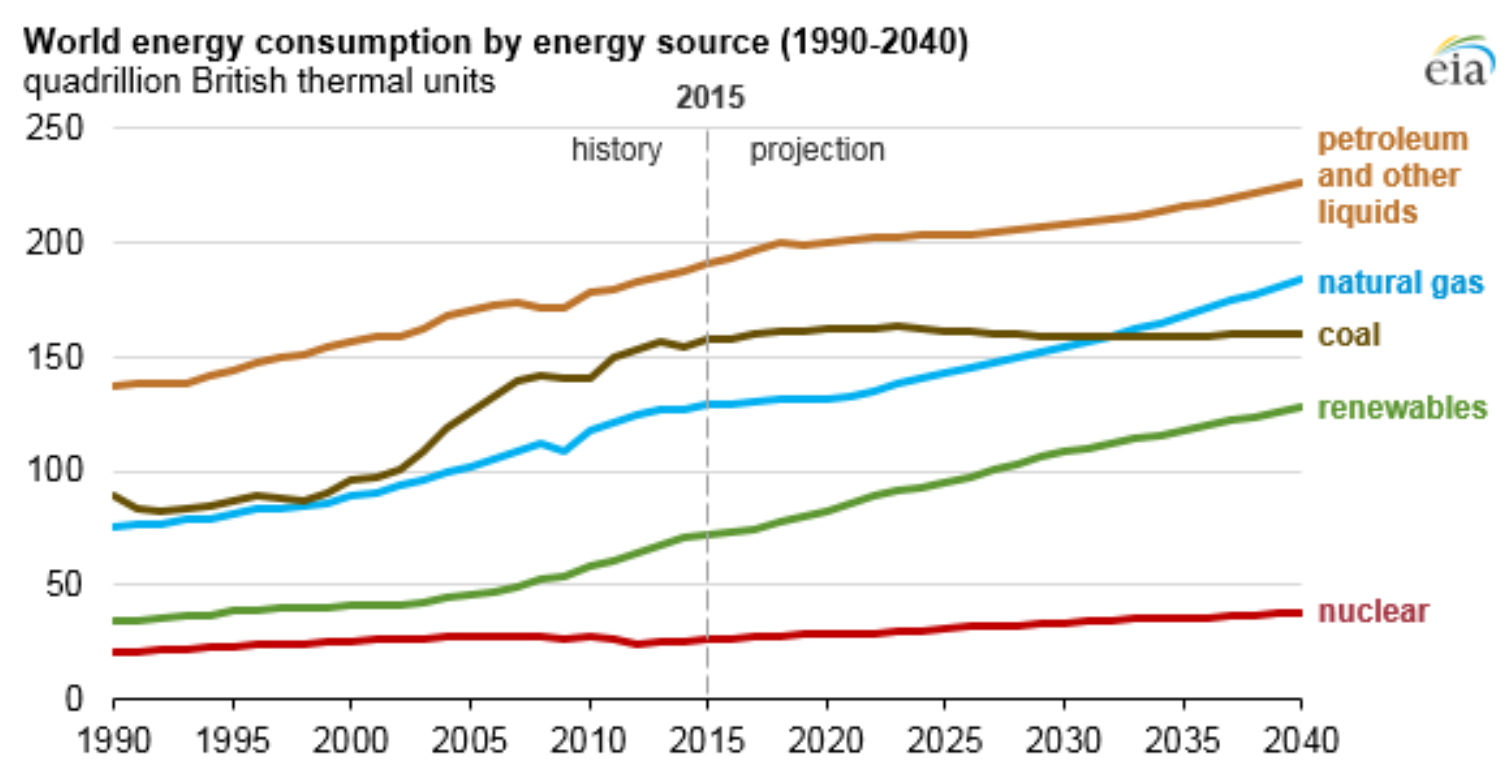

Figure 1: World energy demand prospection. (EIA, International Energy Outlook 2017)

High demand has been driving the oil and gas industry to discover new locations and drilling new wells all around the world. This boost increases the unconventional reservoir production wells as well as the conventional areas. (Figure 2). There are the most recent basins including oil and gas around the world. The number of the area that is subjected of the drilling operation has been increasing since the new horizontal drilling and hydraulic fracturing methods were developed in the oil and gas industry. 


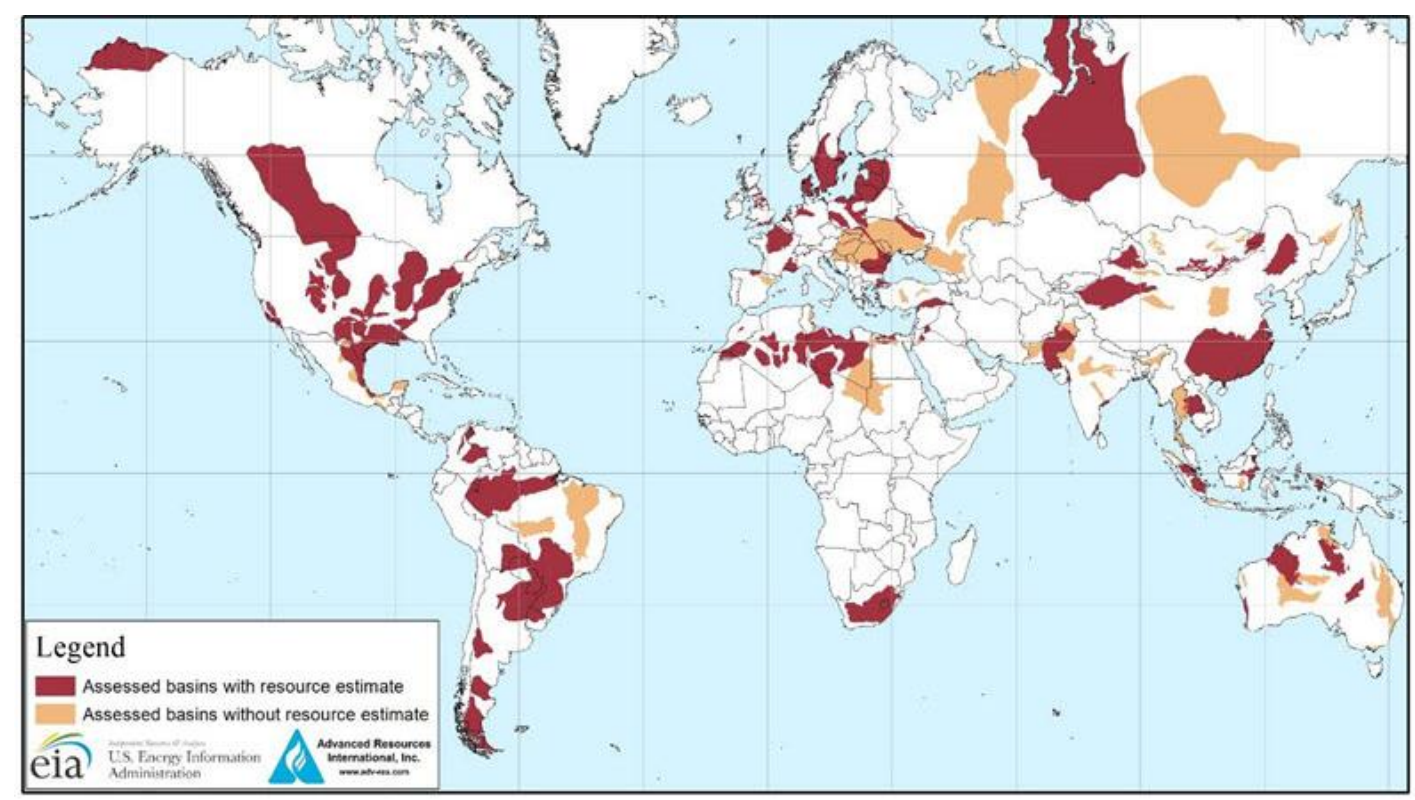

Figure 2: World oil and gas basins. (EIA. Recoverable Shale Oil and Shale Gas Resources 2013)

Alongside the developments of oil and gas industry in the world, in the USA new basins started to be produced (Figure 3). and old productions have become more efficient (Figure 4). In the US, the researches and the eager investors have brought the unconventional shale basins to the sight of the oil and gas companies.

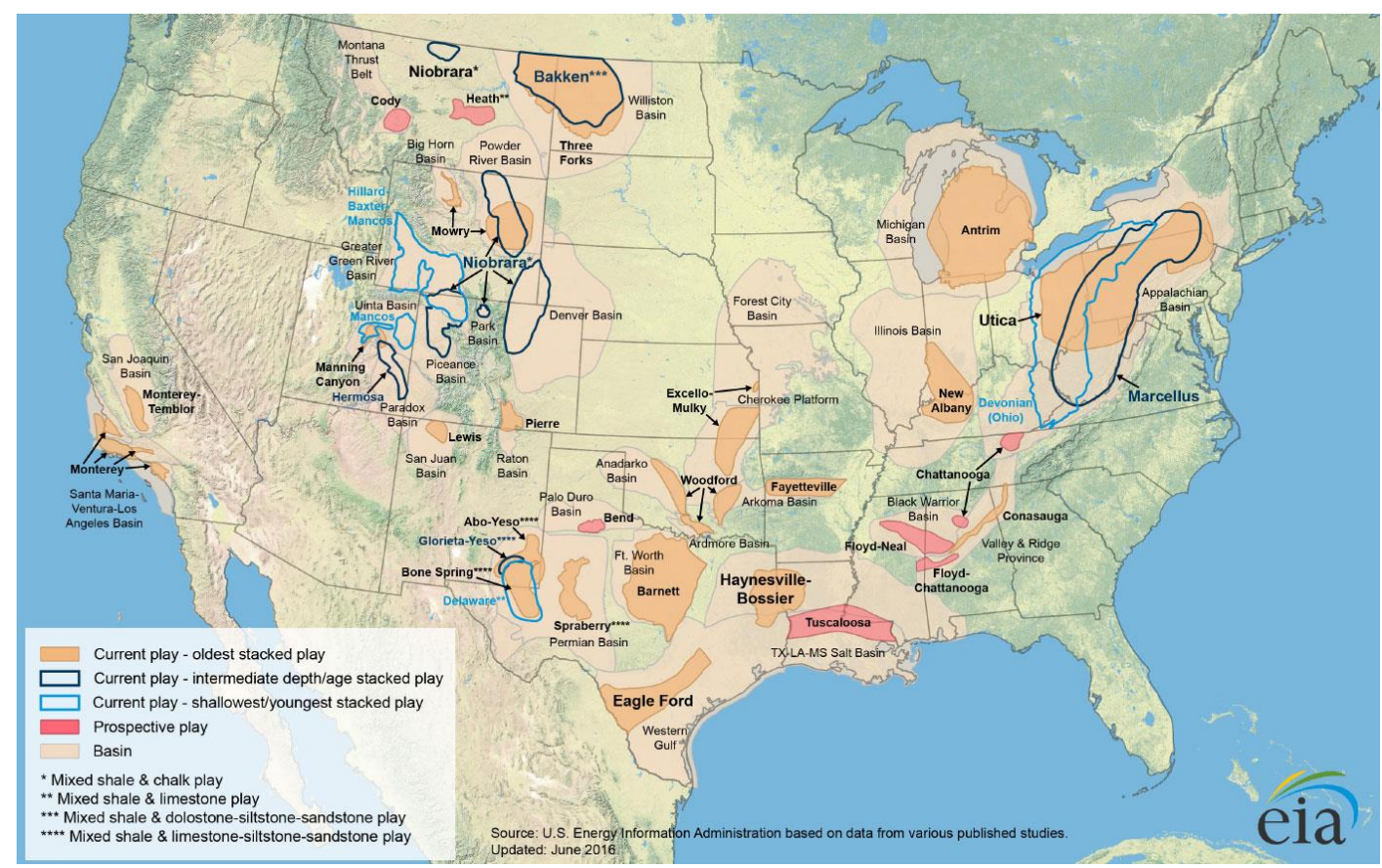

Figure 3: USA current shale plays (EIA, US Shale Oil and Natural Gas Maps 2015) 
Today, drilling operations in the shale basins have a huge expansion. The skyrocketed number of new drilling rigs are visible in almost all promising shales all over the USA. Within the increment of the shale production, five of the shales that are utilized in my study, namely, Bakken, Eagle Ford, Haynesville, Marcellus, and Niobrara are shown in Figure 4.

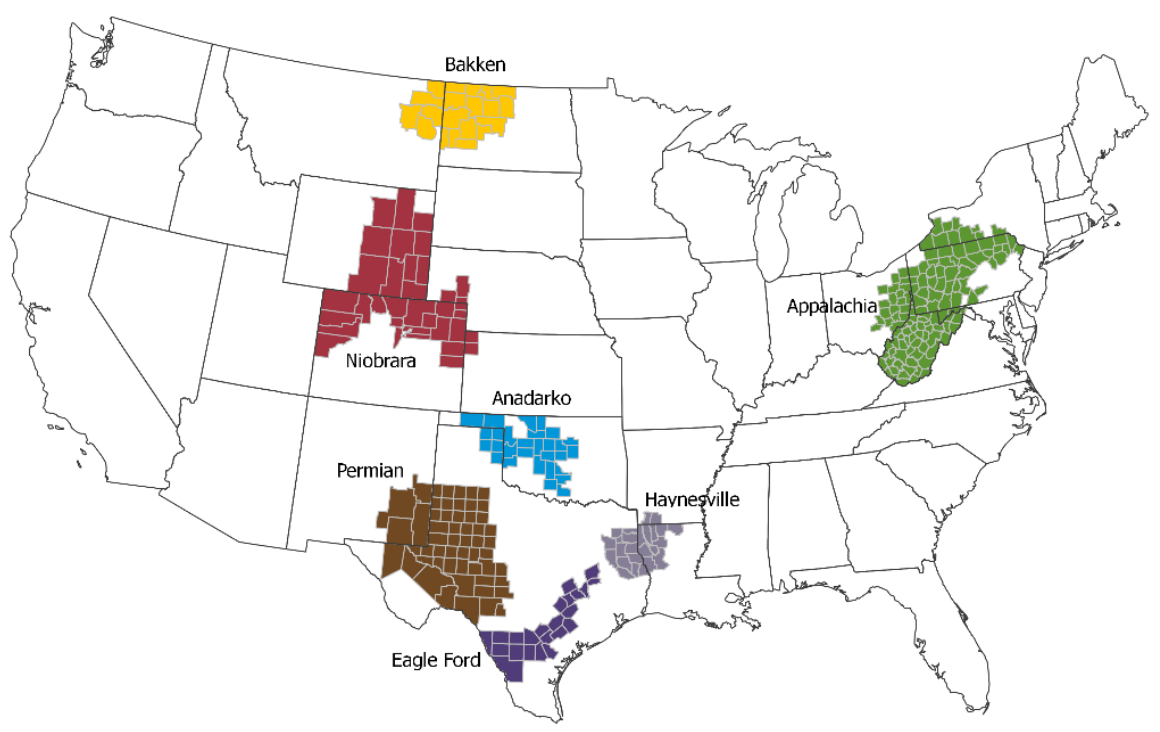

Figure 4: Five Shale Formation in the U.S. (EIA, drilling productivity report 2019) 


\subsection{Statement of Problem}

Shale, as its existence, has a laminated body which has different mechanical properties for different directions like being parallel or perpendicular to its bedding plane. This feature of laminated shale is called as transverse isotropy (TI). In the case of natural fractures' (NFs) appearance in the laminated shale body, the additional mechanical anisotropy is introduced within the bedding plane to make the shale an orthorhombic (OB) medium. Neglecting the additional natural fracture anisotropy in the shale acoustic interpretation model, the estimations of elastic modulus and in-situ stress from acoustic log data become inaccurate. This will hence cause an erroneous calculation in drilling, completion and hydraulic fracturing design.

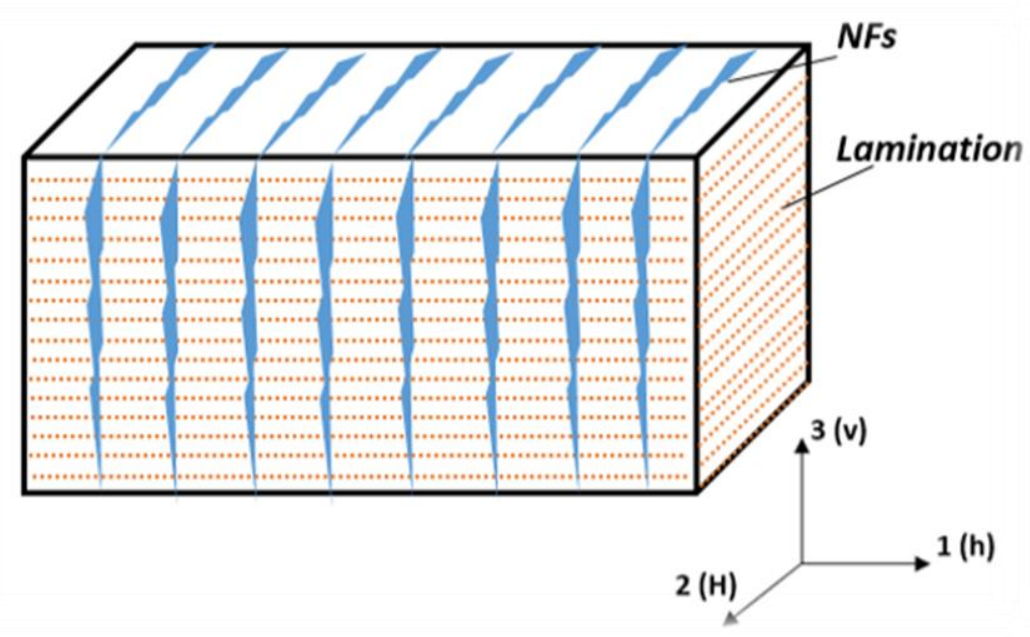

Figure 5: Natural Fractures are perpendicular to the direction of the shale lamination in the shale structure. (Gu et al., 2017)

For field applications, the acoustic and density log data combined with empirical models that are usually used to interpret the stiffness tensor, which is an important geomechanical property to describe stress-strain linear elastic relation inside a rock. Commonly used elastic modulus such as Young's modulus, Shear modulus, and Poisson's ratio are functions of independent stiffness coefficients only. For isotropic (ISO) rock model, the compressional and shear wave slowness (DTC and DTS) provide enough constraints to solve for the two independent stiffness coefficients. For TI rock model, sonic log data DTC, DTS, and DTST (Stoneley wave slowness) provide three constraints, which can be used to solve for three independent stiffness coefficients. To solve for the rest coefficients, different empirical models are proposed (Schoenberg et al., 1996, Quirein et al., 2014, and Gu et al., 2016). For OB model, sonic logging data DTC, DTS-slow (slow shear wave slowness), DTS-fast (fast shear wave slowness), and DTST can only provide four independent constraints, which can be used to solve for the four independent stiffness coefficients. Apparently, that effort is not enough to fully characterize stiffness tensor for an OB rock, which has at least nine independent stiffness coefficients. Currently, to the best of the author's knowledge, no empirical models are available to solve for the rest five stiffness coefficients. Therefore, the OB rock (i.e. shale with transverse natural fractures) are usually treated as TI or ISO rock for simplification by ignoring natural fracture induced anisotropy in geomechanical log interpretations. 
This study will investigate the natural fracture anisotropy effects on the shale reservoirs based on the former studies (Gu., 2017) and (Far et al., 2013). The effects of the natural fracture induced elastic anisotropy, on in-situ stress interpretation as well as drilling/completion/fracturing designs (Khan et al., 2012; Gu et al., 2016) will be investigated for the five different shales in the USA, which are Bakken, Eagle Ford, Haynesville, Marcellus, and Niobrara.

In order to create the stiffness tensors of $\mathrm{OB}$ model, natural fractures are introduced into the VTI background rock by a theoretical algorithm as it is shown in the former study by (Far et al., 2013). Thus, in this study, the VTI models are formed for the five different shales by utilizing the published sonic logs including DTS (shear wave slowness) and DTC (Compressional wave slowness), and density logs from the shales. The most critical hypothesis for the current study is that the current published logs were measured in the shale zones with no or negligible natural fractures.

In the results, both the VTI model which ignores the natural fracture induced anisotropy that comes with the introduced natural fracture, and the OB model which includes both directional anisotropy of which is sourced from the laminated structure of shale, and the natural fracture anisotropy are compared. In comparison, the interpreted minimum horizontal stresses and corresponding stress contrast (i.e. upper and lower stress boundaries) for $\mathrm{TI}$ and OB models are analyzed. Based on that, how Young's modulus, stress magnitude, and stress contrast respond to the natural fracture properties, which is measured by the shear wave splitting (SWS), are analyzed. Moreover, the impact of natural fracture induced elasticity anisotropy on completion and fracturing design is further analyzed. Finally, the inherent relationship between the impact of the natural fracture induced elasticity anisotropy and shale rock minerology/lithology sequence is investigated and discussed. 


\subsection{Bakken Shale}

\section{Play Description}

The Bakken Shale is named after the surface owner of Henry Bakken. Bakken Shale is one of the largest amounts of the oil discoveries of the petroleum industry, and it takes part in the Williston Basin, which is one of the most structurally simple basins in the world. The basin has an oval shape and extends to 200, 000 square miles of the subsurface of the Williston Basin, which stretches over 4 different states, namely, eastern Montana, western North Dakota, South Dakota, and southern Saskatchewan which is a southern state of Canada. Saskatchewan is also known for its rich deposit of petroleum, uranium, and potash. The deepest point of Williston Basin and the Bakken Shale are near Williston, ND.

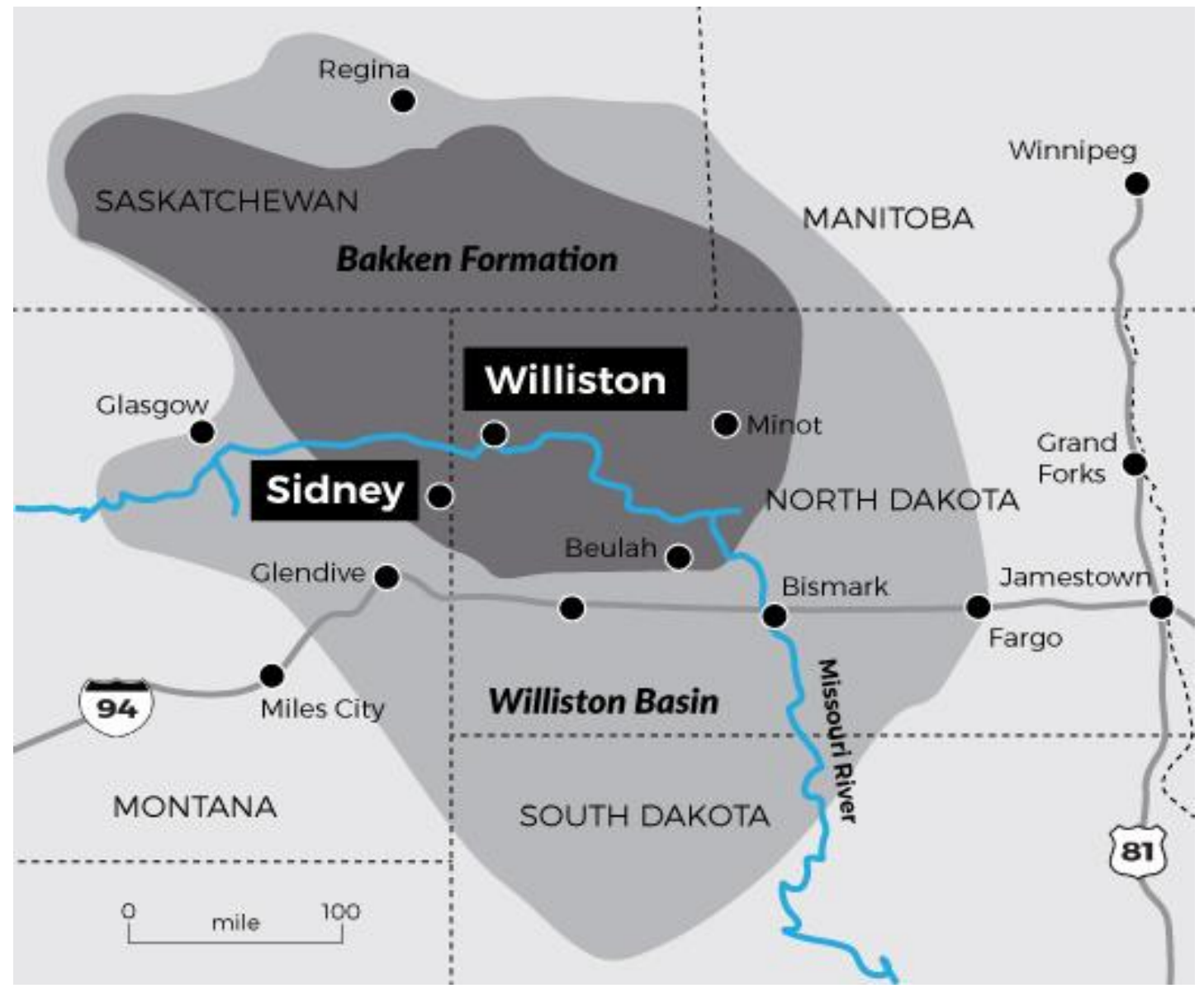

Figure 6: Bakken Shale in Williston Basin (Polzin., 2018) 
When the first discovery was made in 1951, the petroleum existence in Bakken Shale was not economic yet. Alongside the hydraulic fracturing development in the petroleum and the other improvements like horizontal drilling have made the production skyrocketed in Bakken Formation. Now, Bakken Shale is one of the most rapidly raising unconventional oil shales in the United States. Over the last five years, more than 10, 000 wells have been drilled in Bakken Shale and the estimated recovery (EUR) per well is in hundreds or thousands of BOE. Starting with about one stage per well and an average length of 4,000 feet in 2007 , the current technology uses horizontal wells extending up to 10 , 000 feet long with more than 30 stage fractures.

Fracture stages in the hydraulic fracturing design have also increased along with the increasing number of the good length of Bakken Shale. The completion cost has become a remarkable part of the total drilling and the completion costs, with the improvements of the shale production the total cost of drilling and completion have become 60-70\% more economic than before. (Ran et al., 2015).

The Williston Basin takes the place over the Precambrian base layer. Trans-Hudson Orogenic Belt shapes developed this Precambrian geologic basement layer $1.8-1.9$ billion years ago, and this major mountain building orogeny created a weak zone that later led to the cumulation of hydrocarbon at this formation, so the production became available there. The Bakken formation was deposited up to around 360 million years ago during the Devonian-Mississippian period.

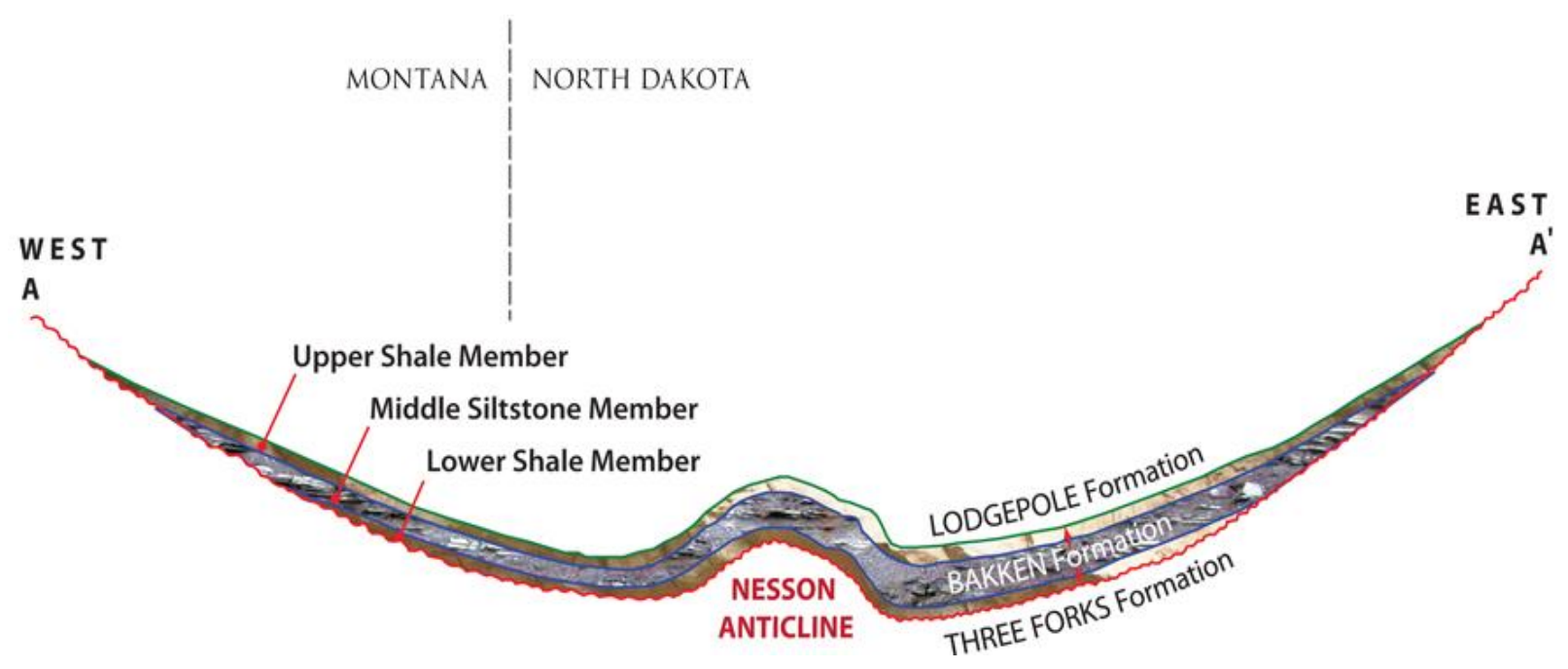

Figure 7: Bakken Shale Depositional Environment (EERC, The Bakken Oil History 2014 ) 


\section{Petrophysical and mineralogical properties}

In general, the formation has three members: The Upper Bakken, which consists of $20+\mathrm{ft}$ thick black marine shale; the Middle Bakken, which consists of a 30- to 80-ft thick interbedded layer of limestone, siltstone, dolomite, and sandstone; and the Lower Bakken, which consists of 10 to $50 \mathrm{ft}$ thick black marine shale. (Ramakrishna et al. 2010). Both the upper and lower members are rich in the total organic carbon, TOC, can rich up to $36 \%$, the middle member, on the other hand, has a lower TOC, around $1 \%$.

Table 1: Average General Properties of the Bakken Shale (Kocoglu et al., 2013)

\begin{tabular}{|l|r|}
\hline Depth (ft) & 9,000 \\
\hline Thickness (ft) & 60 \\
\hline Porosity (\%) & $5-8$ \\
\hline Total Organic Content (\% wt) & 11 \\
\hline
\end{tabular}

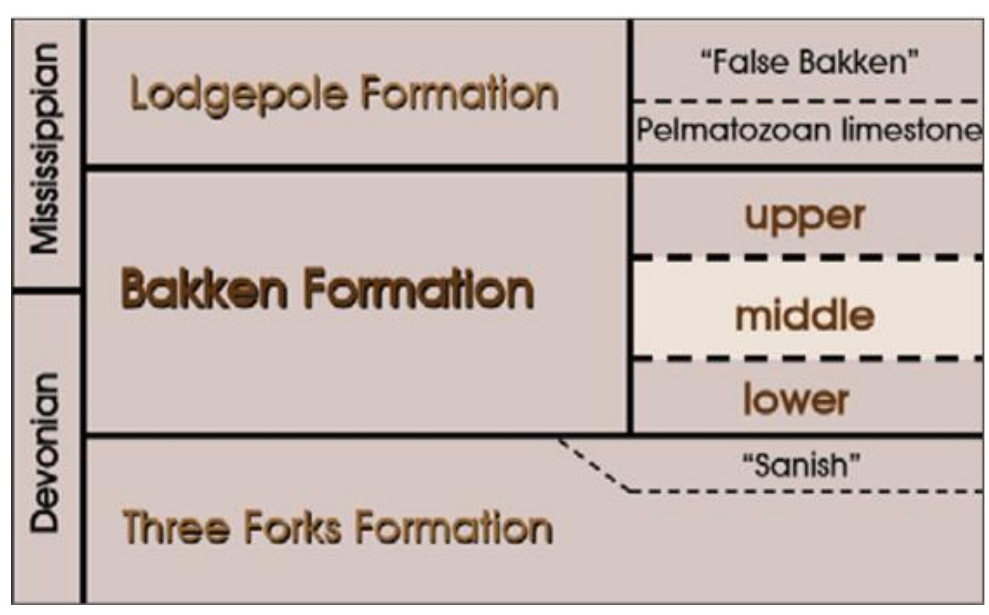

Figure 8: Stratigraphy of Bakken (LeFever, 2005)

Bakken Formation has about $5 \%$ porosity and $0.04 \mathrm{mD}$ average permeability. (Pitman et al, 2001; and Kocoglu et al., 2013) Bakken Shale porosity is determined in the range of $2-3 \%$ with onetenth of that volume or $0.2 \%$ is in microfractures. Fracture / Matrix Permeability ratio is 100 with an effective permeability for the fracture system of $0.6 \mathrm{md}$ at maximum net confining stress. Siltstones and dolomites adjacent to the Bakken Shales make a significant contribution to oil production through the extension fracture system. (Breit et al. 1992). 


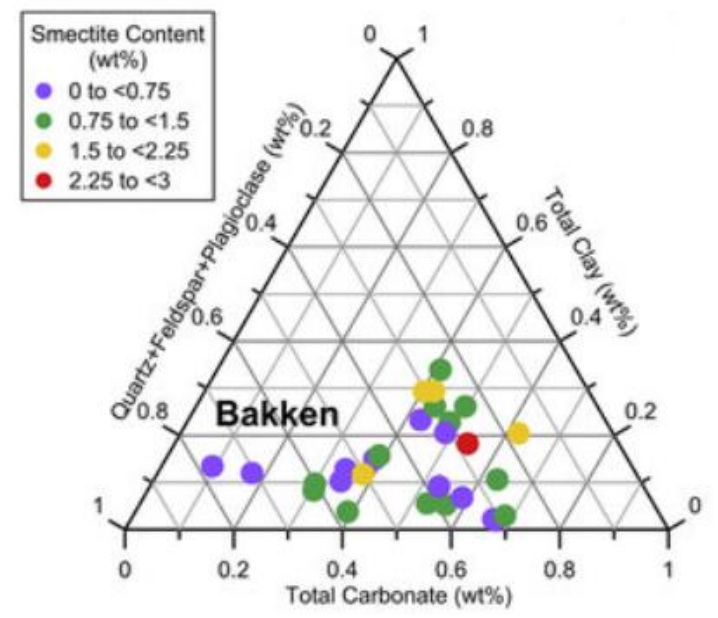

Figure 9: Ternary Diagram of Sandstone distribution in Middle Bakken (Saidian et al., 2016)

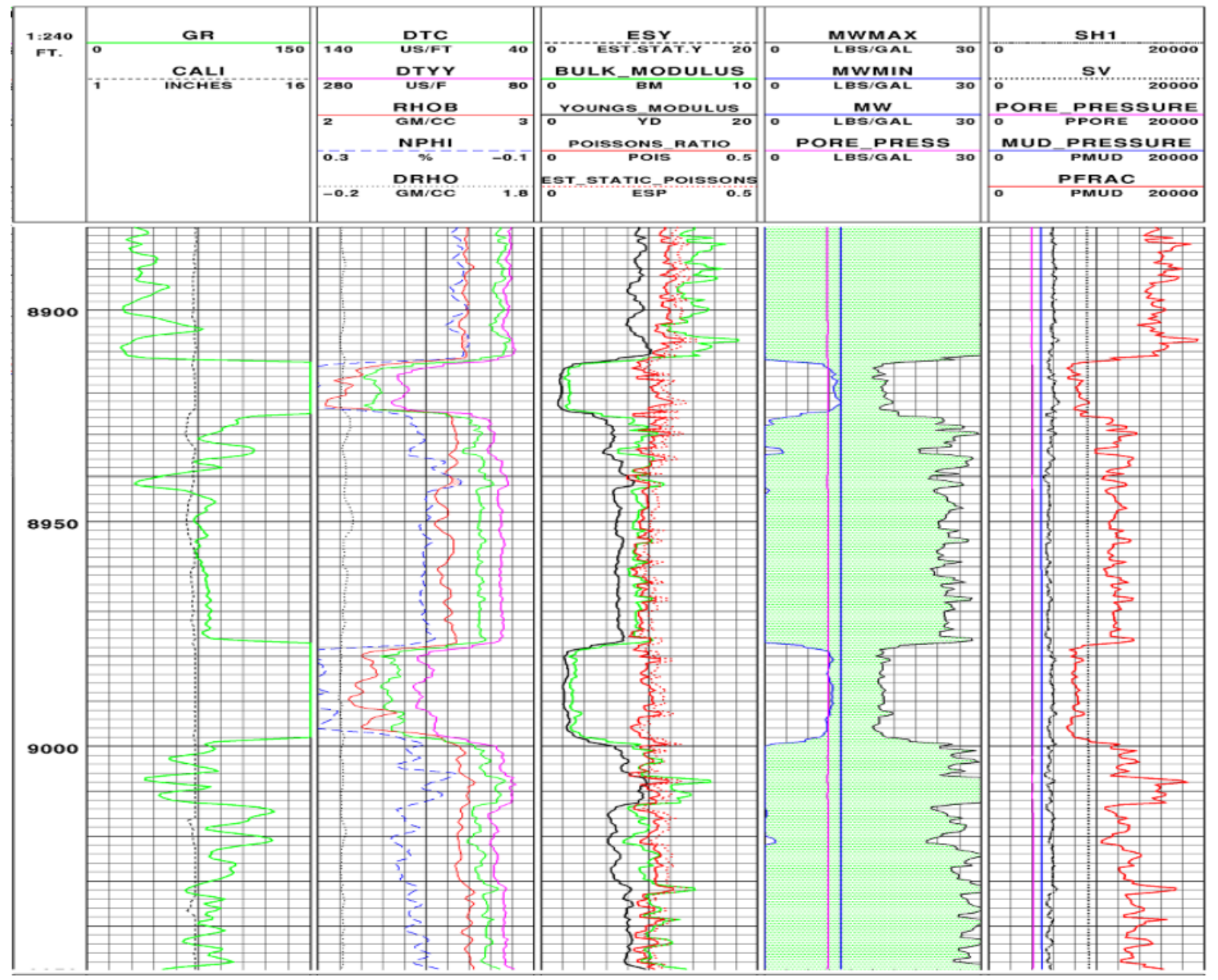

Figure 10: Bakken Shale field sonic log data (Ramakrishna et al., 2010) 


\subsection{Eagle Ford}

\section{Play Description}

The age of Eagle Ford is estimated at Cretaceous age with an existing 1.5 billion bbl. of oil, and 4.2 Tcf gas produced so far. The total body of Eagle Ford is located within the Texas Maverick Basin. The Eagle Ford Play has a high liquid component which has led to three zones, namely, an oil zone, a condensate zone, and a dry gas zone. Since the East Texas Basin includes a very high clay content compared with the rest of the Eagle Ford, so technically it is not always considered as a part of Eagle Ford. This high clay amount also caused some depositional differences along with the East Texas Basin.

The sedimentation of the Eagle Ford Basin is expected to be formed in influx sedimentation through southwest direction. (Bayer et al., 2013). Southwest part of the Eagle Ford Shale Basin was widely formed by marine shelf and slope deposits. The marine deposits are known for their rich carbonate content. South part of the deposition is slope deposits which are more mature deeper than southern shelf deposit area. As a result, the transition from gas to oil exists through the north. (Tuttle et al., 2010, and Gupta et al., 2017). High clay amount of the East Texas Basin caused a high clay fraction in the basin, so at this part of the basin, the form was mainly developed as deltaic deposition.

Eagle Ford Shale is relatively a newer shale play than Barnet which has been produced since the 1980s and Haynesville which had been produced since 2005. Since Eagle Ford started to produce in 2009, the operations' successes and the production goals have been gradually improving. Moreover, as Eagle Ford had been developed day by day, the characteristics of the field have been learned, so work on it still is more precautious. Today, Eagle Ford has become more productive after horizontal drilling and fracturing applications started on a big scale in 2011. The production has been increasing in both oil and gas (dry and wet gas).

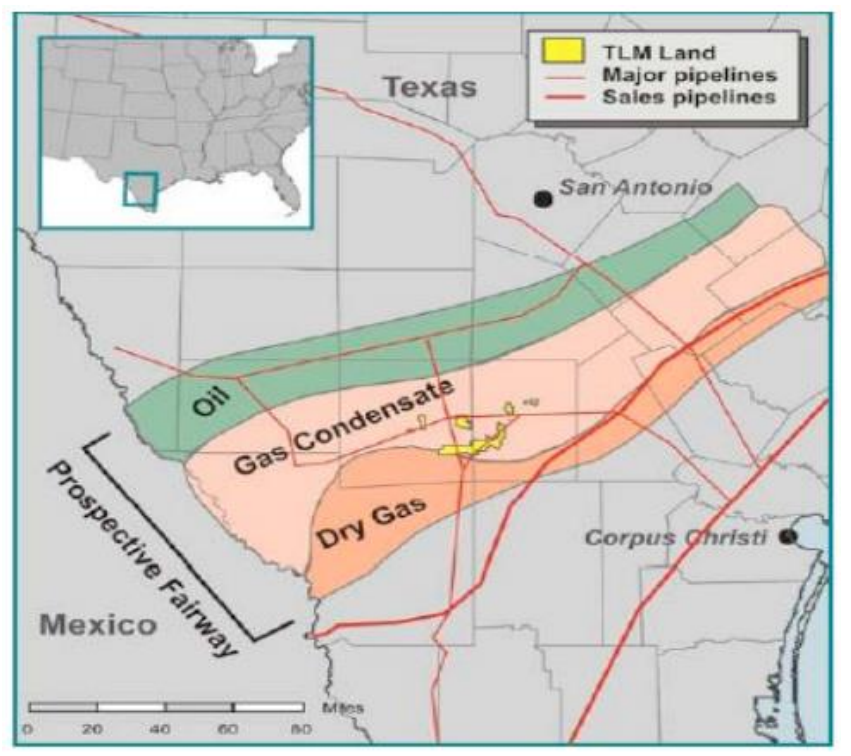

Figure 11: Eagle Ford Shale Play, hydrocarbon types and the location in the South of the Texas. (Mullen j., et al. 2010) 
Eagle Ford lies along with the three lithologies in this area, namely, argillaceous mudrock (shale), calcareous mudrock (marl), and limestone. The marl layer includes coccoliths so includes more total organic content (TOC) than other layers of the basin. The main part of the Eagle Ford Play lies through to the hydrocarbon cluster, from the San Marcos arch in the northeast into the Maverick basin along the international border with Mexico. The highest initial production is in a strike-parallel belt basin ward of the Karnes through and landward of the Cretaceous self-margin.

Eagle Ford Shale is a hydrocarbon-bearing, Late Cretaceous formation that was deposited in a marina continental shelf environment. (EIA., 2014). The formation has a higher percentage of carbonate than other components, and the organic-rich calcareous mudrock's carbonate percentage is as high as 40-90\%. In addition to this high carbonate content, it also includes $15-30 \%$ clay, and $15-20 \%$ silica (quartz). The total organic carbon content of the shale ranges between 2-12\%, thermal maturity ranges between $0.45-1.4 \%$, API gravity ranges between $28-62^{\circ}$, porosity ranges between $8-12 \%$, and pressure gradient ranges between 0.5-0.8 + (psi/ft) (Za Za Energy, 2013).

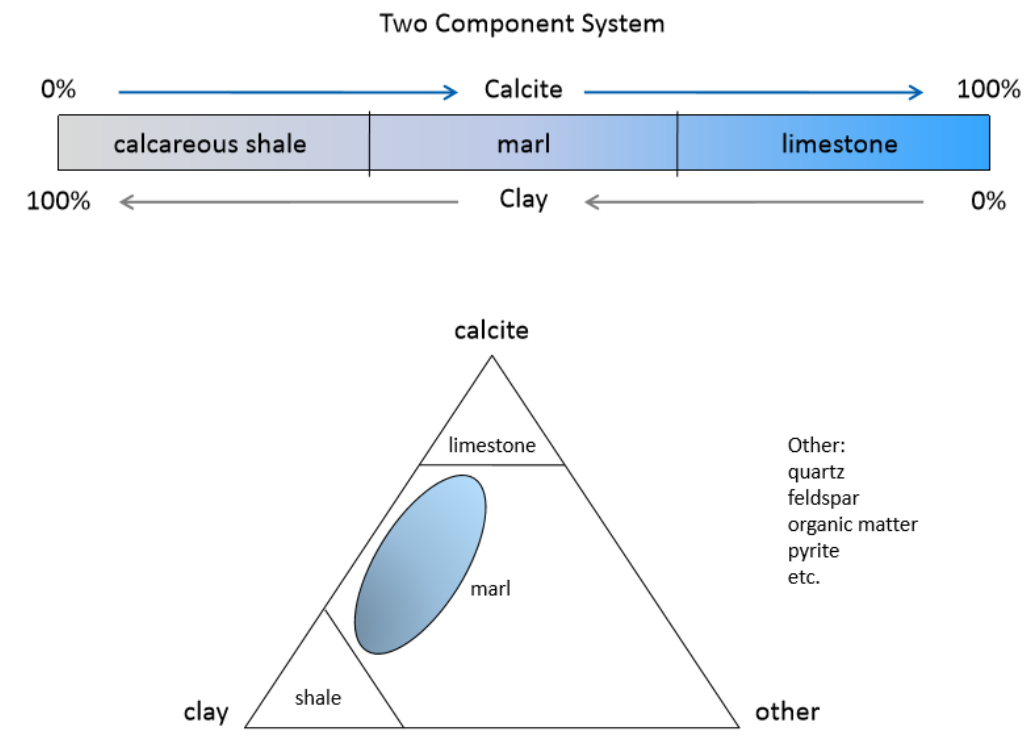

Figure 12: Eagle Ford Compounds (Breyer A. John. et al. 2013) 


\section{Petrophysical and mineralogical properties}

While the thickness of the Eagle Ford Basin is in a range of 150 and $450 \mathrm{ft}$. The depths of Eagle Ford formation vary from 7,000 to 12, $000 \mathrm{ft}$. The pressure gradient of Eagle Ford formation changes between 0.4 and $0.7 \mathrm{psi} / \mathrm{ft}$. The play gets thicker through the Southwest direction, while through Southwest the thickness goes up to $350 \mathrm{ft}$., through the northeast it goes down to $60 \mathrm{ft}$, so it can be summarized as through seaward to the thickness increases. (Gupta et al., 2017).

TOC of the basin also changes from location to location throughout the basin. In general meaning, the lover Eagle Ford has higher TOC in general, between 1 to 6\%, in the upper Eagle Ford, it changes from 3 to $12 \%$. TOC is another important factor governing the prospect of a shale play.

Generally, lower Eagle Ford is richer in TOC. The TOC varies from 1 to $6 \%$ in upper Eagle Ford and from 2 to $12 \%$ in lower Eagle Ford (Tian 2014). The thicker parts of the Eagle Ford play are associated with higher TOC.

The average technical properties of the Eagle Ford Shale are as follow (Table 2), which are depth $(\mathrm{ft})$, thickness (ft), porosity (\%), total organic content (\% wt).

Table 2: Average General Properties for the Eagle Ford Shale Play (EIA, 2011)

\begin{tabular}{|l|r|}
\hline Depth (ft) & 12,000 \\
\hline Thickness (ft) & 250 \\
\hline Porosity (\%) & 8.5 \\
\hline Total Organic Content (\% wt) & 2.25 \\
\hline
\end{tabular}

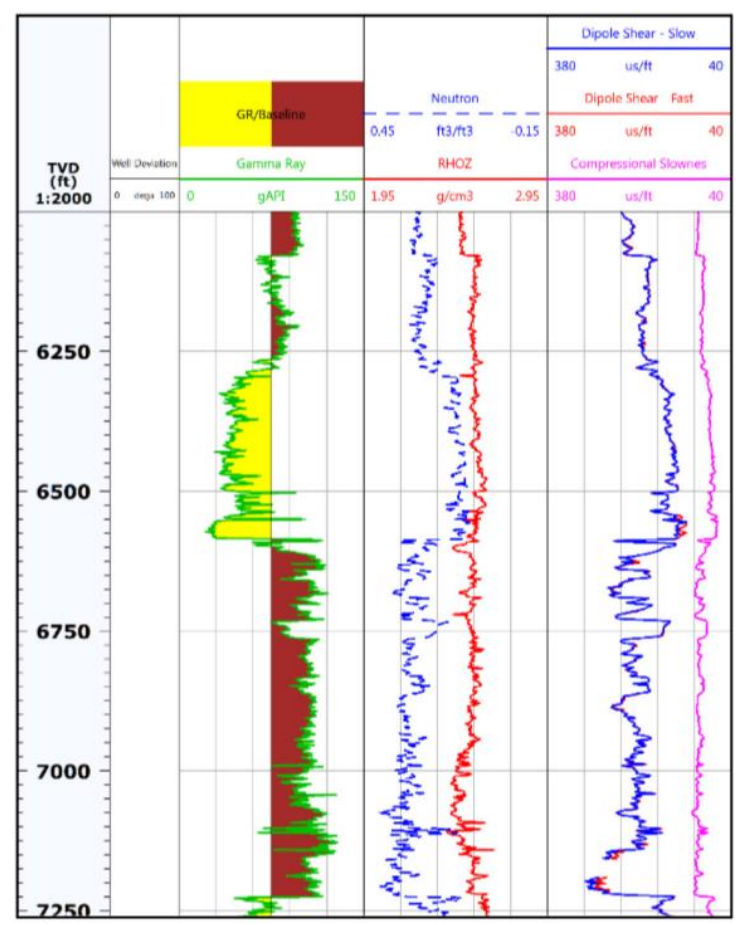

Figure 13: Eagle Ford Shale sonic log data (Brooks et al., 2015) 


\subsection{Haynesville}

\section{Play Description}

The Haynesville Shale, the other name is Haynesville/Bossier Shale, is a Natural Gas Field which is located between East Texas and Southwest Louisiana, and it also extends into Arkansas. When the natural gas price was peaked in the 2000s, the natural gas search has accelerated around the USA, and Haynesville Shale was already a well-known natural gas deposit, but until the new drilling methods and fracturing techniques developed the production costs were too high. Thus, the companies had a rush on Haynesville Shale over a couple of years until around 2011, because of the increasing importance of new shale formations around the Haynesville such as Eagle Ford and Barnet, and the other newly explored Smackover Brown Dense Shale which lies between southern Arkansas and northern Louisiana.

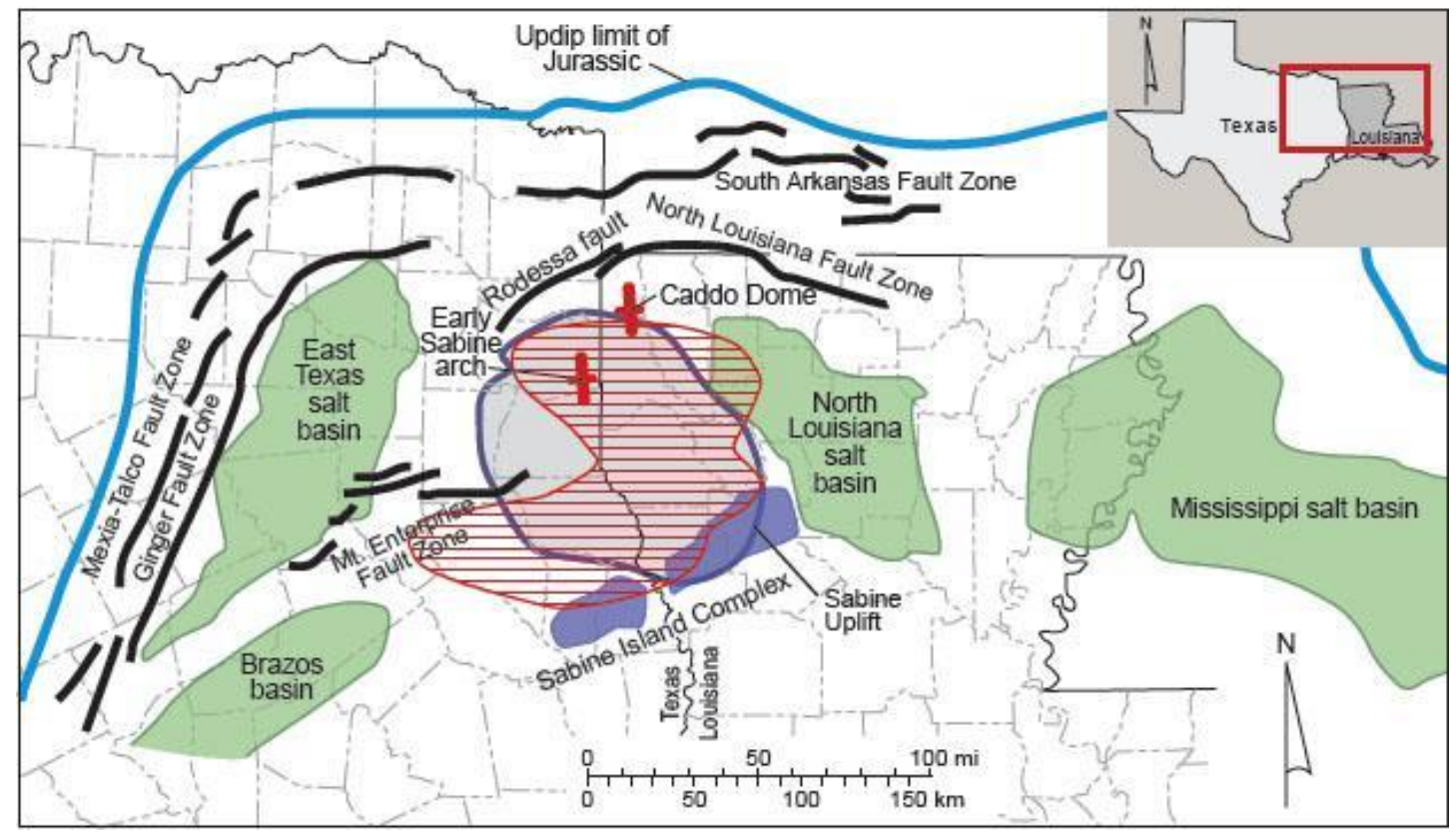

Figure 14: Late Jurassic Structural Elements and the Haynesville Shale Productive area (red stripped area, which is the area located in the middle of the Texas and the Louisiana, Hammes et all., 2011) 


\section{Petrophysical and mineralogical properties}

The pressure gradient of the Haynesville Shale ranges from 0.7 to $0.95 \mathrm{psi} / \mathrm{ft}$. The reservoir is also approximately about 10, 000 psi. Haynesville reservoir is renown as its over-pressure shale reservoir which has a permeability in the nanodarcy range, and the porosity value varies approximately between 8 to $12 \%$. The Haynesville Shale has a total area of about 9, 000 square miles. The reservoir depth ranges from 9000 to $14,000 \mathrm{ft}$. the thickness of the reservoir is between 200 to 300 . (Hammes, U. et al., 2013).

Table 3: Average General Properties for the Haynesville Shale Play (EIA, 2011)

\begin{tabular}{|l|r|}
\hline Depth (ft) & 12,000 \\
\hline Thickness (ft) & 250 \\
\hline Porosity (\%) & 8.5 \\
\hline Total Organic Content (\% wt) & 2.25 \\
\hline
\end{tabular}

The Haynesville Shale is an organic and carbonate-rich mud rock that was deposited seeping in the relatively euxinic and anoxic basin during Kimmeridgian to early Tithonian time. The Haynesville shale basin is enclosed by carbonate ledge of the Smackover and Haynesville lime Louark sequence in the north and west. Then with the contribution of the rivers, the basin was stocked with sand and mud in the direction of northwest, north, and northeast. The spectrum of the mudrock of Haynesville varies with the several different entities, namely, bioturbated, calcareous mudstone; laminated, calcareous mudstone; and silty, peloidal, siliceous mudstone to unlaminated, siliceous, organic-rich mudstone. (Hammes et al., 2012). 


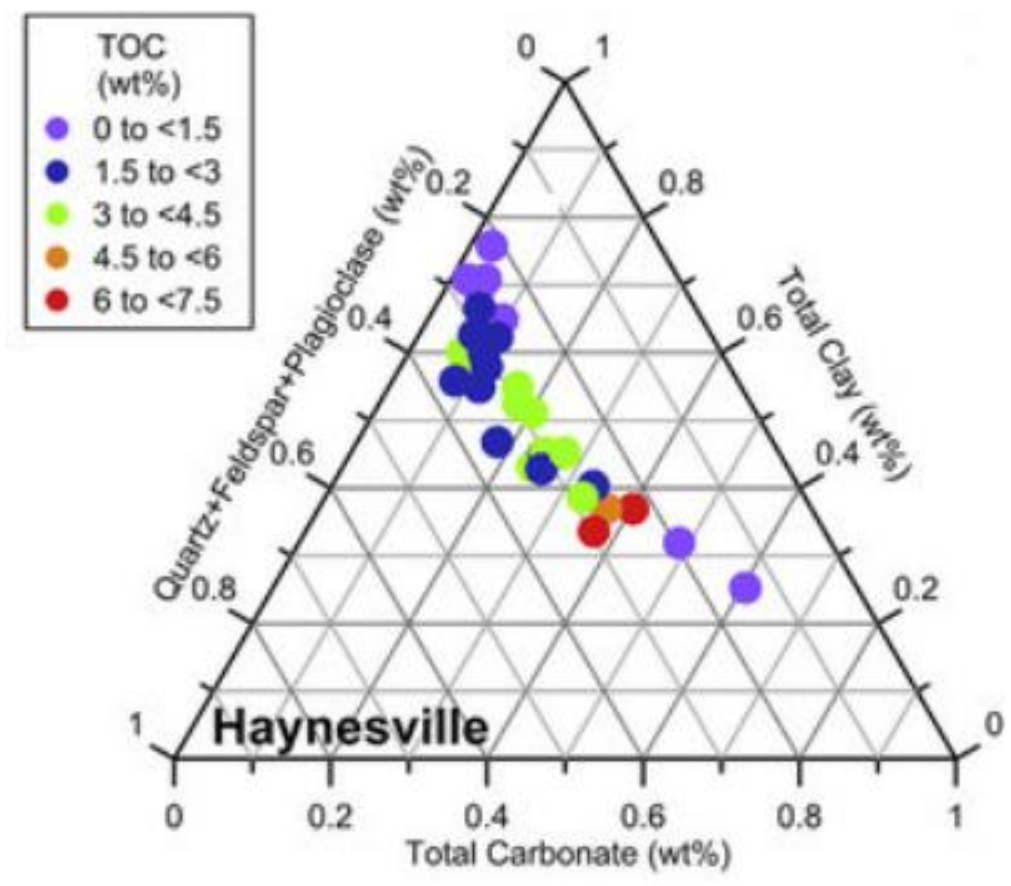

Figure 15: Haynesville minerology analyses (Saidian et al., 2016)

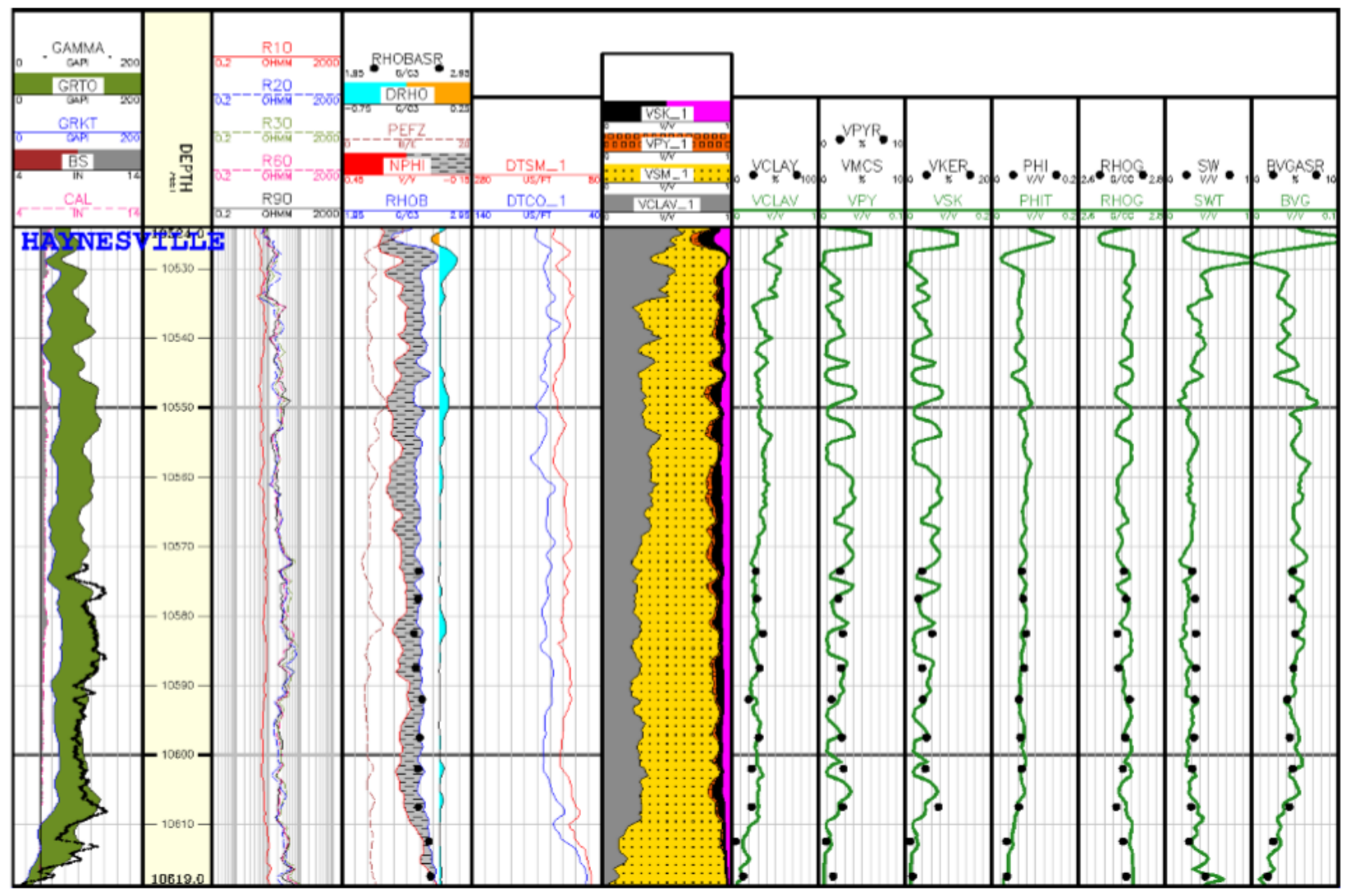

Figure 16: Haynesville Shale Sonic Log Data (Ramirez et al., 2011) 


\subsection{Marcellus}

\section{Play Description}

Marcellus Shale is a Middle Devonian age black shale that lies throughout the Appalachian Basin which stretches over New York, Pennsylvania, West Virginia, Ohio, and Maryland. The Marcellus Shale is renown as the most productive natural gas-producing formation in the Appalachian basin. The Marcellus formation consisted of Upper Marcellus and Lower Marcellus. The lower Marcellus is higher in having organic matter concentration by comparing the Upper Marcellus, and this also can be seen on the high spectral gamma-ray log, so The TOC value of the Lower Marcellus is higher than the Upper Marcellus Shale. (Popova, et al., EIA Geology Review, 2017).

Marcellus can also be divided into two different part as active area which is about 10, 622 square miles, and undeveloped area which is about 84,271 square miles which has not been leased by the companies. (EIA, 2011). The depth of this 95,000 square miles has a total area that ranges between 4, 000 to 8, 500 feet. The thickness also ranges by the tectonism with the structure, namely, it is estimated between $50 \mathrm{ft}$. to $200 \mathrm{ft}$, but the average thickness is close to $100 \mathrm{ft}$. In addition to, the shale formation is known as it gets thicker throughout Northern Pennsylvania as much as $250 \mathrm{ft}$.

Table 4: State Distribution of the Marcellus Shale Play (EIA, 2011)

\begin{tabular}{|l|l|}
\hline \multicolumn{1}{|c|}{ State } & Areal \% of Marcellus \\
\hline Maryland & 1.09 \\
\hline New York & 20.06 \\
\hline Ohio & 18.19 \\
\hline Pennsylvania & 35.35 \\
\hline Virginia & 3.85 \\
\hline West Virginia & 21.33 \\
\hline
\end{tabular}

According to the EIA, the proven reserves in the Marcellus Shale Play was about 77.2 trillion cubic feet (Tcf) by the end of the year 2015. With this reserve estimation, the Marcellus Shale Play comes as one of the biggest natural gas plays in the U.S. Moreover, its proved gas reserves are estimated around 148.7 trillion cubic feet of gas (Tcf). (EIA, 2015). Since the development has not been proceeding at the same pace in the all states, for instance, New York still has a lower level of production development than other states in the Marcellus Shale; total TRR is not exact yet. On the other hand, the level of EUR has been estimated as 1.15 Bcf. (EIA, 2011). 


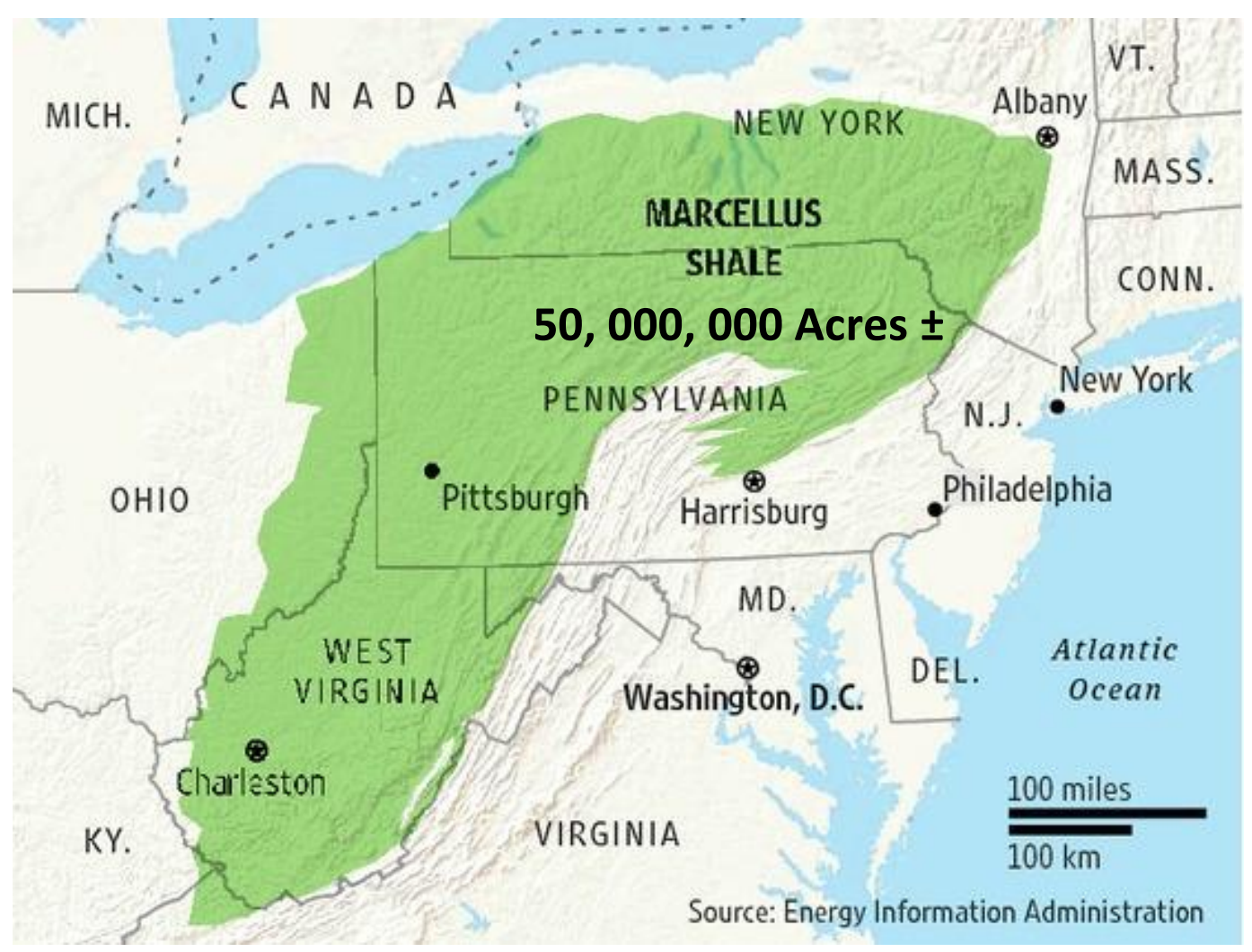

Figure 17: Marcellus/Devonian Shale Play (EIA, 2011)

\section{Petrophysical and mineralogical properties}

Porosity estimates of the shale matrix are in the range $0.5-5 \%$ with outlier magnitude of $9 \%$ recorded in West Virginia. The permeability of Marcellus is very low and must be applied increasing methods to extract gas from its hydrocarbon seal structure. Permeability estimates fall between $10^{-21}$ and $10^{-17} \mathrm{~m}^{2}$ for the Marcellus Shale, with an outlier measurement of $10^{-14} \mathrm{~m}^{2}$ in a West Virginia core sample. (Sung Lee, Dae, et al., 2010).

The average properties for the Marcellus Shale Play were estimated and shown in the Table 5. These estimated properties are depth, thickness, porosity, and Total Organic Content (TOC) which are shown below (Figure 17).

Table 5: Average General Properties for the Marcellus Shale Play (EIA, 2011)

\begin{tabular}{|l|r|}
\hline Depth (ft) & 6,750 \\
\hline Thickness (ft) & 125 \\
\hline Porosity (\%) & 8 \\
\hline Total Organic Content (\% wt) & 12 \\
\hline
\end{tabular}




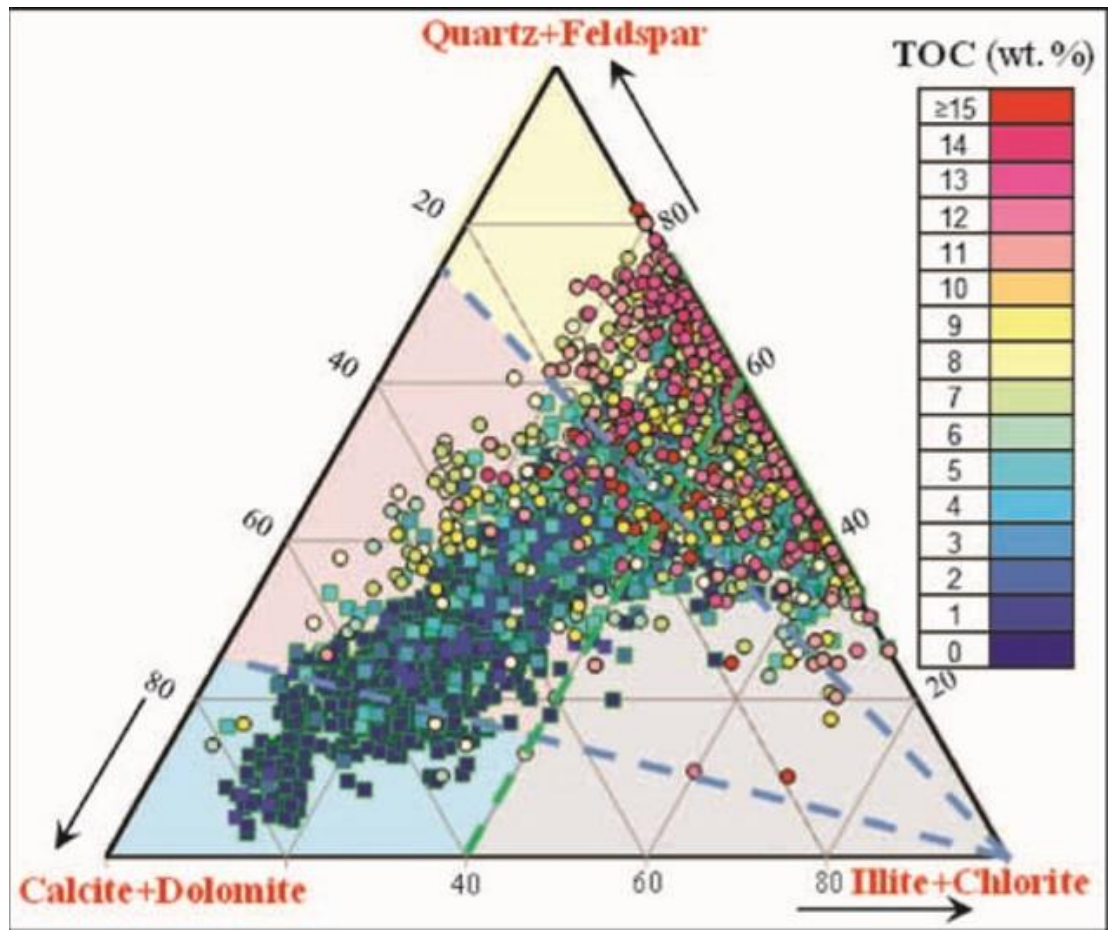

Figure 18: The Marcellus Shale Rock Composition (Wang et al., 2013) 


\subsection{Niobrara}

\section{Play Description}

Niobrara formation locates between Southeast Wyoming, Southwest Nebraska, Northwest Kansas, and Northeast Colorado. In this study, the data of Niobrara well comes from a well located in Rio Blanco County, NW Colorado. Niobrara Formation is one of the carbonate formations which is formed stratigraphically by the Western Interior Seaway (Fig. 18)

The hydrocarbon generation, oil window is estimated around 72 to 67 million years ago. Type of the organic matter is included with Type-2 oil-prone organic matter. TOC of Niobrara also ranges between 0.85 to 2.75 weight percent. The vitrine reflectance $\left(R_{0}\right)$ for the thermal maturation is measured less than 0.60 percent in the southeastern side of the formation, and through the deeper part of the formation it reaches up to 1.35 percent. With this perspective the Niobrara Shale offers a rich oil and natural gas reserves within its reservoirs. (Halliburton, Niobrara Shale Geology).

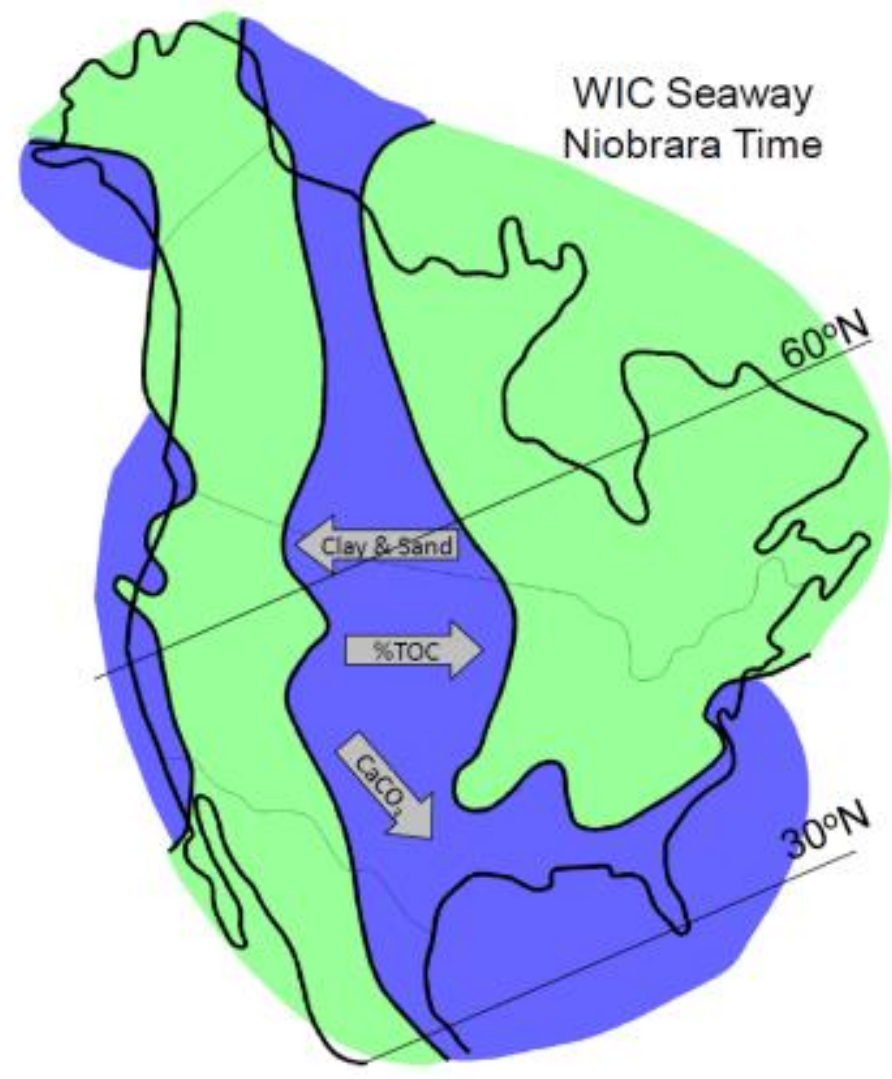

Figure 19: Western Interior Cretaceous Seaway's Location (Sonnenberg, 2013) 
Niobrara gas production is conducted in the Upper Cretaceous Niobrara Formation. The section is a low pressured and low permeable chalk section. The calcareous Niobrara formation lies with either encompassed, above or below the marine shales that prevent the migration through its constitution. Moreover, the Niobrara has a thickness from 900 to 1, 800 feet and consists mainly of interbedded organic-rich shale, calcareous shale, and marl. The Niobrara Shale's reservoir rock includes four lateral chalk benches, namely, Niobrara A, Niobrara B, Niobrara C, and the Fort Hays Limestone. Its source rock is consisted of three organic-rich interbedded shales. (Azar et al., 2014).

Table 6: Average General Properties of the Niobrara Shale (CloverGS et al., 2013)

\begin{tabular}{|l|r|}
\hline Depth (ft) & $6,000-10,000$ \\
\hline Thickness (ft) & $150-500$ \\
\hline Porosity (\%) & 8.5 \\
\hline Total Organic Content (\% wt) & $1-8$ \\
\hline
\end{tabular}

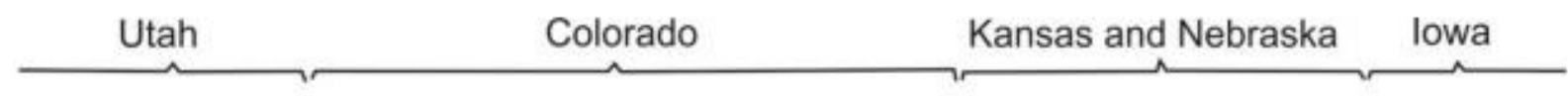

\section{Wasatch Mtns.}

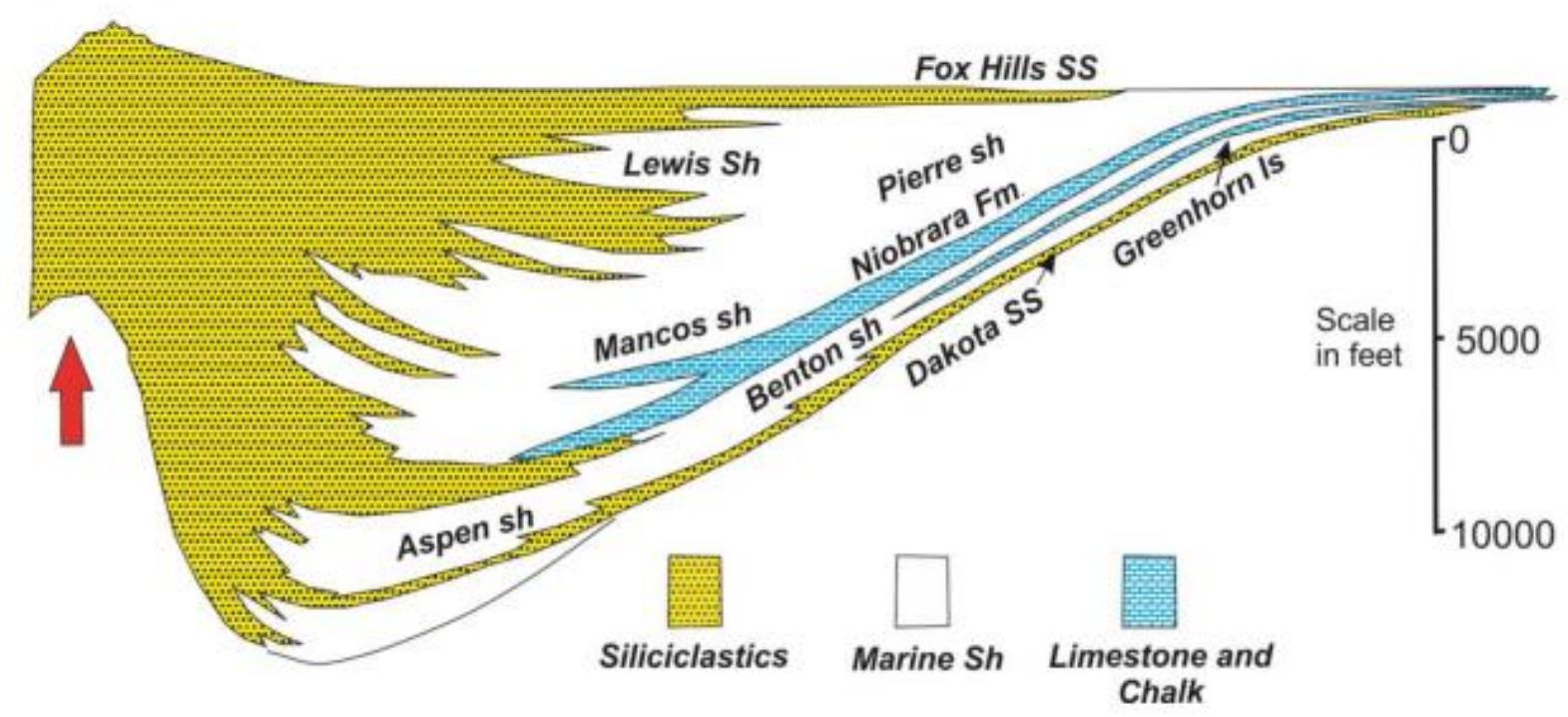

Figure 20: Schematic cross-section of Calcareous Niobrara Shale (modified from Kauffman, 1977; Sonnenberg et al., 2011) 


\section{Petrophysical and mineralogical properties}

Niobrara lithology and TOC also vary in directions. While going through to the west siliciclastic dilution increases, but carbonate content and TOC (total organic content) decrease. In addition to that, through northwest thickness gets higher. High TOC character is the most important reason of the interest of the industry. Its TOC value ranges between 1\% to 3\%, Type 2 and Type 3 kerogen, and favorable mineralogy which is about $25 \%$ to $35 \%$ clays. (McClave et al., 2014).

The porosity value of the Niobrara formation is lower than $10 \%$ and the permeability is also lower than 0.1\% (Weimer, 1996; Luneau et al., 2011; Jarvie, 2012).

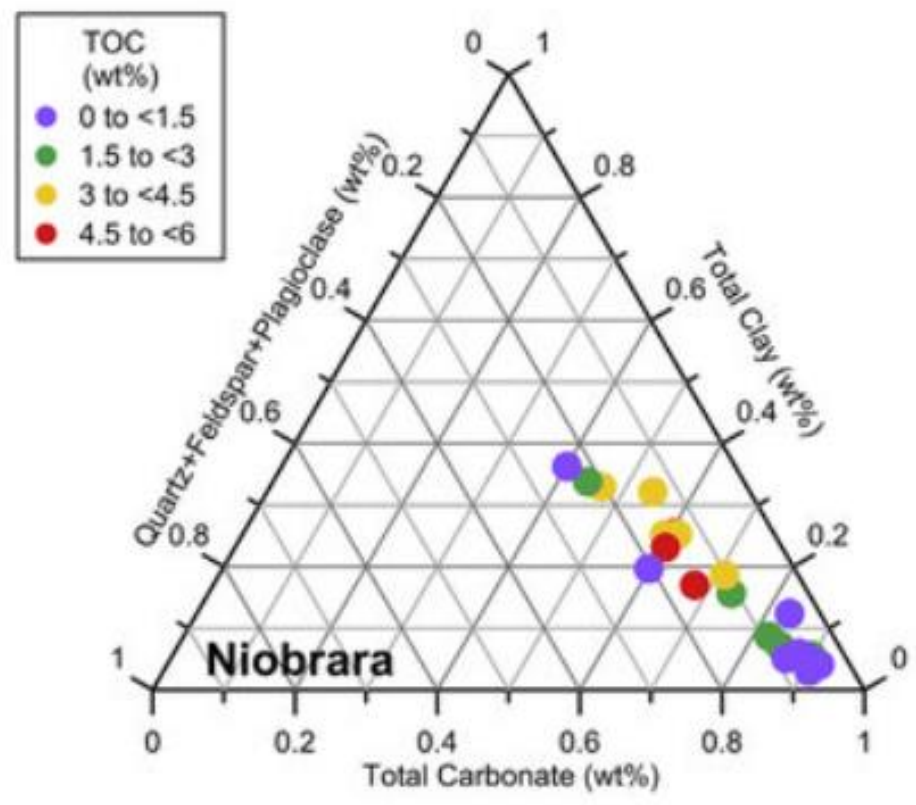

Figure 21: Niobrara Shale rock composition (Saidian et al., 2016) 


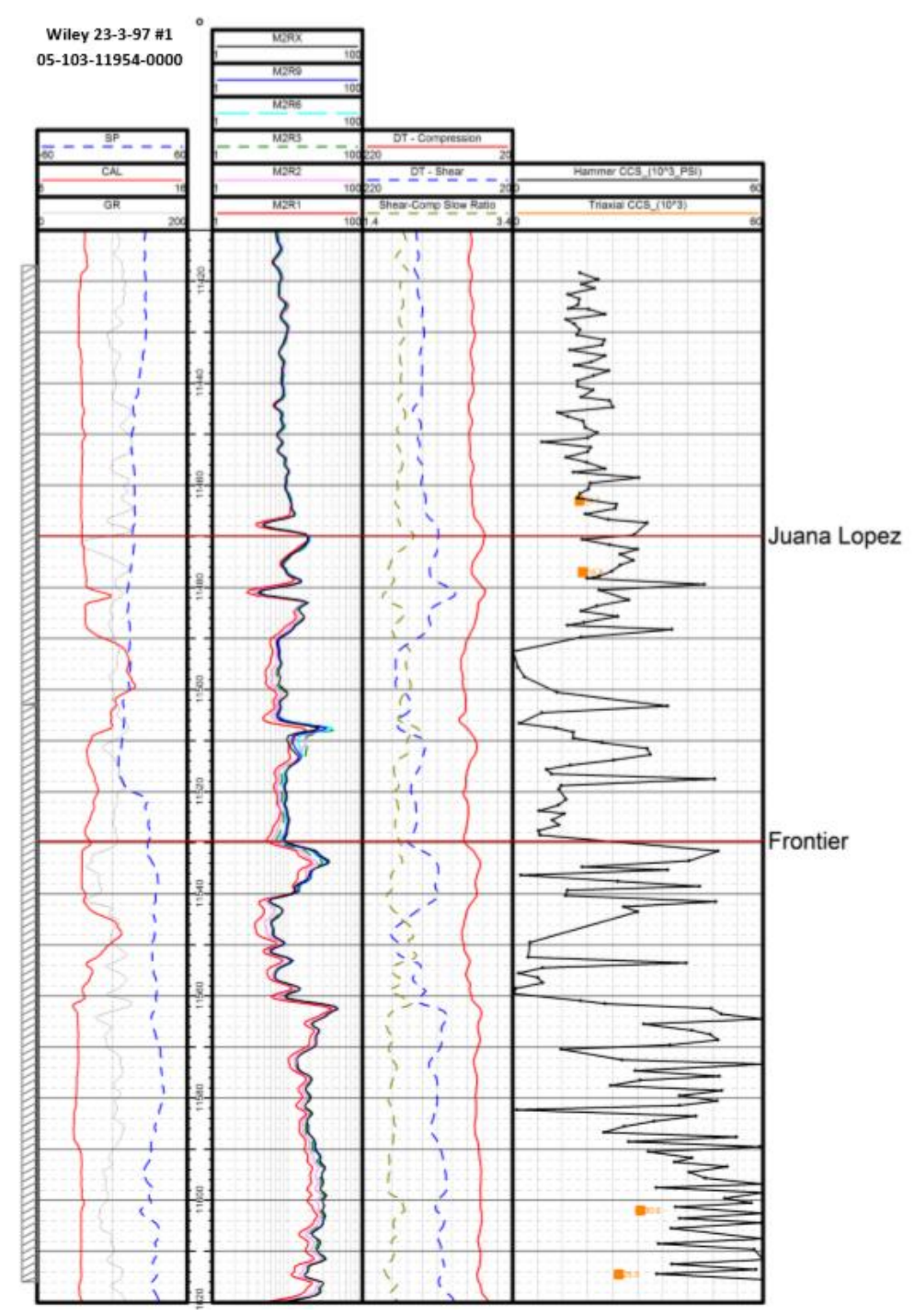

Figure 22: Niobrara Shale Sonic Log Data (Mc.Clave et al., 2014) 


\section{Methodology}

In methodology part; Annie, Modified Annie, and new acoustic anisotropy interpretation methods which are Velocity Regression Model, Modified Annie-2, and Integration method are introduced to calculate the coefficients for transverse isotropic (TI) rocks.

First, to create an OB model, a VTI model is built with the predicted coefficients from vertically propagating $P$ and $S$ waves of sonic log which are respectively $V_{p}(0)$ is for $C_{33}$, and $V_{s}(0)$ is for $C_{44}$. To find out the rest of the 4 different stiffness coefficients, several empirical equations which come from the several methods such as Annie, Modified Annie-1, Modified Annie-2, Velocity Regression and Integration Method, are used.

$$
\begin{aligned}
& \text { Stiffness Tensor }_{I S O}=\left(\begin{array}{cccccc}
C_{33} & C_{12} & C_{12} & 0 & 0 & 0 \\
C_{12} & C_{33} & C_{12} & 0 & 0 & 0 \\
C_{12} & C_{12} & C_{33} & 0 & 0 & 0 \\
0 & 0 & 0 & C_{44} & 0 & 0 \\
0 & 0 & 0 & 0 & C_{44} & 0 \\
0 & 0 & 0 & 0 & 0 & C_{44}
\end{array}\right) \\
& {\text { Stiffness } \text { Tensor }_{T I}}=\left(\begin{array}{cccccc}
C_{11} & C_{12} & C_{13} & 0 & 0 & 0 \\
C_{12} & C_{22} & C_{23} & 0 & 0 & 0 \\
C_{13} & C_{23} & C_{33} & 0 & 0 & 0 \\
0 & 0 & 0 & C_{44} & 0 & 0 \\
0 & 0 & 0 & 0 & C_{55} & 0 \\
0 & 0 & 0 & 0 & 0 & C_{66}
\end{array}\right) \\
& \text { Stiffness Tensor }{ }_{O B}=\left(\begin{array}{cccccc}
C_{11} & C_{12} & C_{13} & 0 & 0 & 0 \\
C_{12} & C_{22} & C_{23} & 0 & 0 & 0 \\
C_{13} & C_{23} & C_{33} & 0 & 0 & 0 \\
0 & 0 & 0 & C_{44} & 0 & 0 \\
0 & 0 & 0 & 0 & C_{55} & 0 \\
0 & 0 & 0 & 0 & 0 & C_{66}
\end{array}\right)
\end{aligned}
$$


Some VTI models use Stoneley velocity in interpretation of one of the stiffness coefficients, but the models fail in the cased holes since Stoneley velocity cannot be measured. In this study, M-Annie2 model, which does not use Stoneley velocity to interpret TI rock stiffness coefficients, takes part. In the first stage of the study, M-ANNIE 2 acoustic log interpretation model is applied to interpret the TI rock stiffness tensor for five US shales, which will be adopted as the background TI rock for building the OB rock in the next stage.

The OB model will be described in the second part of the methodology section. In this study, synthetic $O B$ rock stiffness tensor with different natural fracture intensities are built by introducing a transverse natural fracture set upon a true VTI background rock background using the theory developed by Far et al. (2013). 


\subsection{Hypothesis}

To understand the impact of the natural fracture induced anisotropy within the shale rock, first the $\mathrm{TI}$ rock model, then the $\mathrm{OB}$ rock model are built. As the processes of these modellings are summarized above and explained in detail in the following chapters, the sonic logs from the actual shale reservoirs are used. Since actual logs are all in natural conditions in the reservoir, they include several natural fractures within their bodies. Thus, the sonic logs' data first need to be examined for their availabilities to be utilized for the processes of $\mathrm{TI}$ and $\mathrm{OB}$ rock models in terms of the natural fracture percentage in their bodies.

A further examination is applied for every shales' logs to understand their level of competence regarding to the natural fracture existence in the body. For this reason, a comparison for the separation of fast and slow shear wave slowness (SWS) of every shale are made, and the results of SWSs in percent are graphed alongside the true vertical depths (TVD). Taking the Marcellus case as an example, the expectation from the shale sonic logs' SWS\% values to be no more than $1.7 \%$ which agrees well with out hypothesis that the target shale rock is not naturally fractured and can be threated as a TI background rock.

In the study, other than Marcellus Shale and Eagle Ford Shale, we do not have the actual data of the fast and slow shear wave slowness for every shale to calculate the SWS\% values for rest of the shales. Therefore, Bakken, Haynesville, and Niobrara are assumed as no or negligibly naturally fractured.

In Figure 25, the Eagle Ford Shale's sonic log is shown. The fast shear slowness (red) and slow shear slowness (blue) are slightly deviate at some point, but they behave mostly in accordance with each other's track. The deviated part of the tracks are shown by the arrows.

This outcome is one of the ways to understand how this two slowness have very close values. Thus, the shale rock can be accepted as not fractured for Eagle Ford Shale instance. To support this claim, Figure 26 also shows how slightly $1 \%$ SWS value deviates the minimum horizontal stress. 


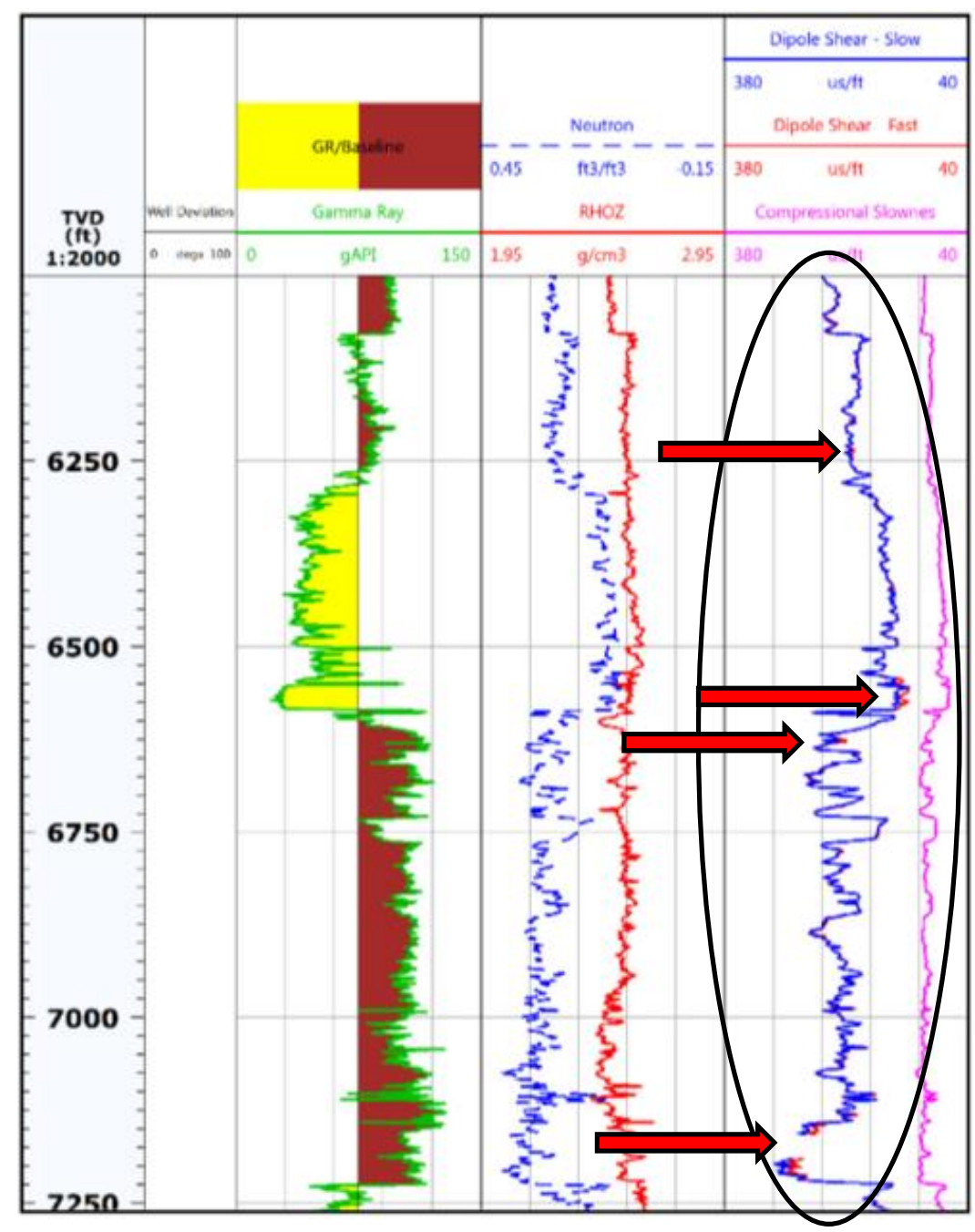

Figure 23: Eagle Ford Shale, SWS in percent to TVD in ft

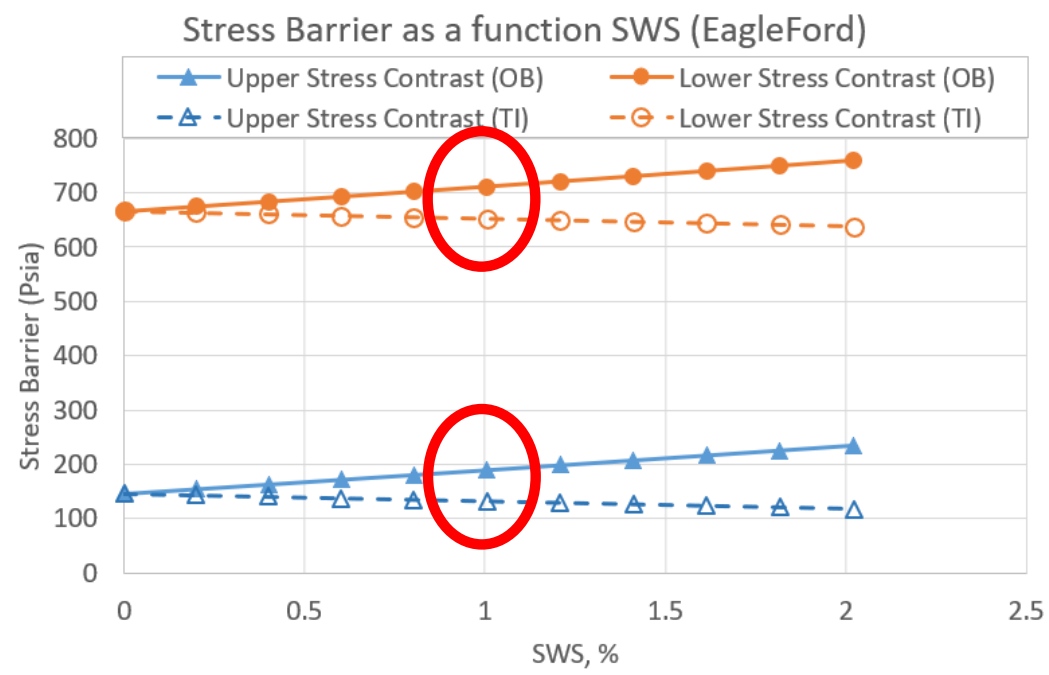

Figure 24: Eagle Ford $O B$ and TI model assumption for SWS in percent to Stress Barriers in psia 
Marcellus Shale's SWS to TVD graph is shown in Figure 23. In this way, how the natural fractures' distribution takes place throughout the depth can be clearly seen. In Figure 23, the density of the natural fractures maximum goes up to $1 \%$ from $7190 \mathrm{ft}$. to $7440 \mathrm{ft}$, then it increases to $1.7 \%$ from $7440 \mathrm{ft}$. to $7540 \mathrm{ft}$.

To see how much horizontal minimum stress changes with the SWS in percent, the Figure 44 is plotted. In this plot, the dashed lines show the real value, OB assumptions. Thus, such an aproximation which claim $1 \%$ approximation is in acceptable range regarding the value of the minimum horizonral stress.

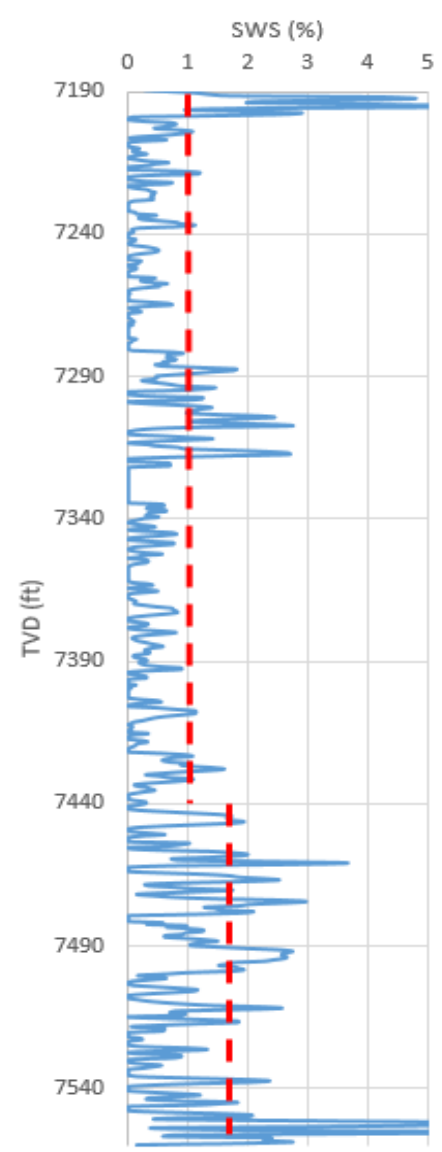

Figure 25: Marcellus Shale SWS to TVD distribution 


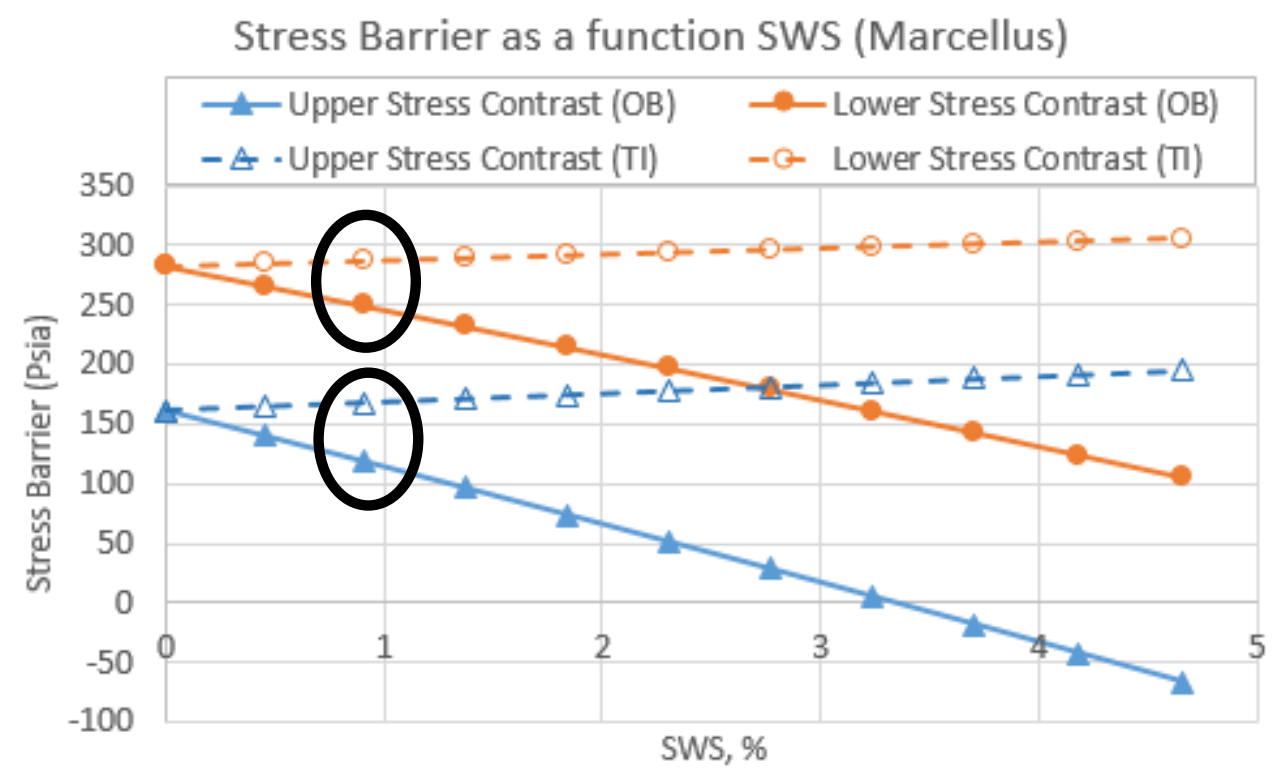

Figure 26: Marcellus $O B$ and TI model assumption for SWS in percent to Stress Barriers in psia

To sum up, for the rest of the shales, namely, Bakken, Haynesville, and Niobrara, the acceptations are based on the asumption of the fast and shear wave slowness tracks' harmony and almost identity. Hence, it is reasonable to assume negative natural fracture impact and use the current log data to derive a TI stiffness tensor for the background rock. There is only small or neglected natural fracture impacts on their log data. 


\subsection{Rock Properties in a VTI Formation}

A VTI rock has 5 different stiffness coefficients. They are $C_{33}, C_{44}, C_{66}, C_{11}$, and $C_{13}$. Using Voigt's notation (Nye, 1985), the fourth-order stiffness tensor (9x9) can be converted to a $6 \times 6$ stiffness tensor. (Gu et al., 2017). Thus, $6 \times 6$ stiffness tensor of TI medium with a symmetry axis along the $x_{3}$ axis:

$$
\left(\begin{array}{cccccc}
C_{11} & C_{12} & C_{13} & 0 & 0 & 0 \\
C_{12} & C_{11} & C_{13} & 0 & 0 & 0 \\
C_{13} & C_{13} & C_{33} & 0 & 0 & 0 \\
0 & 0 & 0 & C_{44} & 0 & 0 \\
0 & 0 & 0 & 0 & C_{44} & 0 \\
0 & 0 & 0 & 0 & 0 & C_{66}
\end{array}\right)
$$

with $C_{12}=C_{11}-2 C_{66}$

As it is seemed in the (Eq. 1), since VTI stiffness tensor has a symmetry axis, $C_{12}$ can be calculated with the formula in the (Eq. 1).

Mathematically, the stiffness matrix needs to be positive to ensure a positive strain energy density. This situation causes the following principal minors (Suarez - Rivera and Bratton, 2012). Thus,

$$
C_{11}>0 ; C_{33}>0 ; C_{44}>0 ; C_{66}>0 ; C_{11}>\left|C_{12}\right| \text { and }\left(C_{11}+C_{12}\right) C_{33}>2 C_{13}^{2}
$$




\subsubsection{Anisotropic Methods}

\subsubsection{Annie Model}

Annie method is first described by Schlumberger. The model has been utilized in such wells without casing, open hole, because Annie Model formulizes the Stoneley velocity which is only measured in the wells without cased.

The Annie Model can directly obtain 3 different independent coefficients from vertical well logs which is perpendicular to the bedding plane. $C_{33}$ and $C_{44}$ can be gotten from respectively $P$ and $S$ wave slowness using the sonic logs. $P$ wave slowness is $V_{p}(O)$, and $S$ wave slowness is $V_{s}(0)$. In addition to $C_{33}$ and $C_{44}, C_{66}$ can also be obtained from low-frequency Stoneley-wave slowness (Ellefsen et al., 1992; Norris and Sinha, 1993; Gu. et al., 2016). In calculation of the stiffness coefficient, with the slowness and Stoneley data, bulk density data is utilized.

As it is described, in VTI models, we can get five different independent stiffness coefficients from both log data and the empirically calculated assumptions. Thus, here two main assumptions of ANNIE model are described below: (Schoenberg et al., 1996; Higgins et al., 2008, Waters et al., 2011, Gu et al. 2016).

Two main assumptions in Annie method calculate the other 2 independent stiffness tensors:

$$
C_{12}=C_{13} \text { and } C_{13}=C_{33}-2 C_{44}
$$

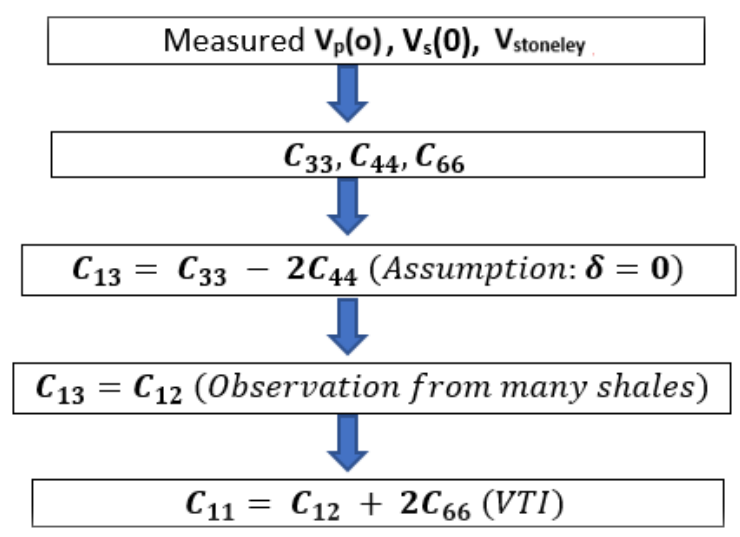

Figure 27: Annie model work flow

However, Annie Model has several limitations other than Stoneley velocity such as calculating the vertical Poisson's ratio greater than horizontal ratio, and predicting the anisotropic and isotropic stresses are equal. 


\subsubsection{Modified Annie Model (M-Annie 1)}

Modified Annie Model is built by Quirein et al. (2014) The difference between the Annie and Modified Annie method is two newly described core-calibrated correction parameters $K_{1}$ and $K_{2}$. These two new correction parameters aim to decrease the bias of estimating $C_{11}$ and $C_{13}$.

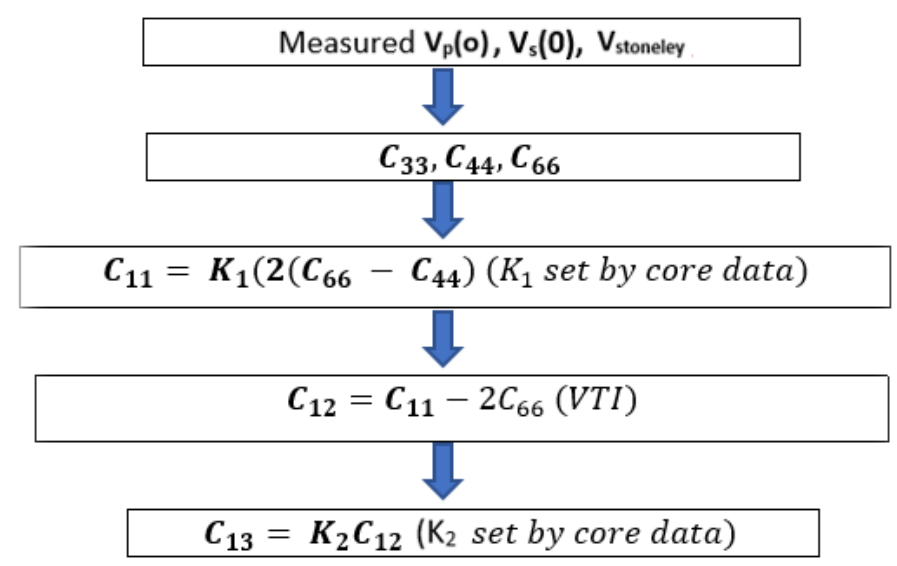

Figure 28: Modified Annie-1 Work Flow

The Figure 28 shows how to calculate the coefficients in terms of the Modified Annie Model. While the $K_{1}$ and $K_{2}$ are decided by the core data, generally, the values of them are $K_{1}=1.1$, and $K_{2}=0.8$. Modified Annie requires to calculate first the coefficient $C_{11}$ after the same first step which calculates $\mathrm{C}_{33}, \mathrm{C}_{44}, \mathrm{C}_{66}$ with $\mathrm{V}_{\mathrm{p}}(\mathrm{O}), \mathrm{V}_{\mathrm{s}}(0), \mathrm{V}_{\text {stoneley. }}$. Then, $\mathrm{C}_{12}$ and $\mathrm{C}_{13}$ are calculated.

As it can seem the both models require Stoneley wave velocity as an input. This requirement restricts the model to be applied only in the open-hole conditions which are not suitable for advance sonic log applications. Moreover, the model assumes an anisotropy of the linear relationship between $\mathrm{C}_{13}$ and $\mathrm{C}_{12}$. However, this is not always the case, so then the models both are erroneous. 


\subsubsection{New Acoustic Anisotropy Interpretation Methods}

Since the Annie and M-Annie models' formulas both contain Stoneley wave velocity and since $C_{66}$ is sensitive to the velocity of Stoneley and drilling fluid velocity, Gu et al. (2016) defined new three models which are Velocity Regression Method, Modified Annie-2, and Integration Method.

\subsubsection{Modified Annie-2 Model (Further Modified Annie Method)}

As a novelty, Modified Annie-2 use a linear correlation between the Thomsen P- and S- wave anisotropy parameters to replace the Stoneley wave velocity in calculation of the coefficient $\mathrm{C}_{66}$. Modified Annie-2 also assumes $C_{11}=k_{1} \times\left(2 \times\left(C_{66}-C_{44}\right)+C_{33}\right)$ and $C_{13}=k_{2} \times C_{12}$. The anisotropy parameters are observed from organic shale formations $\varepsilon=k_{3} \gamma$. All three empirical parameters $k_{1}, k_{2}, k_{3}$ are derived from sonic log data. They can be set with the generic values from shale datasets when there is not any log data.

As it is summarized in the former chapter, from 5 different independent stiffness coefficients two of them are calculated with measured vertical $\mathrm{P}$ and $\mathrm{S}$ wave velocities. Generally, Stoneley wave is used to calculate the third independent coefficient. The Annie assumptions gives two more constraints as it is shown in the work flow tables. As the Annie method accepts $\delta=0$ and $C_{13}=C_{12}$. In modified Annie-2 method, the consideration is also for replacing one constraint. In this method, by considering $\gamma$ $=0.93 \varepsilon$ one of the constraints is substituted by this new formula. In this way, Stoneley wave measurement is cancelled in the calculation of $C_{66}$. This new method is explained in the paper of Gu et al. (2016).

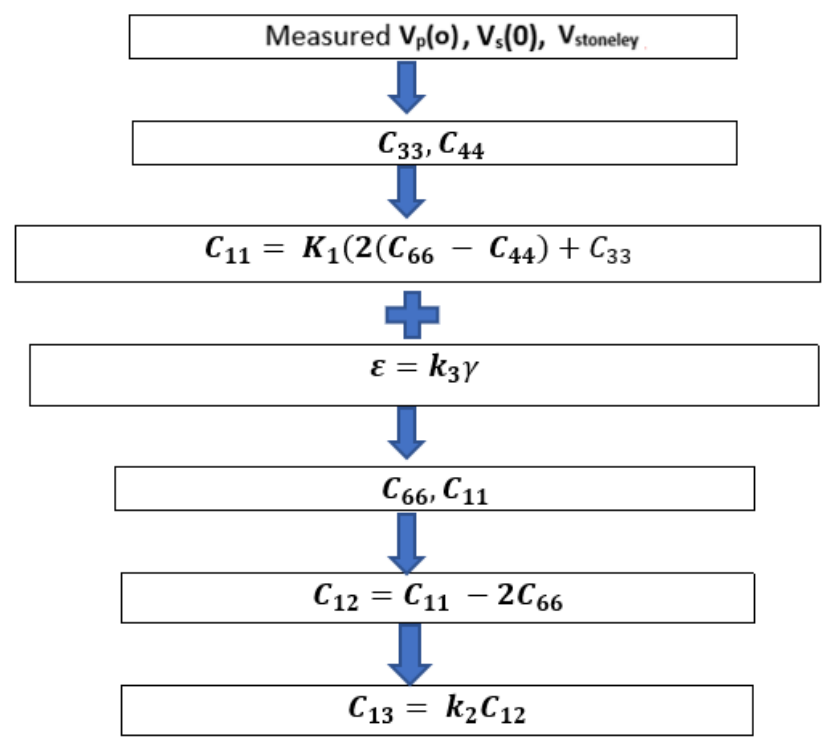

Figure 29: Modified Annie-2 work flow 
In the study, calculations of the M-Annie-2 for fives shales are done as follows:

1. As it is shown in the work flow, two coefficient which is $C_{44}$ and $C_{33}$ are calculated with the constraints $V_{p}(O)$ and $V_{s}(0)$.

(Here, $V_{p}(O)$ is compressional wave velocity, and $V_{s}(0)$ is shear wave velocity).

2. By measured DTC and DTS logs of the shales, following calculations are applied to find out $C_{33}$ and $C_{44}$ :

$$
\begin{gathered}
C_{33}=13475 \times \rho / D T C^{2} \\
C_{44}=13475 \times \rho / D T S^{2}
\end{gathered}
$$

3. Then, to calculate the other coefficient first $C_{66}$ must be calculated with the following formula:

$$
C_{66}=\frac{2 k_{1} \frac{C_{44}}{C_{33}}+1-k_{1}-k_{3}}{2 k_{1} \frac{1}{C_{33}}-k_{3} \frac{1}{C_{44}}}
$$

4. After $C_{66}$ is calculation with the new assumption of Gu et al. (2016), rest of the calculations are just based on the formulas that use the first 3 coefficients and the new parameters $k_{1}$ and $k_{3}$ as follows:

$$
\begin{gathered}
C_{11}=k_{1} \times\left(2 \times\left(C_{66}-C_{44}\right)+C_{33}\right) \\
C_{12}=C_{11}-2 \times C_{66} \\
C_{13}=0.8 \times C_{12}
\end{gathered}
$$

As a result, applying the M-Annie method made able to get the all independent coefficients of VTI model without Stoneley wave velocity. OB Model's coefficients will be to calculate by utilizing the variable we calculated. This method is also the one we use to calculate our coefficients in this study. 


\subsubsection{Velocity Regression Method}

One of the new acoustic anisotropy interpretation method is velocity regression method which is described by Gu et al. (2016). The idea behind this model is making a correlation between measured sonic wave velocities at $\left(0^{\circ}\right)$ and the wave velocities at other angles (i.e., $90^{\circ}$ or $45^{\circ}$ ). The work flow also represents the steps to make the correlations and to find out the stiffness coefficients.

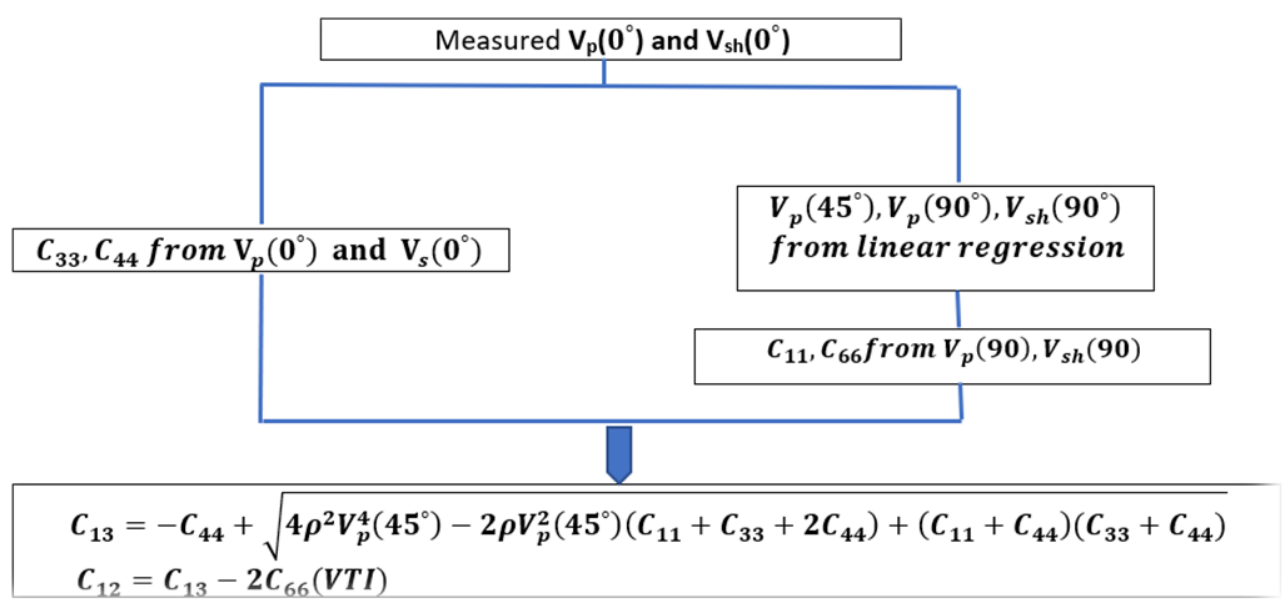

Figure 30: Velocity Regression model work flow (Gu et al., 2016). 


\subsubsection{Integration Method (Combination of V-reg and M-Annie-2)}

The logic behind of this method is to make the calculation of the coefficient possible for any data, so it offers to combine the data that is own at the time for calculations. For instance, within the VTI models several $C_{66}$ calculation method is shown, but in case of missing Stoneley or having not reliable data, the other method's calculation ways can be applied to get the result.

In this logic, all the methods, namely, Annie, M-Annie, M-Annie-2, and V-reg data allows to form a new method to calculate the coefficients, which is called Integration Method. (Gu et al., 2016).

Table 7: Constraints Concluded for C66, C11, and C13 (Gu et al., 2016)

\begin{tabular}{|c|c|}
\hline Stiffness Coefficient & Constraints from ANNIE, M-ANNIE 1, V-Reg and M-ANNIE 2 \\
\hline $\mathrm{C}_{66}$ & $\begin{array}{l}\text { 1-1. The Stoneley wave velocity measured from the pilot or offset well is } \\
\text { projected to the target well based on gamma-ray log. P-wave log or other } \\
\text { logs. The pseudo-Stoneley-wave log data is used to derive the } \mathrm{C}_{66} \text { for the } \\
\text { target well. } \\
\text { 1-2. } \mathrm{V}_{\text {sh }}\left(90^{\circ}\right) \text { reconstructed from } \mathrm{V}_{s}\left(0^{\circ}\right) \text {. (V-reg) } \\
\text { 1-3. } \mathrm{V}_{\text {sh }}\left(45^{\circ}\right) \text { reconstructed from } \mathrm{V}_{s}\left(0^{\circ}\right) \text {. (V-reg) } \\
\text { 1-4. } \varepsilon=k 3 \gamma(\mathrm{M}-\mathrm{ANNIE} 2) \\
\text { 1-5. } \mathrm{C}_{11}=\mathrm{k}_{1}\left(2 \mathrm{C}_{66}-2 \mathrm{C}_{44}+\mathrm{C}_{33}\right)(\mathrm{M} \text {-ANNIE } 1 \text { and } 2)\end{array}$ \\
\hline $\mathrm{C}_{11}$ & $\begin{array}{l}\text { 2-1. } V_{p}\left(90^{0}\right) \text { reconstructed from } V_{p}\left(0^{0}\right) .(V-r e g) \\
\text { 2-2. } V_{p}\left(45^{0}\right) \text { reconstructed from } V_{p}\left(0^{0}\right) .(V-r e g) \\
\text { 2-3. } V_{s v}\left(45^{0}\right) \text { reconstructed from } V_{s}\left(0^{0}\right) .(V-r e g) \\
\text { 2-4. } \varepsilon=k 3 \gamma(M-A N N I E 2) \\
\text { 2-5. } C_{11}=k_{1}\left(2 C_{66}-2 C_{44}+C_{33}\right)(M-A N N I E 1 \text { and } 2)\end{array}$ \\
\hline $\mathrm{C}_{13}$ & $\begin{array}{l}\text { 3-1. } V_{p}\left(45^{0}\right) \text { reconstructed from } V_{p}\left(0^{0}\right) .(V-r e g) \\
\text { 3-2. } V_{s v}\left(45^{\circ}\right) \text { reconstructed from } V\left(0^{\circ}\right) .(V-r e g) \\
\left.\text { 3-3. } C_{13}=k_{2} C_{12} \text { (ANNIE: } k_{2}=1, M-A N N I E 1 \text { and } 2: k_{2} \neq 1\right) \\
\text { 3-4. } C_{13} \text { is a linear function of } C_{33}, C_{44}, V_{\text {clay }}, V_{\text {kerogen, }} \text { and rock density. The } \\
\text { linear coefficients are obtained from core data calibration. }\end{array}$ \\
\hline $\mathrm{C}_{12}$ & 4-1. $C_{12}=\left(C_{11}-2 C_{66}\right)$ (VTI Symmetry) \\
\hline
\end{tabular}




\subsection{OB Rock Model}

A single set of parallel transverse symmetric NFs in a VTI background seems as (Figure 5), and the effective excess compliance $\Delta S$ due to the existence of the NF is shown as (Far et al., 2013).

$$
\Delta S=\left(\begin{array}{cccccc}
B_{N} \rho_{n f} & 0 & 0 & 0 & 0 & 0 \\
0 & 0 & 0 & 0 & 0 & 0 \\
0 & 0 & 0 & 0 & 0 & 0 \\
0 & 0 & 0 & 0 & 0 & 0 \\
0 & 0 & 0 & 0 & B_{T} \rho_{n f} & 0 \\
0 & 0 & 0 & 0 & 0 & B_{T} \rho_{n f}
\end{array}\right)
$$

$B_{N}$ : Normal fracture compliance

$B_{T}:$ Shear fracture compliance

$\rho_{n f}:$ Natural Fracture Density (number of fractures per length).

$B_{N}$ and $B_{T}$ are the fracture compliance parameters, which is assumed the linear correlation parameters to link the fracture displacement discontinuity vector across the interface and the stress traction vector on the fracture interface (Schoenberg, 1980). They are usually determined from the lab or field data. Figure 31 exhibits the published measurements of fracture compliances collected by Worthington (2008). It indicates that fracture compliance increases with fracture size. A key step in the acoustic modeling of fractured rock is the choice of fracture compliance values. However, laboratory or field measurements of individual fracture compliance are extremely scarce. In addition to that, the compliance value varies in a large range (as shown in Fig. 31) with many parameters such as fracture size, in-situ pressure etc. According to Eq. (13), the excess compliance of one set of parallel fractures is a function of individual fracture compliance multiplied by the fracture density. Thus, by adjusting the fracture density, the magnitude of effective excess compliance of natural fracture and the natural fracture induced anisotropy can be varied in a specified range. Compared with the magnitude of the compliance, the ratio of compliances, $B_{N} / B_{T}$, is of more interest. Considering the case of an open circular crack modeled as an oblate spheroid with the size to be small compared to the wavelength (Sayers and Kachanov, 1995), the ratio is a function of Poisson's ratio, $\mathrm{B}_{\mathrm{N}} / \mathrm{B}_{\mathrm{T}}=1-\mathrm{v} / 2$. Because the Poisson's ratio of a rock is typically larger than 0 and smaller than 0.5 , the ratio has a range of $0.75-1$.

In this study, the excessive shear compliance $\left(\mathrm{B}_{\mathrm{T}}\right)$ and normal compliance $\left(\mathrm{B}_{\mathrm{N}}\right)$ are set as $6.25 \mathrm{e}-7$ $\mathrm{m} / \mathrm{pa}(0.00431 \mathrm{~m} / \mathrm{psi})$ and $5 \mathrm{e}-7 \mathrm{~m} / \mathrm{pa}(0.00345 \mathrm{~m} / \mathrm{psi})$, respectively, with a ratio of compliances (BN/BT) to be 0.8 . The other parameter $\rho_{n f}$ is the number of the fractures per length, which will be varied within a specified range to achieve different extents of natural fracture induced anisotropy. The other assumptions are equal spacing and full vertical expansion of NFs. 


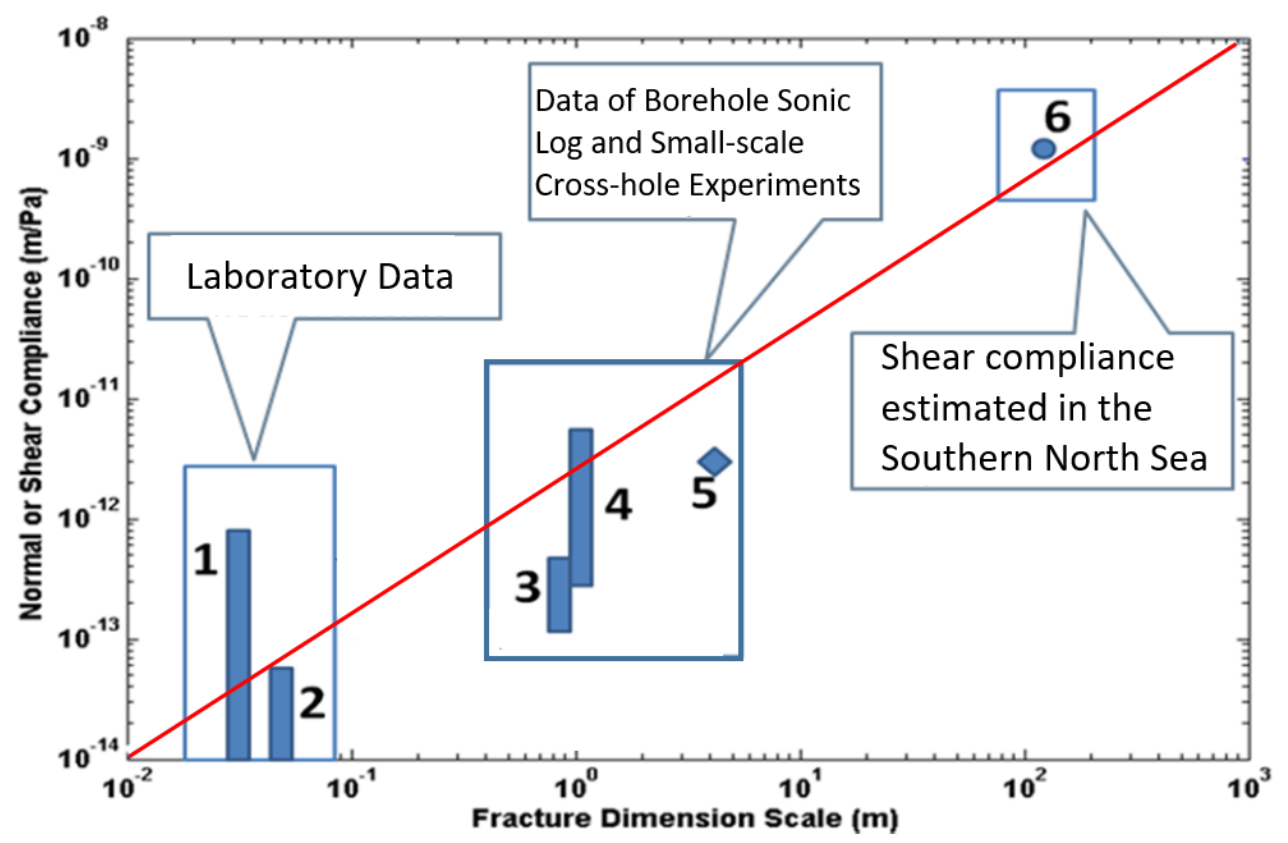

Figure 31: Fracture compliance as a function of the fracture dimension on field and laboratory data (modified from Worthington, 2008)

In case of the effective excess compliance $\Delta S$ is much smaller compared with background one, a simplified equation (Eq. 11) can be applied to directly calculate the OB stiffness tensor from the VTI background stiffness tensor (Sayers 2009; Gu 2017).

$$
C_{O B}=C_{V T I}-C_{V T I} \Delta \mathrm{SC}_{V T I}
$$

Therefore, substituting the TI matrix (Eq. 2) and effective stress compliance $\Delta S$ (Eq. 13) into (Eq. 14), the following matrix shape (Eq. 15).

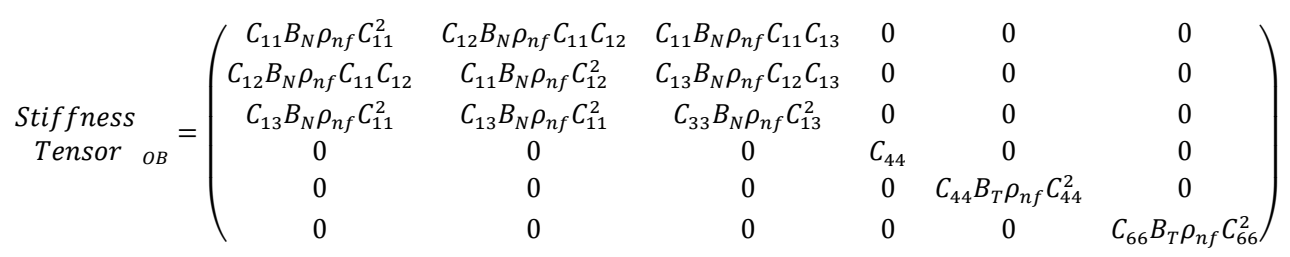

For the new equation (Eq. 6), the anisotropy which is cause by natural fractures can be formulize as three non-dimensional parameters as Thomsen anisotropy parameters (Thomsen. 1986; Gu 2017). 


$$
\begin{gathered}
\epsilon=\frac{C_{22}^{O B}-C_{11}^{O B}}{C_{11}^{T I}}=\frac{B_{N} \rho_{n f}\left(C_{11}^{T I^{2}}-C_{12}^{T I^{2}}\right)}{C_{11}^{T I}} \\
\varphi=\frac{C_{44}^{O B}-C_{55}^{O B}}{C_{44}^{T I}}=\frac{B_{T} \rho_{n f}\left(C_{44}^{T I^{2}}\right)}{C_{44}^{T I}} \\
\omega=\frac{C_{23}^{O B}-C_{13}^{O B}}{C_{13}^{T I}}=\frac{B_{N} \rho_{n f}\left(C_{11}^{T I^{2}} C_{13}^{T I}-C_{12}^{T I} C_{13}^{T I}\right)}{C_{13}^{T I}}=B_{N} \rho_{n f}\left(C_{11}^{T I}-C_{12}^{T I}\right)
\end{gathered}
$$

Calculations of the mechanical properties of the OB Model, such as horizontal stress and the other mechanic properties are briefly described below:

$$
\begin{aligned}
& \sigma_{1}=C_{11} \varepsilon_{1}+C_{12} \varepsilon_{2}+C_{13} \varepsilon_{3} \\
& \sigma_{2}=C_{12} \varepsilon_{1}+C_{22} \varepsilon_{2}+C_{23} \varepsilon_{3} \\
& \sigma_{3}=C_{13} \varepsilon_{1}+C_{23} \varepsilon_{2}+C_{33} \varepsilon_{3}
\end{aligned}
$$

To solve to orthogonal horizontal stresses which are $\sigma_{1}$ and $\sigma_{2}, \varepsilon_{3}$ from the (Eq. 21) is substituted into (Eq. 19) and (Eq. 20), so the following equations are created.

$$
\begin{gathered}
\sigma_{1}=\sigma_{h \min }=\frac{C_{13}}{C_{33}} \sigma_{3}+\left(C_{11}-\frac{C_{13}^{2}}{C_{33}}\right) \varepsilon_{1}+\left(C_{12}-\frac{C_{23} C_{13}}{C_{33}}\right) \varepsilon_{2} \\
\sigma_{2}=\sigma_{\text {hmax }}=\frac{C_{23}}{C_{33}} \sigma_{3}+\left(C_{12}-\frac{C_{13}^{2}}{C_{33}}\right) \varepsilon_{1}+\left(C_{22}-\frac{C_{23} C_{13}}{C_{33}}\right) \varepsilon_{2}
\end{gathered}
$$


The porous rock requires to consider the pore pressure $\left(p_{p}\right)$ to calculate the effective stress with considering pore elasticity effect. The effective stress is expressed by $\sigma^{\prime}$ and the $\alpha$ also signs the biot coefficient.

$$
\sigma^{\prime}=\sigma-\alpha p_{p}
$$

The horizontal stresses (minimum and maximum) can also be written as the function of elastic moduli and principle strains (Far et al., 2016).

The strains are also be solved bellowed as a function of $\varepsilon_{1}$ by assuming $\sigma_{2}$ and $\sigma_{3}$ to zero in the (Eq. 19, 20, and 21).

$$
\begin{aligned}
& \varepsilon_{2}=\frac{C_{23} C_{12}-C_{33} C_{12}}{C_{22} C_{33}-C_{23}^{2}} \varepsilon_{1} \\
& \varepsilon_{3}=\frac{C_{23} C_{12}-C_{22} C_{13}}{C_{22} C_{33}-C_{23}^{2}} \varepsilon_{1}
\end{aligned}
$$

Young modulus are also calculated by substituting the (Eq. 25 and 26) into (Eq. 19). In this was the young modulus in the lamination direction can be calculated as it is shown below:

$$
\begin{aligned}
& E_{1}=\frac{o_{1}}{\varepsilon_{1}}=C_{11}+\frac{C_{23} C_{13} C_{13}-C_{33} C_{12}^{2}}{C_{22} C_{33}-C_{23}^{2}}+\frac{C_{23} C_{13} C_{12}-C_{22} C_{13}^{2}}{C_{22} C_{33}-C_{23}^{2}} \\
& E_{2}=\frac{o_{2}}{\varepsilon_{2}}=C_{22}+\frac{C_{12} C_{23} C_{12}-C_{33} C_{12}^{2}}{C_{11} C_{33}-C_{13}^{2}}+\frac{C_{13} C_{23} C_{12}-C_{11} C_{23}^{2}}{C_{11} C_{33}-C_{13}^{2}} \\
& E_{3}=\frac{o_{3}}{\varepsilon_{3}}=C_{33}+\frac{C_{12} C_{13} C_{23}-C_{11} C_{23}^{2}}{C_{11} C_{22}-C_{12}^{2}}+\frac{C_{12} C_{13} C_{23}-C_{22} C_{13}^{2}}{C_{11} C_{22}-C_{12}^{2}}
\end{aligned}
$$

The Poisson's ratio calculations can also be interpreted with the strain formulations (Eq. 25 and 26). 


$$
\begin{aligned}
& \gamma_{12}=-\frac{\varepsilon_{2}}{\varepsilon_{1}}=\frac{C_{23} C_{13}-C_{33} C_{12}}{C_{23}^{2}-C_{22} C_{33}} \\
& \gamma_{13}=-\frac{\varepsilon_{2}}{\varepsilon_{1}}=\frac{C_{23} C_{12}-C_{22} C_{13}}{C_{23}^{2}-C_{22} C_{33}}
\end{aligned}
$$

The other Poisson's rations can be derived in this similar way as well:

$$
\begin{aligned}
& \gamma_{21}=-\frac{\varepsilon_{1}}{\varepsilon_{2}}=\frac{C_{13} C_{23}-C_{33} C_{12}}{C_{13}^{2}-C_{11} C_{33}} \\
& \gamma_{23}=-\frac{\varepsilon_{3}}{\varepsilon_{2}}=\frac{C_{13} C_{12}-C_{11} C_{23}}{C_{13}^{2}-C_{11} C_{33}} \\
& \gamma_{31}=-\frac{\varepsilon_{1}}{\varepsilon_{3}}=\frac{C_{12} C_{23}-C_{13} C_{22}}{C_{12}^{2}-C_{11} C_{22}} \\
& \gamma_{32}=-\frac{\varepsilon_{2}}{\varepsilon_{3}}=\frac{C_{12} C_{13}-C_{23} C_{11}}{C_{12}^{2}-C_{11} C_{22}}
\end{aligned}
$$

From the (Eq. 22) to the (Eq. 33) can be employed by considering $C_{11}=C_{22}, C_{13}=C_{23}, C_{44}=C_{55}$, and $C_{13}=C_{11}-2 C_{66}$ for the TI Model Case. For the ISO case the same equation from the (Eq. 22) to the (Eq. 33) can be applied by considering $C_{11}=C_{22}=C_{33}, C_{12}=C_{13}=C_{23}, C_{44}=C_{55}=C_{66}$, and $C_{12}=C_{11}-2 C_{66}$ 


\section{Results and Discussions}

Results from $\mathrm{OB}$ and TI models are compared with different comparison methods for the shales. The main comparison was in the TVD to minimum horizontal stress values because the main effect that is generally considered as vital in the hydraulic fracturing modelling and all kind of the completion applications. Moreover, the upper and lower stress barriers are plotted and compared within every shale. With this effort, more clear vision to understand how these estimations are successful are aimed. The basic logic behind these comparisons can be formulized as follows:

$$
\begin{aligned}
& \sigma_{\text {upper barrier }}=\sigma_{\text {upper }}-\sigma_{\text {frac }} \\
& \sigma_{\text {lower barrier }}=\sigma_{\text {lower }}-\sigma_{\text {frac }}
\end{aligned}
$$

Deviations between the $\mathrm{OB}$ and $\mathrm{TI}$ models' results are first can be seen in these upper and lower stress barrier results graphs. These graphs are plotted with the stress barriers in psia to SWS in percentage values.

SWS is basically the separation of DTS fast and DTS slow. It is introduced to measure the relative difference between the fast and slow shear wave slowness measured in vertical well. The new parameter SWS is directly proportional to the natural fracture intensity. Thus, it is a good measure of the natural fracture-induced anisotropy. The higher SWS, the larger anisotropy introduced by natural fractures. The SWS parameter is defined by the equation below,

$$
S W S=\frac{D T S_{\text {slow }}-D T S_{\text {fast }}}{D T S_{\text {slow }}} \times 100
$$

The results are lastly discussed in the discussion part to obtain an inclusive result which summarizes the necessity of the OB model. To have a clear and meaningful look at the results, two summarized upper and lower stress barrier graphs are plotted. There graphs also provide a deeper understanding of the importance of the consideration of natural fracture anisotropy.

More than stress barrier comparison, cap zone and frac zone comparison and shear wave splitting, the discussion part also aims to examine the impacts on the mechanical properties and in-situ stress comparison, optimization of the drilling operation, and operation parameters and quality aspects of the proppant pumping and the drilling. 


\subsection{Bakken Shale}

\subsubsection{Bakken Shale Stress Contrasts Results}

The well data of Bakken shale involves between $8880 \mathrm{ft}$. and $9050 \mathrm{ft}$. depth with an average density value of $2.6 \mathrm{~g} / \mathrm{cc}$.

Three graphs were plotted for Bakken shale case. While, Figure 32 is a comparison of the minimum horizontal stress vis a vis TVD for TI and OB cases of Bakken Shale. Figure 33 is the upper and lower stress barriers as a function of separation of DTS fast and DTS slow. Figure 34 is also plotted to see the differences between the upper and the lower stress barriers between the two models.

One important observation from the Bakken Shale's minimum stress versus TVD plot is that the natural fracture induced anisotropy leads to a decrease of the stress magnitude, which agrees well with the previous published study (Gu, 2017).

Another benefit of plotting Figure 32 is that it helps to understand how the natural fracture induced anisotropy impacts the stress contrast between the cap rock and pay rock (stress barrier), the pay zone and cap zones which were chosen and highlighted in the Figure 32. According to the Figure 32. The upper stress barrier is stated between $8925 \mathrm{ft}$. to $8975 \mathrm{ft}$. The frac zone for the Bakken Shale is set between $8975 \mathrm{ft}$. to 8995 $\mathrm{ft}$.

The lower stress barrier is located between $8995 \mathrm{ft}$. to $9050 \mathrm{ft}$.
Bakken Shale

ohmin (psia)

4000450050005500600065007000

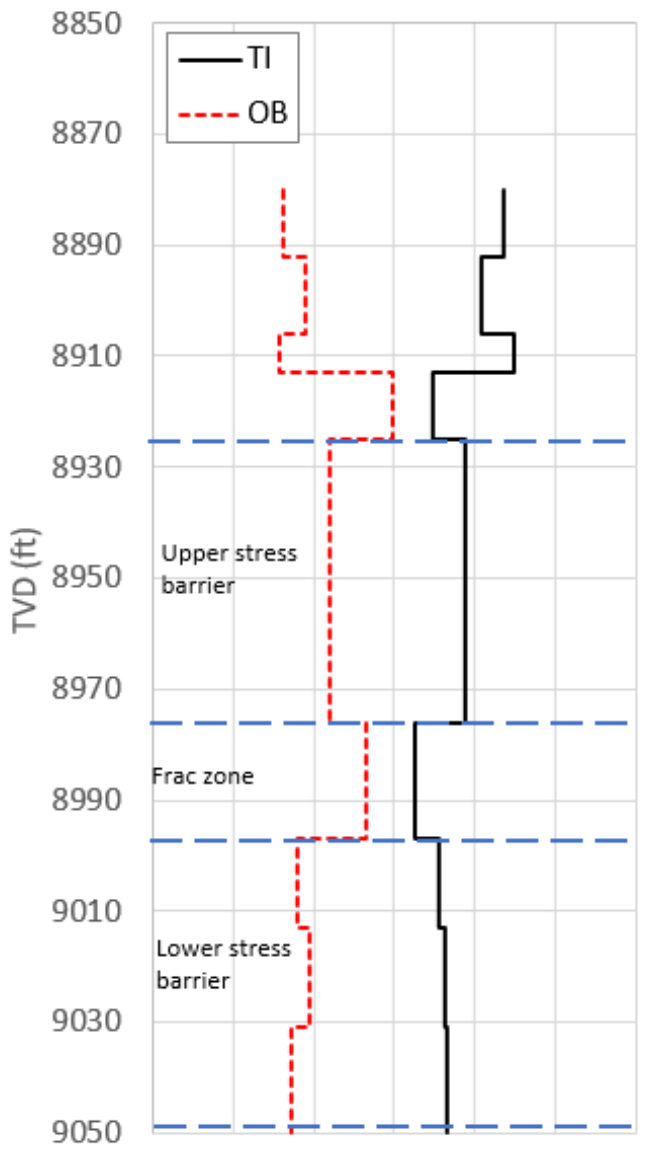

Figure 32: Minimum horizontal stress vs. TVD plot of the

Bakken Shale. 


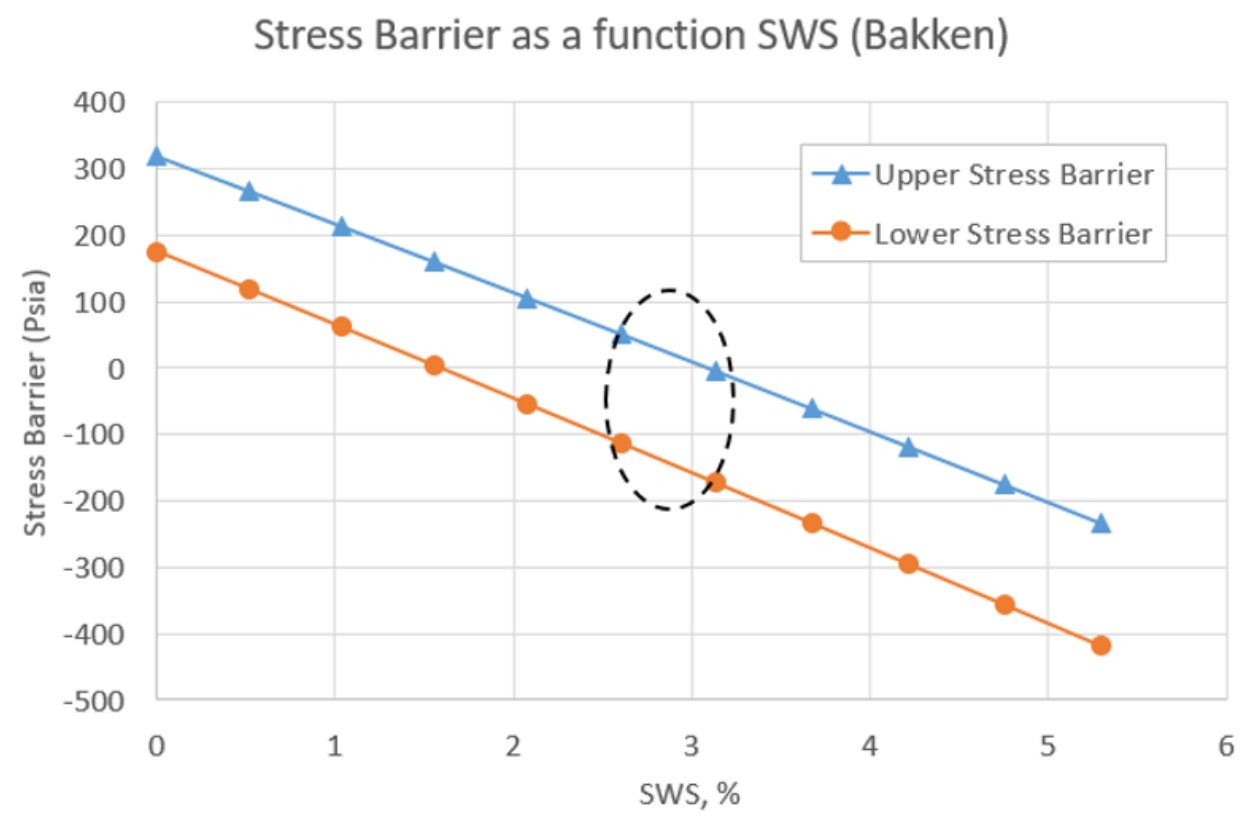

Figure 33: SWS vs. Stress Barrier plot of the Bakken Shale.

According to Figure 33, as SWS increases, both the upper and lower stress barriers decreaseAnother interesting observation is that, at around 3\% SWS, the stress barriers become negative, which suggests a disappeared stress barrier under high natural fracture intensity situation in Bakken. Inputting these stress profiles in a frac simulation model, one can expect to see that the hydraulic fracture tends to grow more in the vertical direction in Bakken shale with higher natural fracture intensity.

From the frac design point of view, if a naturally fractured Bakken shale rock is treated as a TI rock by ignoring the natural fracture induced anisotropy in acoustic log interpretation and lab measurement, both the upper and lower stress barriers will be overestimated, which can lead to the suboptimal (excessive) design of proppant laden fluid viscosity and proppant pumping loads. 


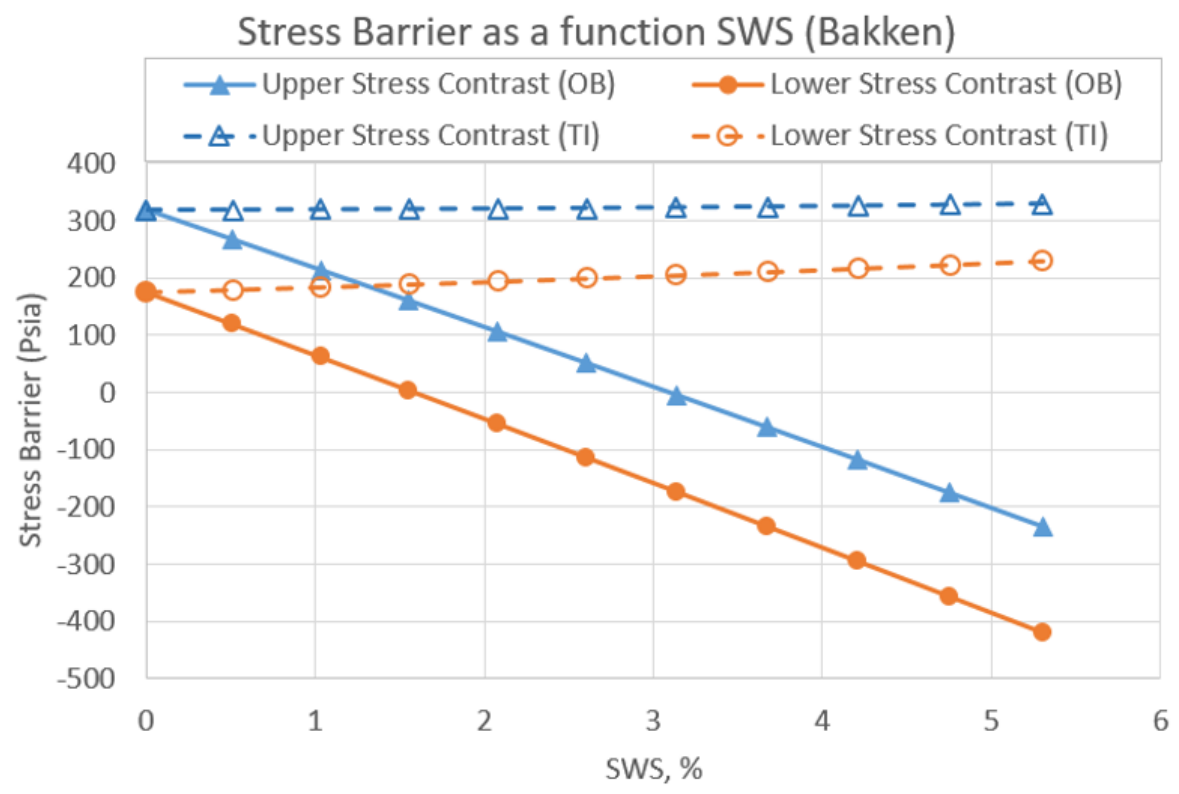

Figure 34: Upper and lower stress barriers vs. SWS plot of Bakken Shale.

In the plot in Figure 34, the solid lines are the stress contrast results predicted based on the OB model, whereas the dashed lines are the results by treating the OB rock as a simplified TI model in acoustic log interpretation. Comparing the upper and lower stress contrasts from the OB model and TI approximation, by ignoring the natural fracture induced anisotropy, both the upper and lower stress contrast will be overestimated. Quantitatively, the upper stress contrast will be overestimated by a value range of 52.57 to 563.14 psia, while the lower stress contrast will be overestimated by a value range of 60.81 to 649.00 psia, as the SWS increases from $0.515 \%-5.3 \%$.

According to the previous works (Far et al., 2015), the perforation and staging design can be optimized based upon the closure stress (minimum horizontal stress) gradient along the horizontal wellbore. The hypothesis is that, for a target stage, more perforation clusters can be fully fractured when the closure stress to overcome at each perforation cluster is similar. Thus, to improve the frac efficiency, it is better to have lower stress contrast (more uniform stress gradient) within a single stage. Minimizing the stress contrast between clusters within any one stage allows the stimulation of each cluster at a similar fracture propagating rate, which hence improves the completion efficiency. For the current case, since the stress contrast is quite uniform within the target frac payzone, the stress contrast does not change much when treating an OB rock with the TI rock model. Therefore, applying TI assumption to a naturally fractured Bakken shale rock will not affect the completion design when conducting the completion design based on the closure stress gradient. 


\subsubsection{Young's Modulus approach for NFs impact on the Bakken Shale}

Figure 35 shows how young's modulus change was examined within the shale rock. For a better understanding, horizontal young's modulus and the SWS in percent were studied in three sections for Bakken Shale, namely, lower zone, middle zone, and upper zone. The figure also shows the OB model, which is true value of the estimation with solid line, and TI models were drawn with the dashed lines for three sections. TI estimations show the shale rock model without natural fractures within the rock body.

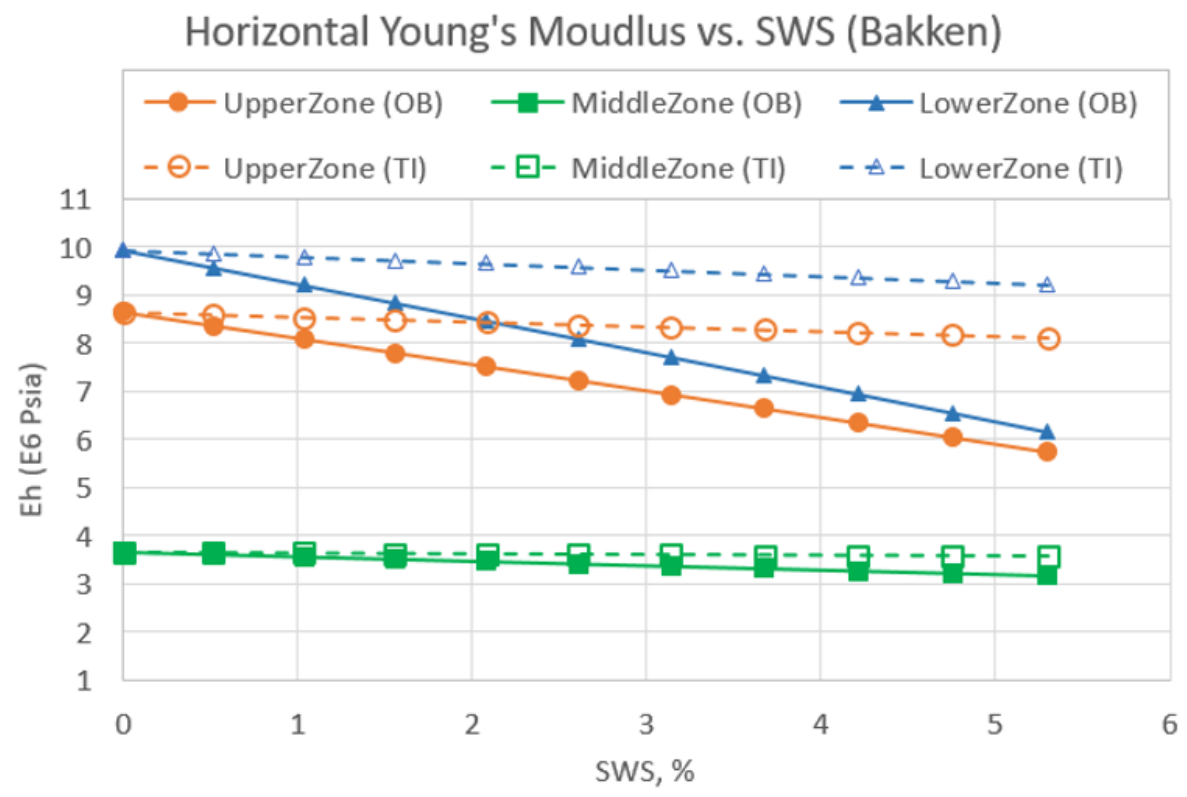

Figure 35: Bakken Shale's Young's Modulus distribution vs. SWS\%

Figure 35 shows that the middle section deviates slightly from the OB estimation which is the true value. While the OB rock model's estimation for the middle zone is underestimated, the lower and upper zones estimations are lower than TI estimations as well. Thus, ignoring the natural fracture anisotropy estimates the Young's modulus more than the true value, so the TI values are overestimated as SWS increases from $0.51 \%$ to $5.3 \%$. Consequently, the overestimated values are ranged for upper, middle and lower zones respectively as follows: $2.71 \%-41.63 \%, 1.07 \%-12.34 \%$, and $3.06 \%-49.94 \%$. 


\subsection{Eagle Ford Shale}

\subsubsection{Eagle Ford Shale Stress Contrasts Results}

Eagle Ford sonic log were obtained between $5900 \mathrm{ft}$. $-7300 \mathrm{ft}$. depth with an average density value of $2.53 \mathrm{~g} / \mathrm{cc}$.

Three plots were drawn for Eagle Ford Shale case. Figure 36 is a comparison of the minimum horizontal stresses of the $\mathrm{TI}$ and $\mathrm{OB}$ rock from the same shale. Figure 37 . is the upper and lower stress barriers' graph as a function of the separation of DTS fast and DTS slow. On the other hand, Figure 38 is plotted to see the differences between the upper and the lower stress barriers between the two models.

One important observation from Eagle Ford's minimum stress versus TVD plot is that the natural fracture induced anisotropy leads to a decrease of the stress magnitude, which agrees well with the previous published study (Gu, 2017).

Another benefit plotting Figure 35 is that it helps to understand how the natural fracture induced anisotropy impacts the stress contrast between the cap rock and pay rock (stress barrier), the pay zone and cap zone were selected and highlighted in the Figure 35. According to the Figure 35, the upper stress barrier was located between $6150 \mathrm{ft}$. to 6300 $\mathrm{ft}$, and the frac zone for the Bakken Shale was set between $6300 \mathrm{ft}$. to $6600 \mathrm{ft}$. The lower stress barrier was also located between $6600 \mathrm{ft}$. to $7200 \mathrm{ft}$.

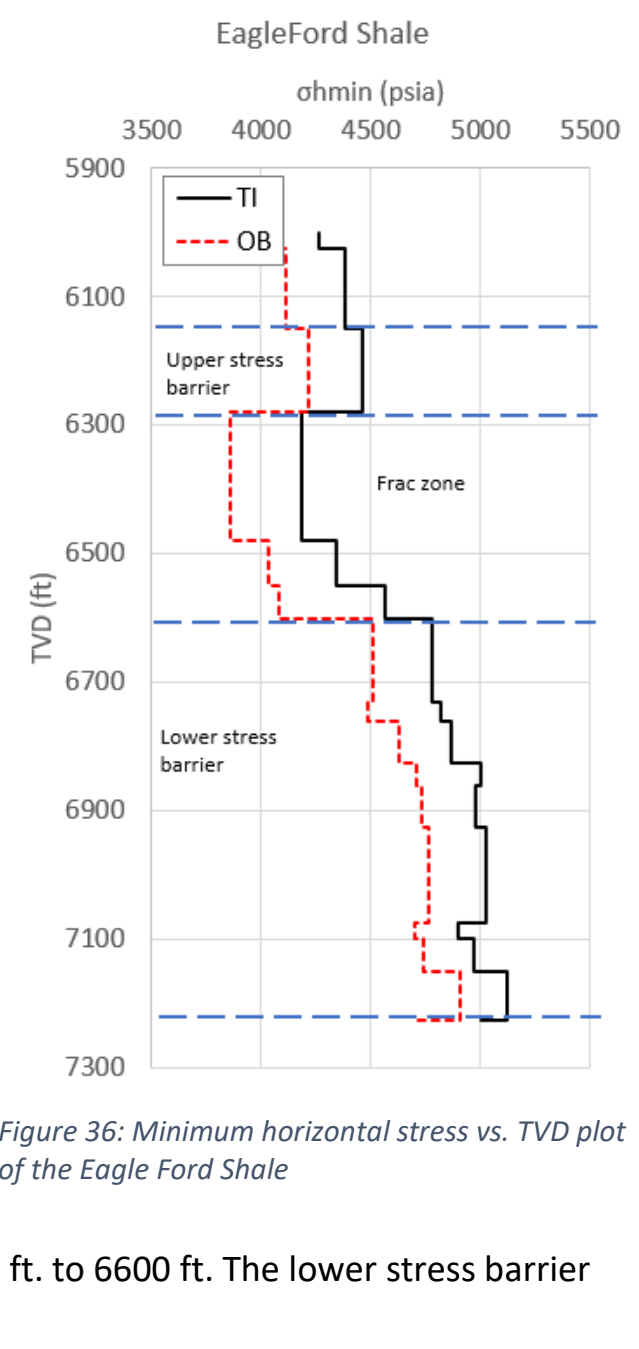




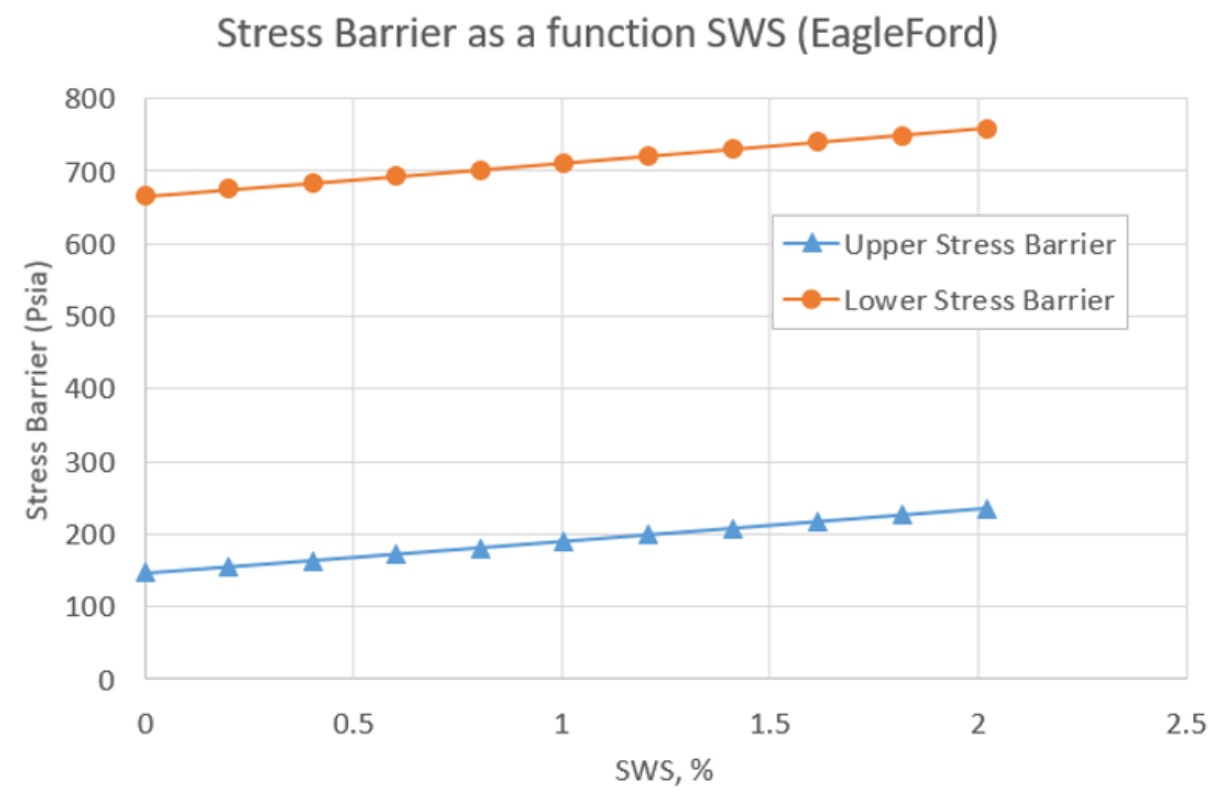

Figure 37: SWS vs. Stress Barrier plot of the Eagle Ford Shale

According to Figure 37, as SWS increases, both the upper and lower stress barriers increase, which contrasts with what we observed in the previous Bakken Shale case. The upper and lower stress barriers increase by $28 \%$ and $10 \%$ respectively, when SWS increases from 0 to $2 \%$. Inputting these stress profiles in a frac simulation model, one can expects to see that the hydraulic fracture tends to grow less in the vertical direction in zones with higher natural fracture intensity of Eagle Ford Shale.

From the frac design point of view, if a naturally fractured Eagle Ford shale rock is treated as a TI rock by ignoring the natural fracture induced anisotropy in acoustic log interpretation and lab measurement, both the upper and lower stress barriers will be underestimated, which can lead to the suboptimal (insufficient) design of proppant laden fluid viscosity and proppant pumping loads. 


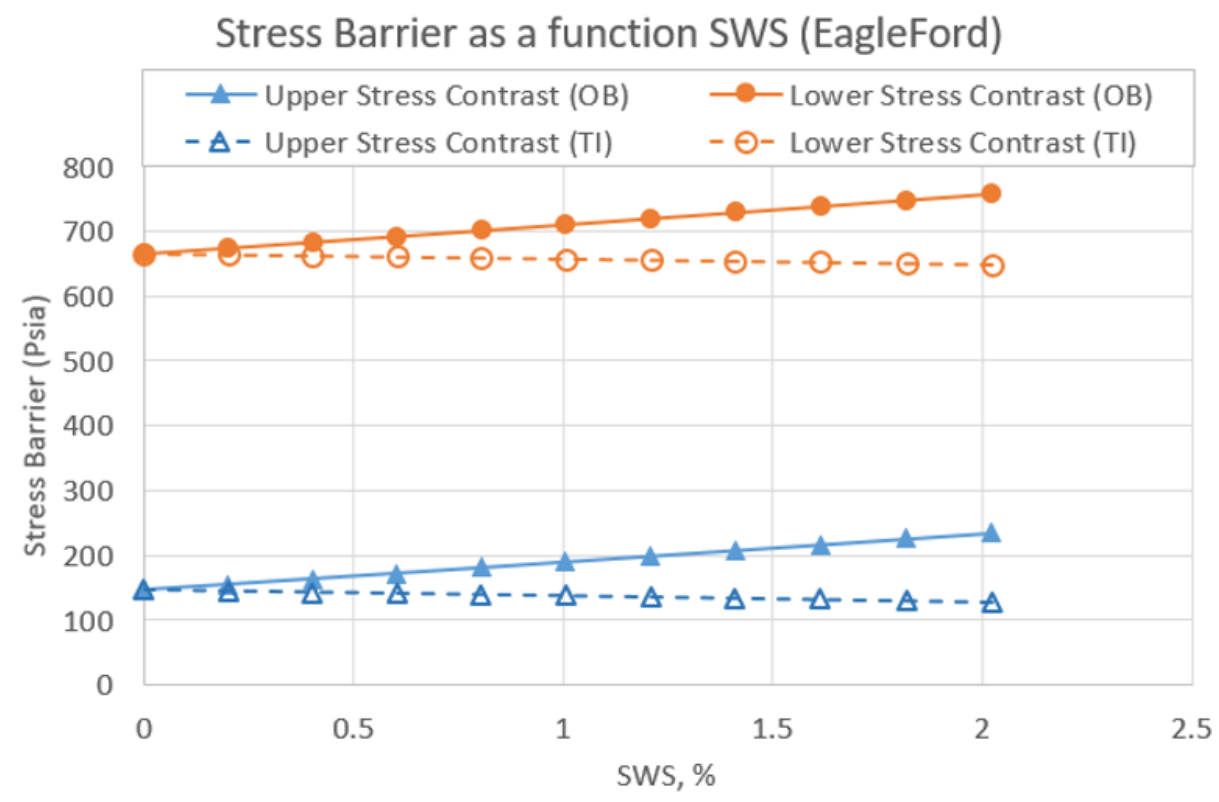

Figure 38: Upper and lower stress barriers vs. SWS plot of Eagle Ford Shale

According to Figure 38 , the solid lines are the stress contrast results predicted based on the OB model, whereas the dashed lines are the results by treating the OB rock as a simplified TI model in acoustic log interpretation. Comparing the upper and lower stress contrasts from the OB model and TI approximation, by ignoring the natural fracture induced anisotropy, both the upper and lower stress contrasts will be underestimated. Quantitatively, the upper stress contrast will be underestimated by $6.62 \%-45.47 \%$, while the lower stress contrast will be underestimated by $1.54 \%-14.41 \%$, as the SWS increases from $0.2 \%-2 \%$.

For Eagle Ford Shale, similar as Bakken Shale, the stress contrast is uniform within the target frac payzone. As a result, there should be not much difference in designing stage length and perforation cluster location with or without considering natural fracture induced anisotropy.

According to the Figure 39 and Figure 40, the frac zone which is between $6300 \mathrm{ft}$. to $6600 \mathrm{ft}$ were examined with the different SWS values. SWS is directly proportional to the natural fracture intensity, hence the increment in the SWS from 1\% to $2 \%$ means the increase in the natural fracture intensity proportionally. Thus, Figure 39 and Figure 40 are views in detail of the fracture zone of the Eagle Ford Shale. 
Stress Contrast within the EagleFord Pay (SWS=1\%)

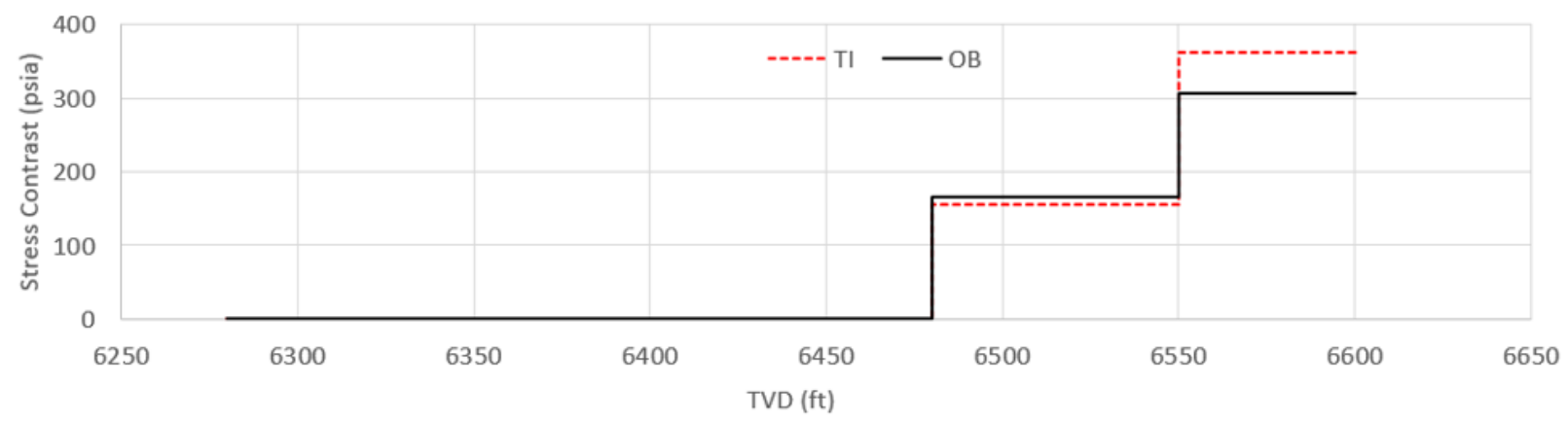

Figure 39: Stress contrasts of OB and TI within the Eagle Ford versus TVD while the SWS is 1 percent

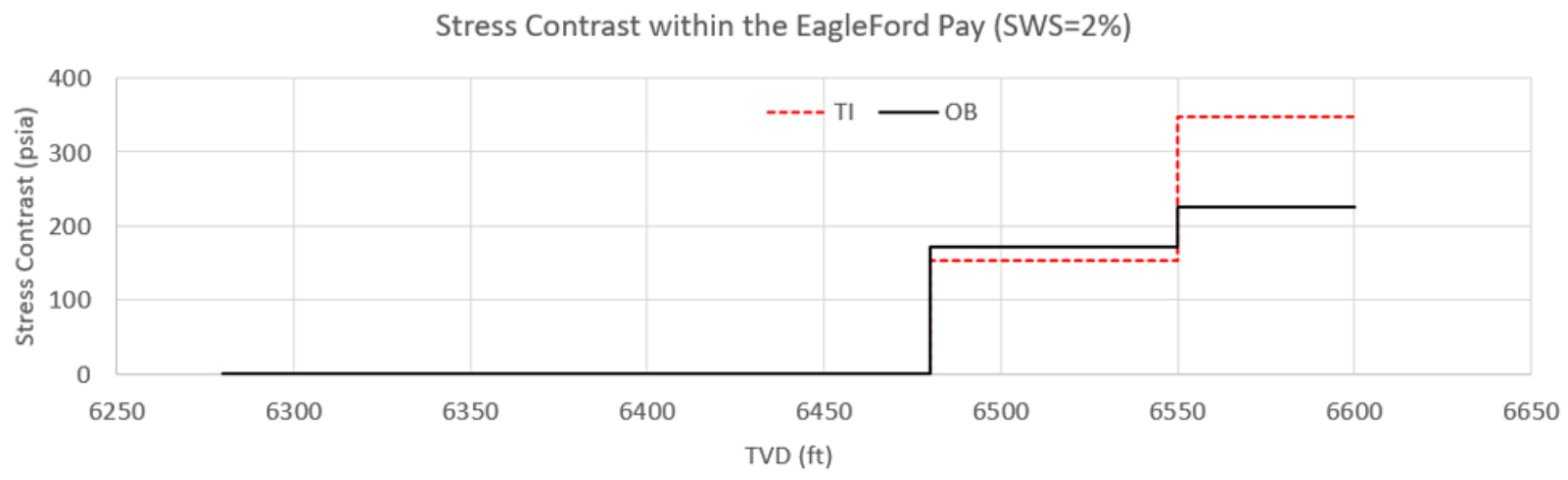

Figure 40: Stress contrasts of $O B$ and TI within the Eagle Ford versus TVD while the SWS is 2 percent 


\subsubsection{Young's Modulus approach for NFs impact on the Eagle Ford Shale}

Figure 41 shows how young's modulus change was examined within the shale rock. For a better understanding, horizontal young's modulus and the SWS in percent were studied in three sections for Eagle Ford Shale, namely, lower zone, middle zone, and upper zone. The figure also shows the OB model, which is true value of the estimation with solid line, and TI models were drawn with the dashed lines for three sections. TI estimations show the shale rock model without natural fractures within the rock body.

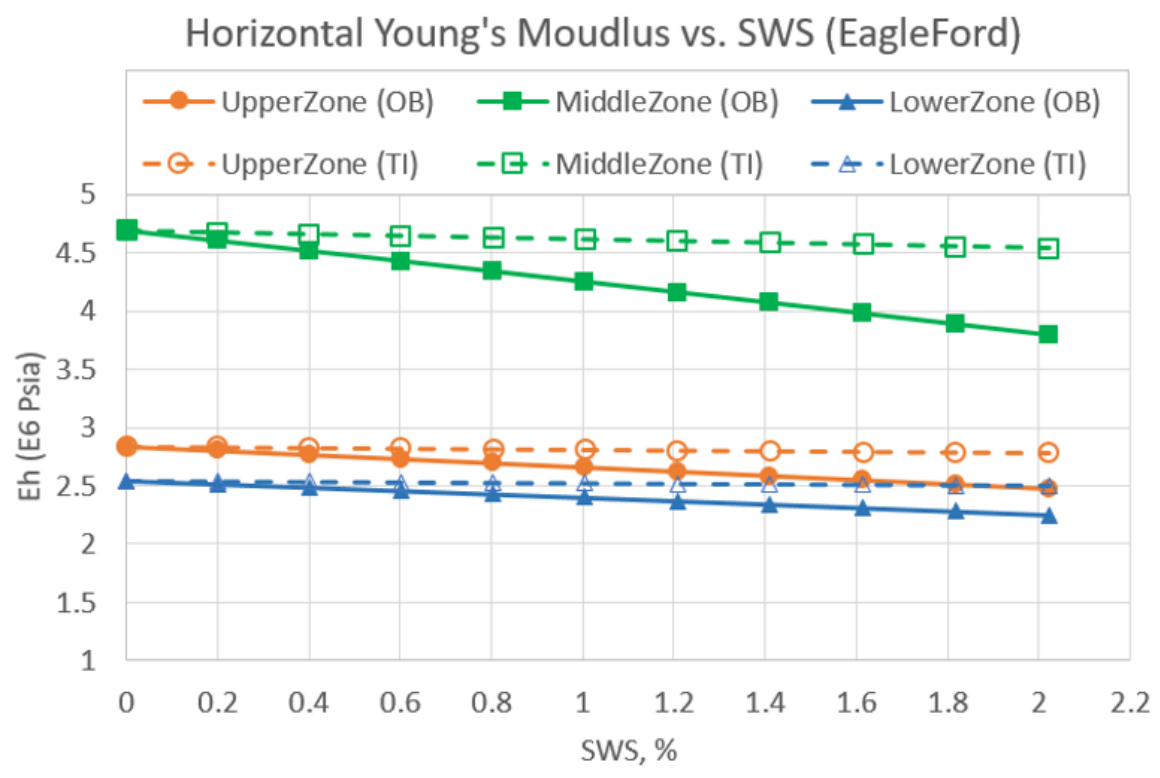

Figure 41: : Eagle Ford Shale's Young's Modulus distribution vs. SWS\%

Figure 41 shows that the middle section deviates more than the upper and the lower zones. While both lower, middle, and upper zone estimations for the $\mathrm{TI}$ zone are overestimated, the lower and the upper zones are slightly overestimated, but the middle zone has an overestimation range as $1.56 \%$ $19.75 \%$, while the SWS increases from $0.2 \%$ to $2 \%$, The other two zones are overestimated as follows $1.06 \%-12.42 \%, 0.95 \%-10.95 \%$ for upper and lower zones respectively. 


\subsection{Haynesville Shale}

\subsubsection{Haynesville Shale Stress Contrasts Results}

Plots in this section are related between the $10520 \mathrm{ft}$. - $10620 \mathrm{ft}$. depths of the Haynesville Shale. The average density of the related well is $2.46 \mathrm{~g} / \mathrm{cc}$.

Three plots were drawn for each shale case. Figure 42 is a comparison of the $\mathrm{TI}$ and $\mathrm{OB}$ rock mediums' minimum horizontal stresses and TVD values from the same shale. Figure 43 is the upper and lower stress barriers as a function of separation of DTS fast and DTS slow. Figure 44 is plotted to see the differences between the upper and the lower stress barriers between the two models.

One important observation is that the natural fracture induced anisotropy leads to a decrease of the stress magnitude, which agrees well with the previous published study (Gu, 2017).

Another benefit plotting Figure 42. is that it helps to understand how the natural fracture induced anisotropy impact the stress contrast between the cap rock and pay rock (stress barrier), the pay zone and cap zone are selected and highlighted in the Figure 40. According to the Figure 42 the upper stress barrier is stated between $10535 \mathrm{ft}$. to $10560 \mathrm{ft}$. The frac zone for the Bakken Shale was set between

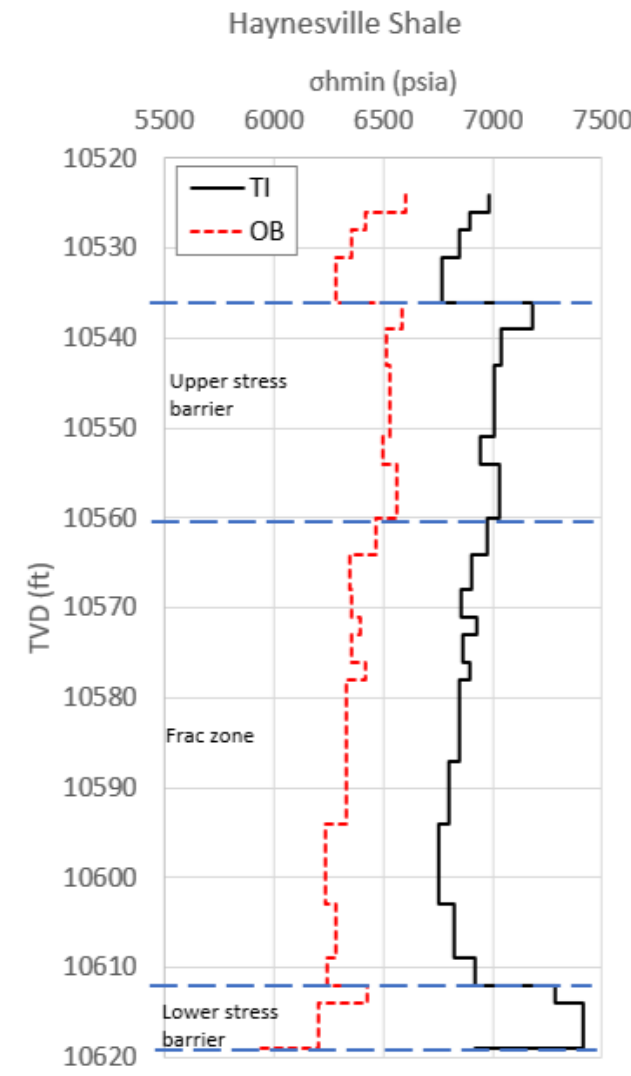
$10560 \mathrm{ft}$ to $10610 \mathrm{ft}$. The lower stress barrier was located between $10610 \mathrm{ft}$. to $10620 \mathrm{ft}$. 


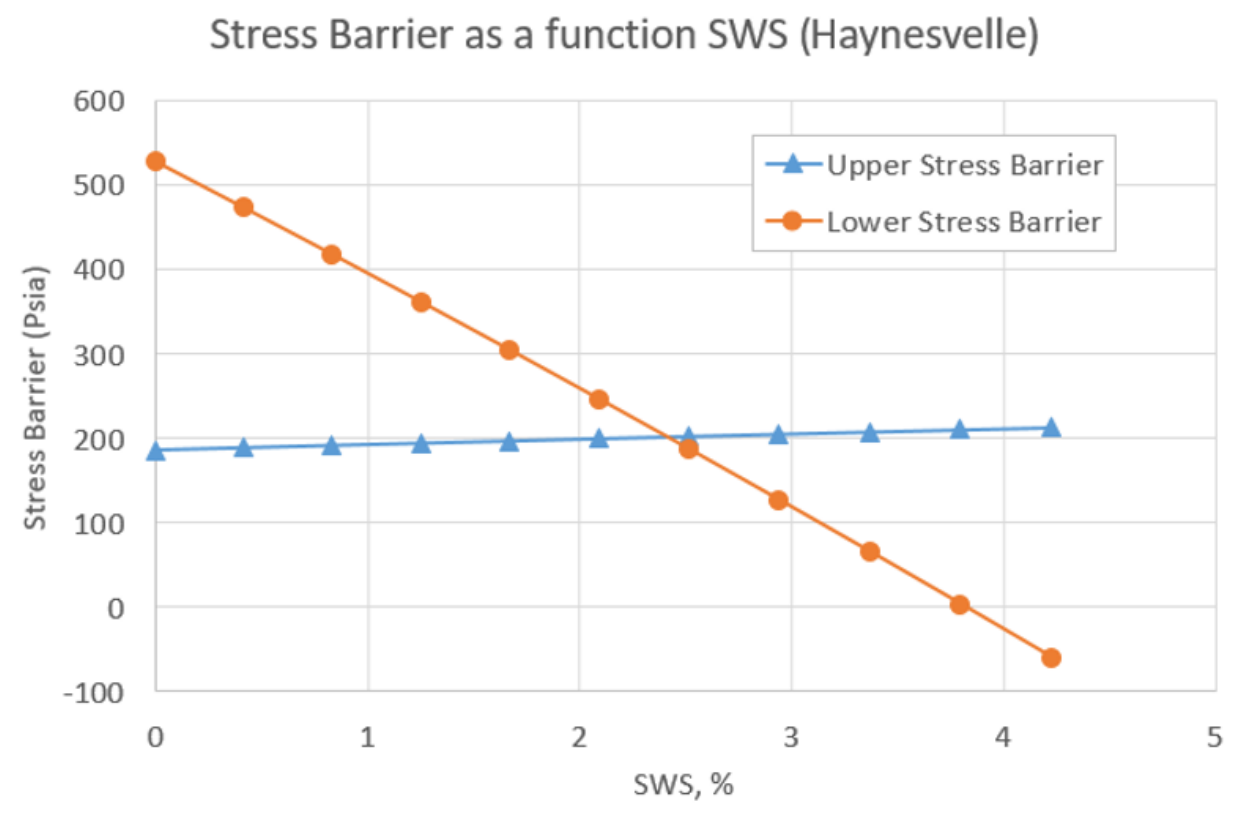

Figure 43: SWS vs. Stress Barrier plot of the Haynesville Shale

According to Figure 43, as SWS increases, the upper stress barrier slightly changes while the lower stress barrier decreases significantly, which is different from all previous shale cases. Another important observation is that the lower stress barrier disappears (lower stress barrier becomes negative) when SWS is beyond $3.8 \%$. Inputting these stress profiles in a frac simulation model, one can expect to see that the hydraulic fracture tends to grow downwards in zones with higher natural fracture intensity of Haynesville Shale.

From the frac design point of view, if a naturally fractured Haynesville shale rock is treated as a TI rock by ignoring the natural fracture induced anisotropy in acoustic log interpretation and lab measurement, the lower stress barriers will be misinterpreted significantly. The overestimated lower stress barrier can lead to several frac design problems such as first, the perforation cluster position is designed too low, second, the suboptimal (excessive) design of proppant laden fluid viscosity, and third, the excessive design of proppant pumping amount. 


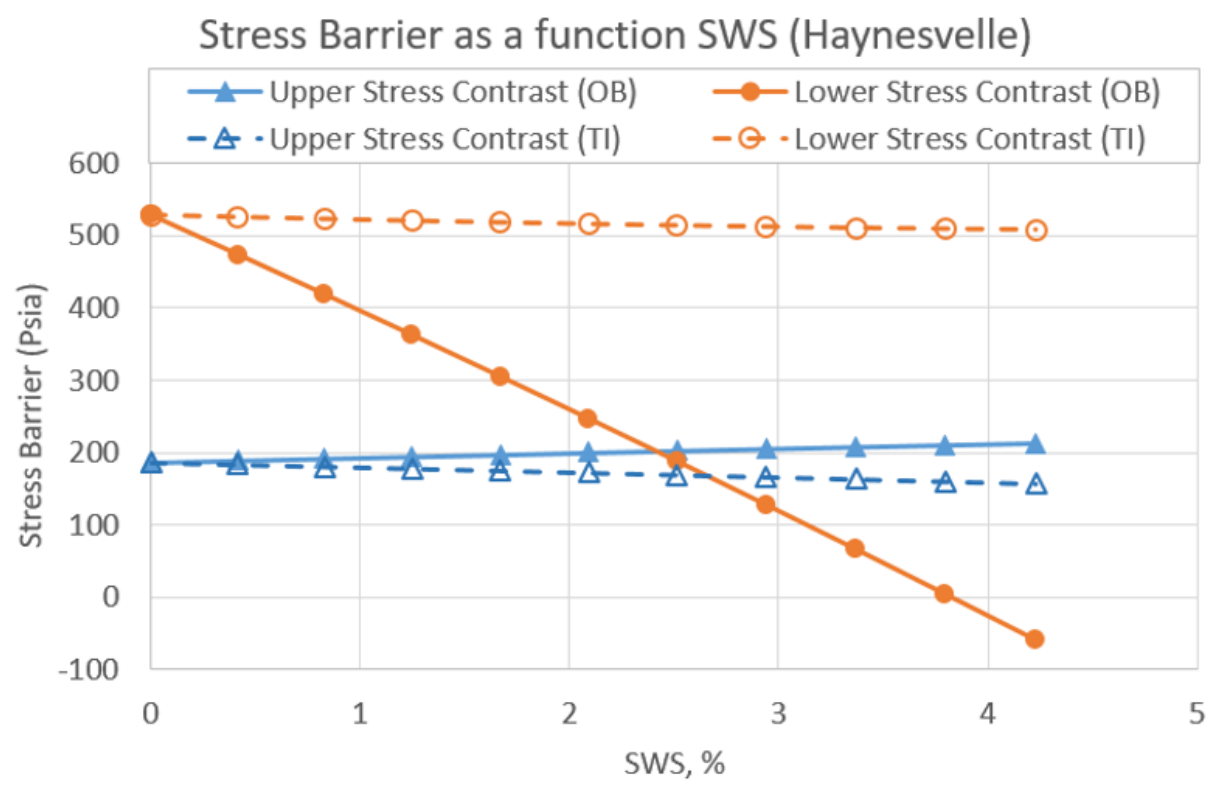

Figure 44: Upper and lower stress barriers vs. SWS plot of Haynesville Shale

In Figure 44, the solid lines are the stress contrast results predicted based on the OB model, whereas the dashed lines are the results by treating the OB rock as a simplified TI model in acoustic log interpretation. Comparing the upper and lower stress contrast from the OB model and $\mathrm{TI}$ approximation, by ignoring the natural fracture induced anisotropy, the upper stress contrast will be slightly underestimated while the lower stress contrast will be highly overestimated. Quantitatively, the upper stress contrast will be slightly underestimated by $2.89 \%-26.41 \%$ as the SWS increases from $0.415 \%$ $4.23 \%$. The lower stress contrast will be overestimated by a value range of 51.57 psia to 567.84 psia as the SWS increases from $0.415 \%$ to $4.23 \%$.

Unlike Bakken and Eagle Ford, there is an obvious stress variation along the depth within the payzone for Haynesville. In Figure 45 and Figure 46, the stress contrast of the payzone was plotted against TVD for the two models. Figure 45 shows the comparison at SWS $=1.25 \%$, while Figure 46 shows the comparison at SWS $=4.23 \%$. The stress contrast within the payzone was calculated by subtracting the minimum stress within the pay from the stress of each layer. According to Figure 45, if the shear wave splitting is $1.25 \%$, the stress contrast changes slightly for the most parts of the payzone when treating the $\mathrm{OB}$ rock as a simplified TI model in acoustic log interpretation. The only exception is at the depth from 10605-10612 ft. The stress contrast is overestimated by around 50 psia when treating the $\mathrm{OB}$ rock with the $\mathrm{TI}$ model by ignoring the natural fracture induced elastic anisotropy. As SWS increases to $4.23 \%$, the overall stress contrast is exaggerated when simplifying the OB rock as $\mathrm{TI}$ model. Specifically, the stress contrast is overestimated by 40-60 psia from 10564-10576 ft, by $60 \mathrm{ft}$ from 10578-10594 ft, and by $150 \mathrm{ft}$ from 10594-10612 ft, when assuming OB rock as a TI medium. Therefore, ignoring the anisotropy induced by natural fractures will lead to a too short stage length design. 
Stress Contrast within the Haynesvelle Pay (SWS=1.25\%)

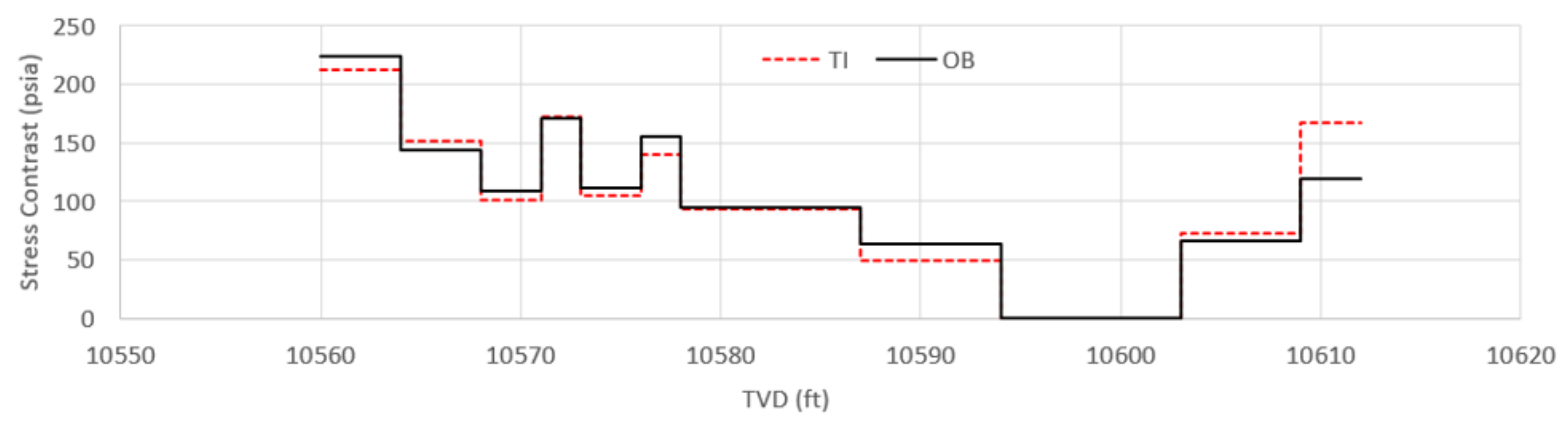

Figure 46: Stress contrasts of $O B$ and TI within the Haynesville Shale versus TVD while the SWS is 1.25 percent

Stress Contrast within the Haynesvelle Pay (SWS=4.23\%)

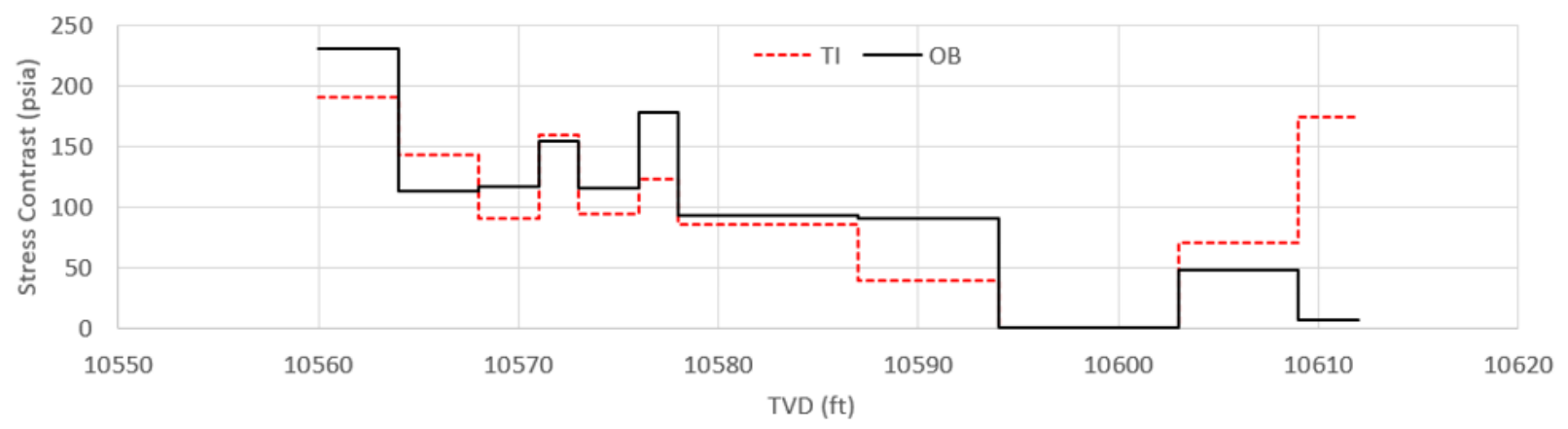

Figure 45: Stress contrasts of $O B$ and TI within the Haynesville Shale versus TVD while the SWS is 4.23 percent 


\subsubsection{Young's Modulus approach for NFs impact on the Haynesville Shale}

Figure 47 shows how young's modulus change was examined within the shale rock. For a better understanding, horizontal young's modulus and the SWS in percent were studied in three sections for Haynesville Shale, namely, lower zone, middle zone, and upper zone. The figure also shows the OB model, which is true value of the estimation with solid line, and TI models were drawn with the dashed lines for three sections. TI estimations show the shale rock model without natural fractures within the rock body.

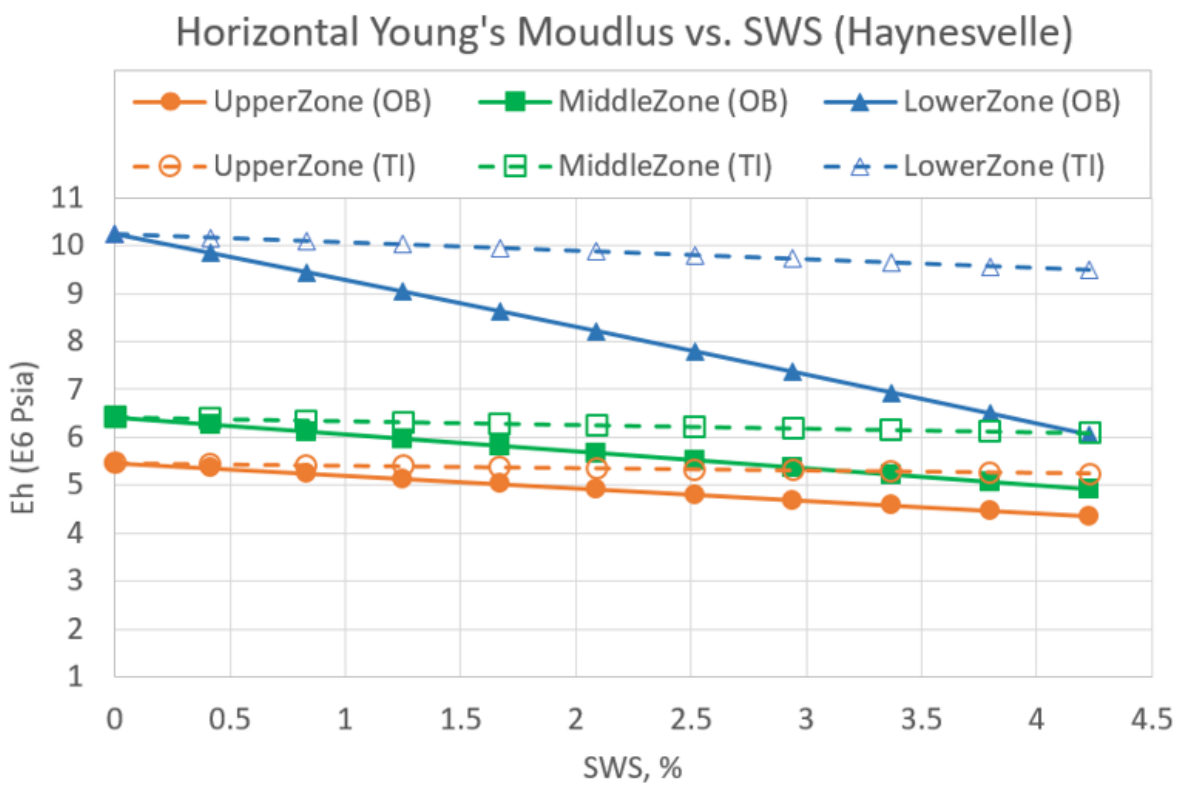

Figure 47: Young's Modulus approach for NFs impact on the Haynesville Shale

Figure 47 supports that more the SWS increases, the young's modulus increases, so the natural fracture omission misestimates the mechanical values. In Haynesville Shale, OB model estimations for the lower zone is underestimated and more deviated than upper and middle zones. While the upper and lower zones have an overestimation in TI values in the range of $1.62 \%-20.45 \%, 1.83 \%-24.04 \%$, with the increment of SWS from $0.544 \%$ to $4.23 \%$, the lower zone is overestimated in the range of $3.28 \%-56.79 \%$. Not like the other shale rocks, the Haynesville's lower zone shows a big deviation than other zones within the rock. The reason of this behavior was concluded as the effect of the mineralogical change through to the deepest part of the reservoir. As it is shown in the Figure 62, minerology drastically changes in the deeper zone of the Haynesville. While the upper and middle zones includes thicker quartz zone within the reservoir, poorest zone is deepest part of the Haynesville shale in terms of the quartz existence as it is shown in the sonic log data. 


\subsection{Marcellus Shale}

\subsubsection{Marcellus Shale Stress Contrasts Results}

The plots in this section are related between the $6700 \mathrm{ft}$. $-7900 \mathrm{ft}$. depths of the Haynesville Shale. The average density of the related well is $2.65 \mathrm{~g} / \mathrm{cc}$.

Three plots were gathered for each shale case. Figure 48 is a comparison of the minimum horizontal stresses of a $\mathrm{TI}$ and OB rock from the same shale. Figure 49 is the upper and lower stress barriers as a function of separation of DTS fast and DTS slow. Figure 50 was plotted to see the differences between the upper and the lower stress barriers between the two models.

One important observation is that the natural fracture induced anisotropy leads to a decrease of the stress magnitude, which agrees well with the previous published study (Gu, 2017).

Another benefit of plotting Figure 48 is that it helps to understand how the natural fracture induced anisotropy impact the stress contrast between the cap rock and pay rock (stress barrier), the pay zone and cap zone were selected and highlighted in the Figure 45 . According to the Figure 48 the upper stress barrier were stated between $7300 \mathrm{ft}$. to $7400 \mathrm{ft}$. The frac zone for the Bakken Shale were set between $7400 \mathrm{ft}$. to $7530 \mathrm{ft}$.

The lower stress barrier was located between $7530 \mathrm{ft}$. to $7550 \mathrm{ft}$.

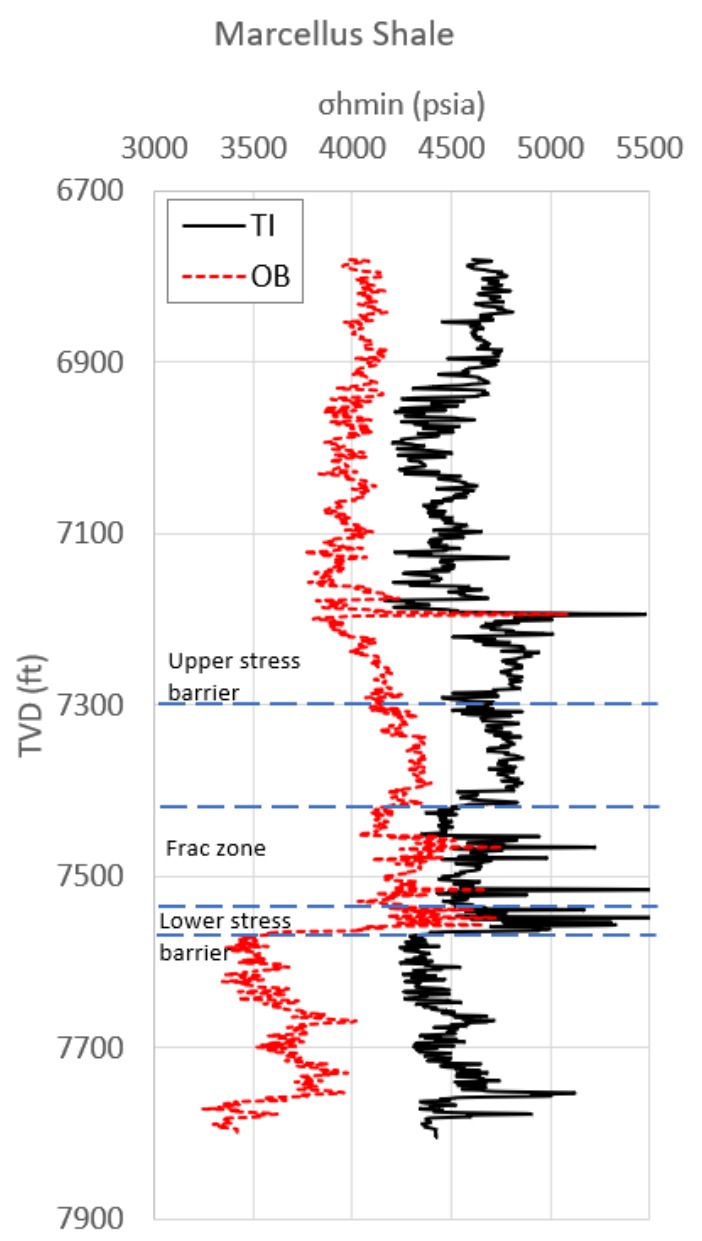

Figure 48: Minimum horizontal stress vs. TVD plot of the Marcellus Shale 


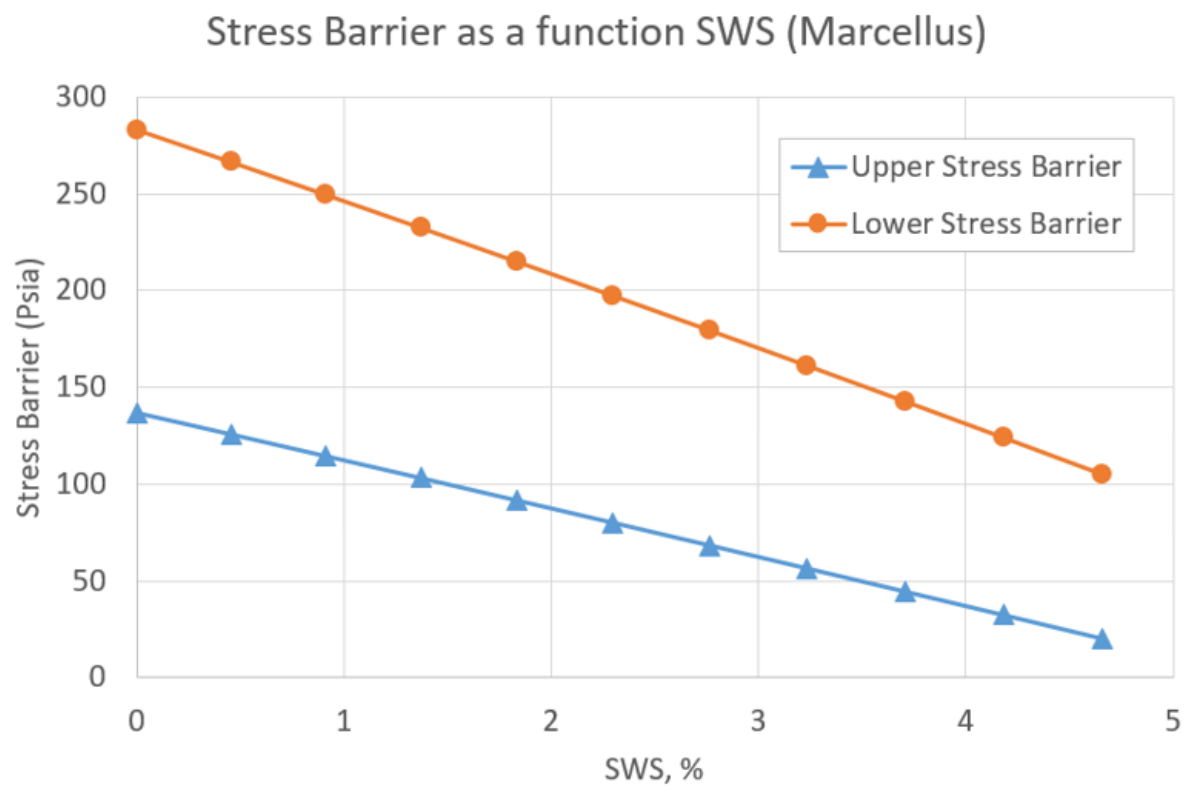

Figure 49: SWS vs. Stress Barrier plot of the Marcellus Shale.

According to Figure 49, as SWS increases, both the upper and lower stress barrier decrease. Inputting these stress profiles in a frac simulation model, one can expect to see that the hydraulic fracture tends to grow upward and downward more in Marcellus shale with higher natural fracture intensity.

From the frac design point of view, if a naturally fractured Marcellus shale rock is treated as a TI rock by ignoring the natural fracture induced anisotropy in acoustic log interpretation and lab measurement, both the upper and lower stress barrier will be overestimated, which can lead to the underestimation of fracture height and overestimation of fracture length, and hence lead to the suboptimal (excessive) design of proppant laden fluid viscosity and proppant pumping loads. 


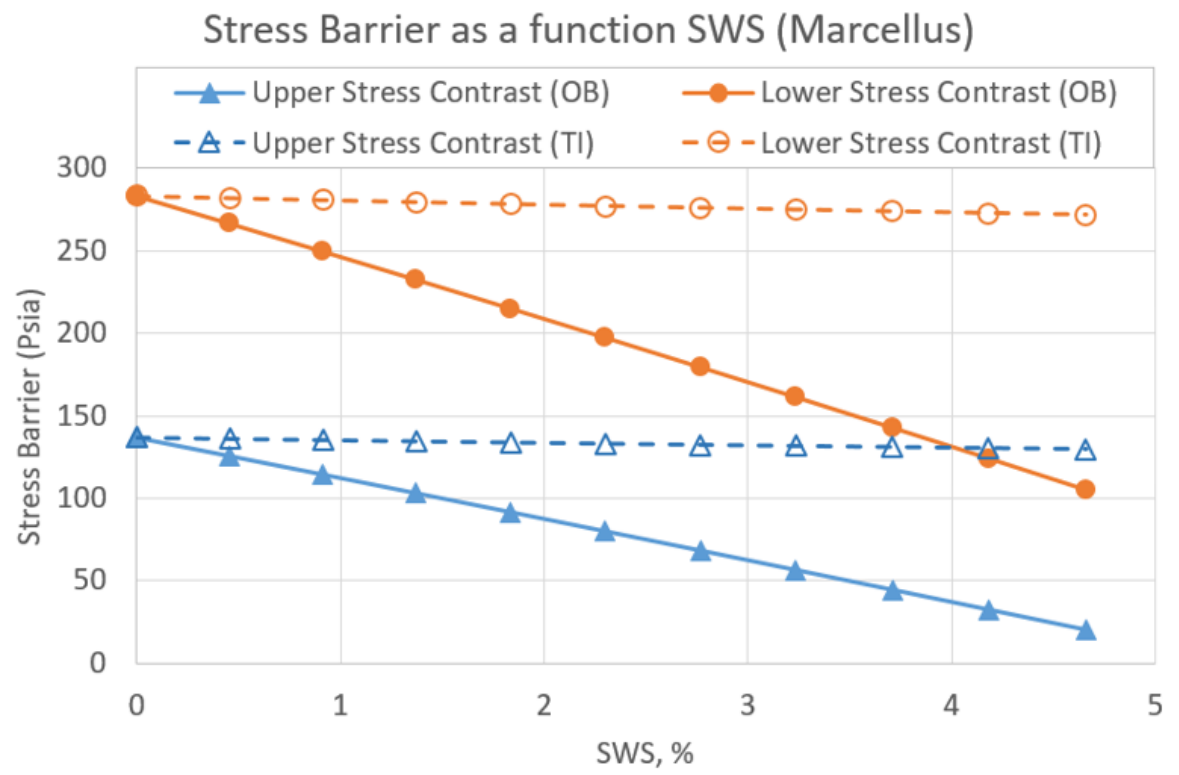

Figure 50: Upper and lower stress barriers vs. SWS plot of Marcellus Shale.

In the Figure 50, the solid lines are the stress contrast results predicted based on the OB model, whereas the dashed lines are the results which are obtained by treating the OB rock as a simplified TI model in acoustic log interpretation. Comparing the upper and lower stress contrast from the OB model and $\mathrm{TI}$ approximation, by ignoring the natural fracture induced anisotropy, both the upper and lower stress contrasts will be overestimated . Quantitatively, the upper stress contrast will be overestimated by a value range of 10.31 to 109.38 psia, while the lower stress contrast will be overestimated by 15.39 to $166.36 \mathrm{psia}$, as the SWS increases from $0.455 \%-4.66 \%$.

Like Haynesville Shale, there is an obvious stress variation along the depth within the payzone for Marcellus Shale. In Figure 51 and Figure 52, the stress contrast of the payzone is plotted against TVD for the two models. The upper plot shows the comparison at SWS $=1.37 \%$, while the lower plot shows the comparison at SWS $=4.18 \%$. The stress contrast within the payzone was calculated by subtracting the minimum stress within the pay from the stress at each depth. According to the upper plot, if the shear wave splitting is $1.37 \%$, the stress contrast almost doesn't change along the TVD within the payzone, which leads to a conclusion that the completion design is almost not affected by natural fracture induced anisotropy as along as SWS is around or smaller than $1.37 \%$ for Marcellus Shale. As SWS increases to $4.18 \%$, it is clear to notice an overestimation of stress contrast for depth range of 7454-7480 ft and 7516-7540 ft, when simplifying the OB rock as TI model. For the other zones within the payzone, the stress magnitudes decrease but the stress contrast does not change much. Therefore, ignoring the anisotropy induced by natural fractures will lead to a too short stage length design for the two depth rages that are highlighted in the lower plot of Figure 52. 
Stress Contrast within the Marcellus Pay (SWS=1.37\%)

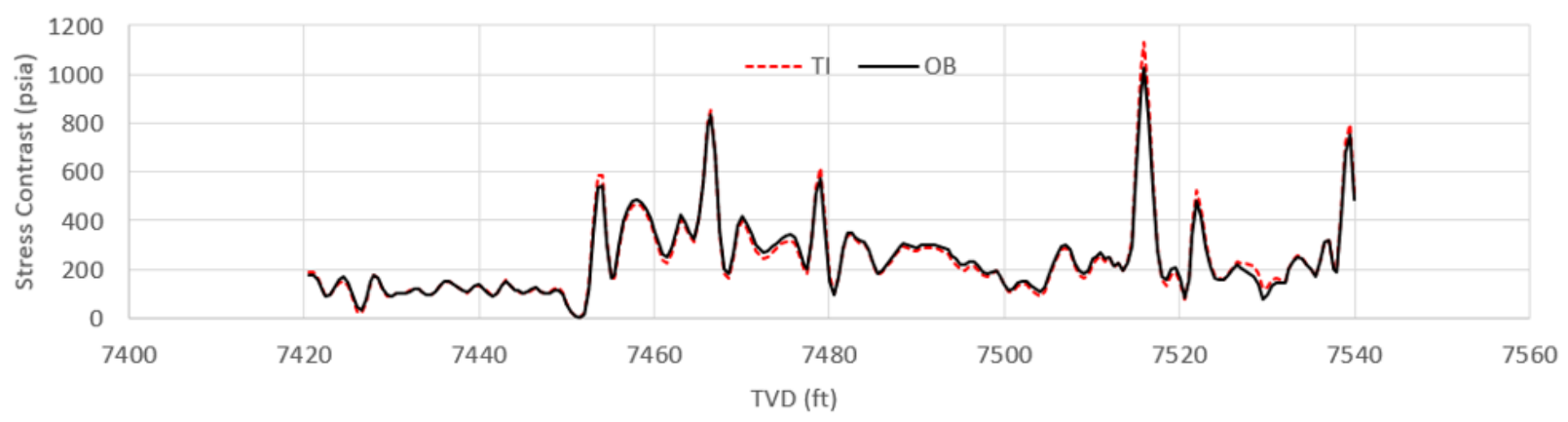

Figure 52: Stress contrasts of $O B$ and TI within the Marcellus Shale versus TVD while the SWS is 1.37 percent

Stress Contrast within the Marcellus Pay (SWS=4.18\%)

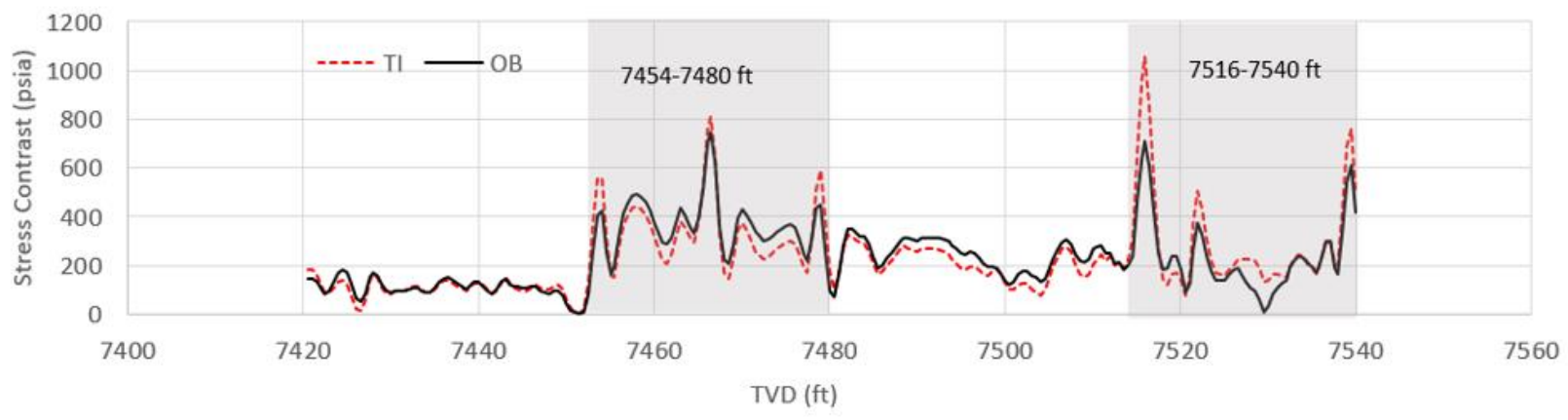

Figure 51: Stress contrasts of $O B$ and TI within the Marcellus Shale versus TVD while the SWS is 4.18 percent 


\subsubsection{Young's Modulus approach for NFs impact on the Marcellus Shale}

Figure 53 shows how young's modulus change was examined within the shale rock. For a better understanding, the horizontal young's modulus and the SWS in percent were studied in three sections for Marcellus Shale, namely, lower zone, middle zone, and upper zone. The figure also shows the OB model, which is true value of the estimation with solid line, and TI models were drawn with the dashed lines for three sections. TI estimations show the shale rock model without natural fractures within the rock body.

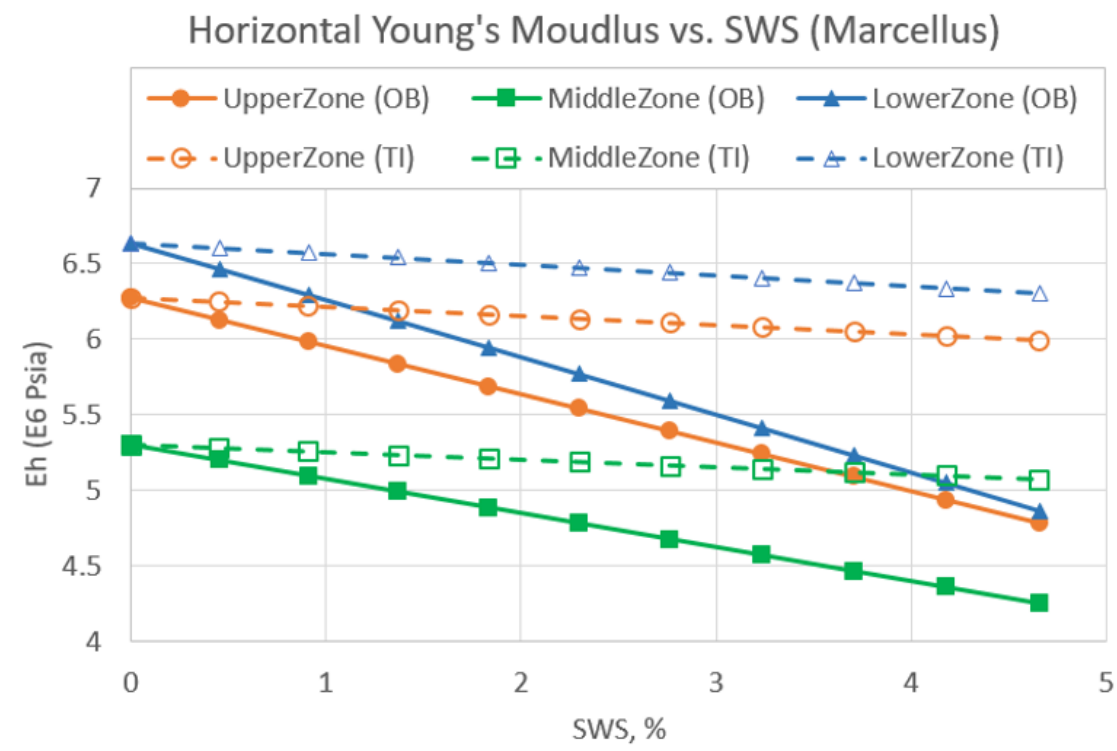

Figure 53: Young's Modulus approach for NFs impact on the Marcellus Shale

In the plot the solid lines are the Young's modulus predicted by the OB model (true value), whereas the dashed lines are the results predicted by treading the OB rock as a simplified TI model by ignoring NF induced anisotropy in the acoustic log interpretation. Figure 53 shows how the Young's modulus is parallel to the minimum horizontal stress (perpendicular to the natural fracture) and it is calculated and compared for $\mathrm{TI}$ and $\mathrm{OB}$ models at varying SWS. The first important observation is that the actual OB rock Young's modulus decreases with increasing SWS. The decreasing rate is the largest for the upper zone, while smallest for the middle zone. The second observation is that, when ignoring the natural fracture induced anisotropy, the Young's modulus are overestimated for all three zones. As SWS increases from $0.45 \%$ to $4.65 \%$, the overestimation is $1.91 \%-25.23 \%, 1.54 \%-19.25 \%$, and $2.13 \%$ $29.55 \%$ for upper, middle and lower zones respectively. 


\subsection{Niobrara Shale}

\subsubsection{Niobrara Shale Stress Contrasts Results}

Three graphs were plotted in this section for between the $11200 \mathrm{ft}$. $-11800 \mathrm{ft}$. depths of the Niobrara Shale. The average density of the related well is $2.55 \mathrm{~g} / \mathrm{cc}$.

Three plots were drawn for each shale case. Figure 54 is a comparison of the minimum horizontal stresses of a $\mathrm{TI}$ and OB rock from the same shale. The second plot is the upper and lower stress barriers as a function of separation of DTS fast and DTS slow. The third one was plotted to see the differences between the upper and the lower stress barriers between the two models.

One important observation is that the natural fracture induced anisotropy leads to a decrease of the stress magnitude, which agrees well with the previous published study (Gu, 2017).

Another benefit plotting Figure 54 is that it helps to understand how the natural fracture induced anisotropy impact the stress contrast between the cap rock and pay rock (stress barrier), the pay zone and cap zone are selected and highlighted in the Figure 54. According to the Figure 54 the upper stress barrier was located between

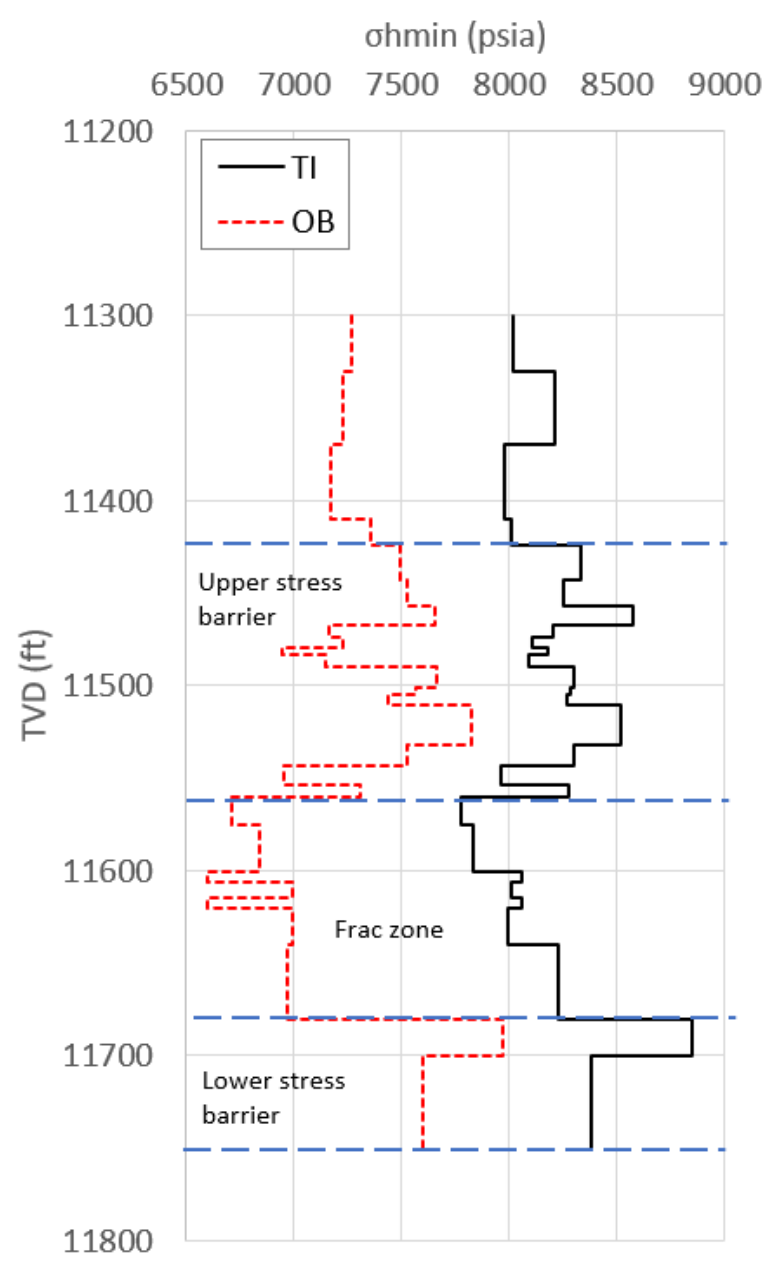

Figure 54: Minimum horizontal stress vs. TVD plot of the Niobrara Shale. $11430 \mathrm{ft}$. to $11550 \mathrm{ft}$. The frac zone for the Bakken Shale was set between $11550 \mathrm{ft}$. to $11680 \mathrm{ft}$.

The lower stress barrier was located between $11680 \mathrm{ft}$. to $11750 \mathrm{ft}$. 


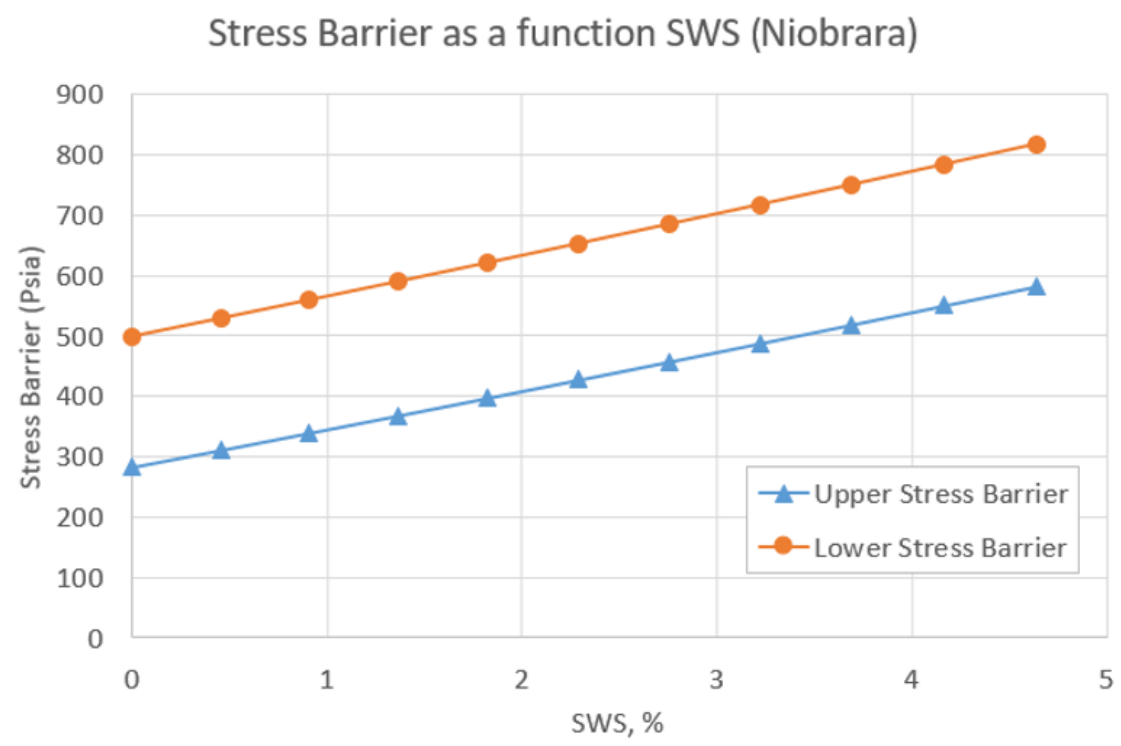

Figure 55: SWS vs. Stress Barrier plot of the Niobrara Shale

According to Figure 55, as SWS increases, both the upper and lower stress barriers increase, which is similar as the previous Eagle Ford Shale case. The upper and lower stress barriers increase by $120 \%$ and $34 \%$ respectively, when SWS increases from 0 to $4.6 \%$. Inputting these stress profiles in a frac simulation model, one can expect to see that the hydraulic fracture tends to grow less in the vertical direction in zones with higher natural fracture intensity of Niobrara Shale.

From the frac design point of view, if a naturally fractured Niobrara shale rock is treated as a TI rock by ignoring the natural fracture induced anisotropy in acoustic log interpretation and lab measurement, both the upper and lower stress barriers will be underestimated, which can lead to the suboptimal (insufficient) design of proppant laden fluid viscosity and proppant pumping loads. 


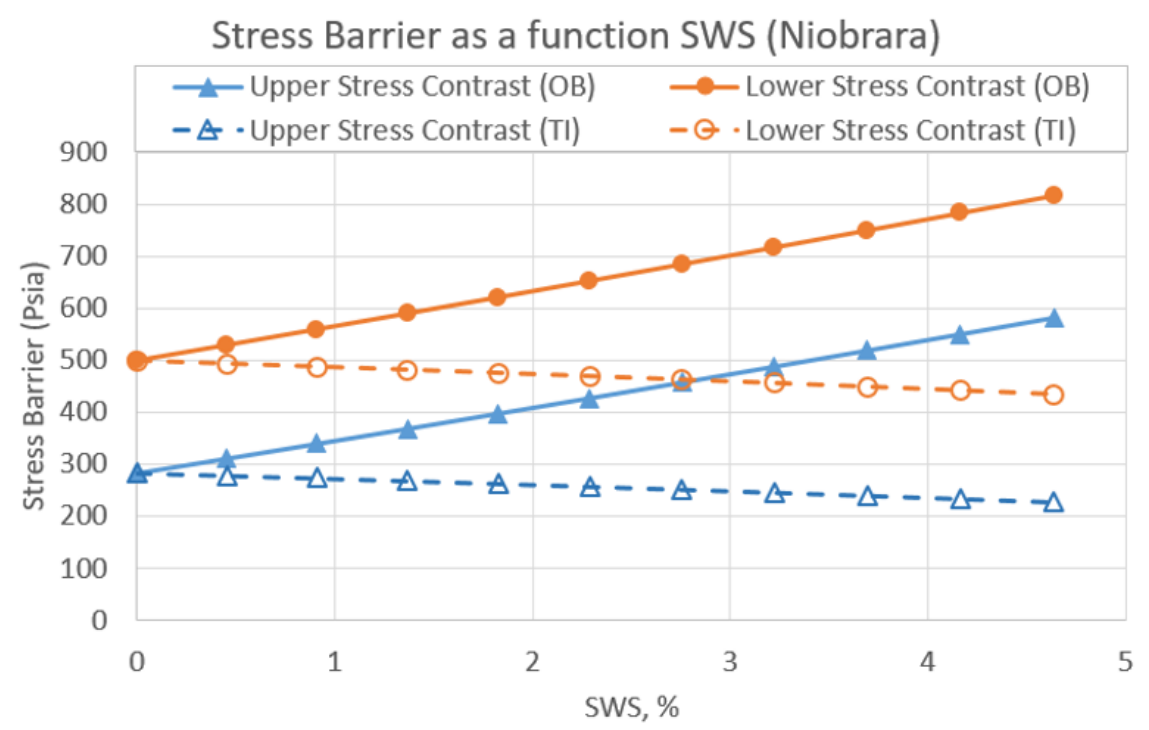

Figure 56: Upper and lower stress barriers vs. SWS plot of Niobrara Shale

In Figure 56, the solid lines are the stress contrast results predicted based on the OB model, whereas the dashed lines are the results by treating the $\mathrm{OB}$ rock as a simplified TI model in acoustic log interpretation. Comparing the upper and lower stress contrasts from the OB model and $\mathrm{TI}$ approximation, by ignoring the natural fracture induced anisotropy, the upper and lower stress contrast will both be underestimated. Quantitatively, the upper stress contrast will be underestimated by $10.59 \%$ - $61 \%$, while the lower stress contrast will be underestimated by $6.72 \%-46.89 \%$, as the SWS increases from $0.45-4.6 \%$.

Like Haynesville and Marcellus Shale, there is an obvious stress variation along the depth within the payzone for Niobrara Shale. In Figure 57 and Figure 58, the stress contrasts of the payzone are plotted against TVD for the two models. Figure 57 shows the comparison at SWS $=1.37 \%$, while Figure 58 shows the comparison at SWS $=4.16 \%$. The stress contrast within the payzone is calculated by subtracting the minimum stress within the pay from the stress at each depth. Unlike the two previous cases, the impact of natural fracture induced anisotropy on stress contrast in the payzone is more complicated. Based on the results, the payzone can be divided into three subzones. The alteration of stress contrast in each subzone is different when treating the naturally fractured OB Niobrara Shale rock as a TI model. According to Figure 57 with a relatively low SWS (1.37\%), when ignoring the natural fracture induced anisotropy in log interpretation, the stress contrast is slightly underestimated by 20 psia for the upper subzone (11560-11602 ft), almost does not change for the middle subzone (11602$11620 \mathrm{ft}$ ) and overestimated by 70 psia for the lower subzone (11620-11680ft). If the SWS increases to $4.16 \%$, the alteration of stress contrast by using different rock models becomes significant. According to Figure 58 , the stress contrast is underestimated by 100 psia for the upper subzone (11560-11602 ft), is largely underestimated by over 200 psia for the middle subzone (11602-11620 ft), and largely overestimated by over 200 psia for the lower subzone (11620-11680ft). In conclusion, ignoring the anisotropy induced by natural fractures will lead to a too long stage length for the upper and middle subzones, while a too short stage length design for the lower subzone. 
Stress Contrast within the Niobrara Pay (SWS=1.37\%)

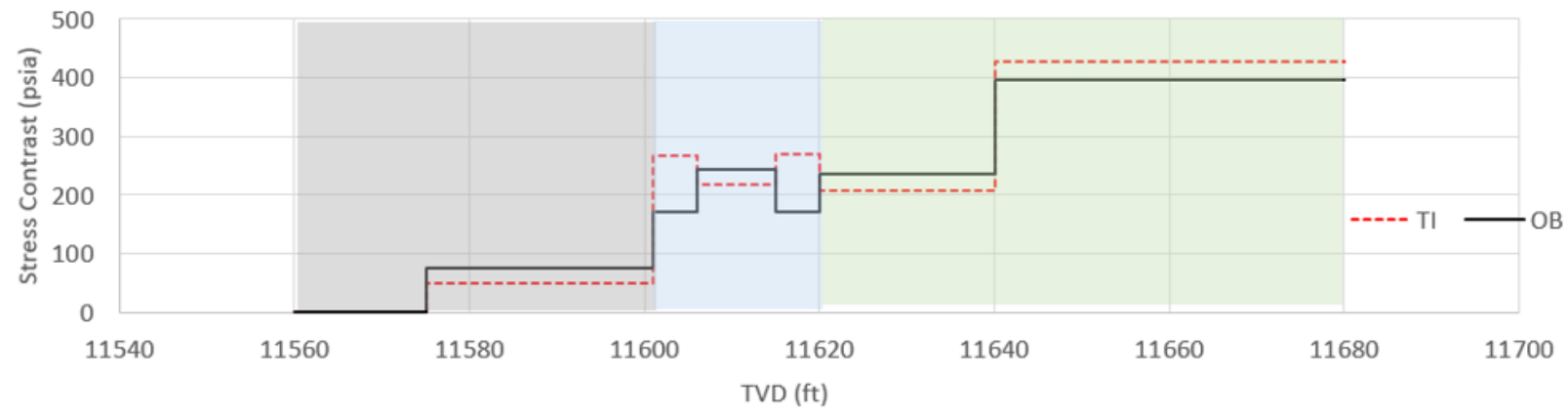

Figure 57: Stress contrasts of $O B$ and TI within the Niobrara Shale versus TVD while the SWS is 1.37 percent

Stress Contrast within the Niobrara Pay (SWS=4.16\%)

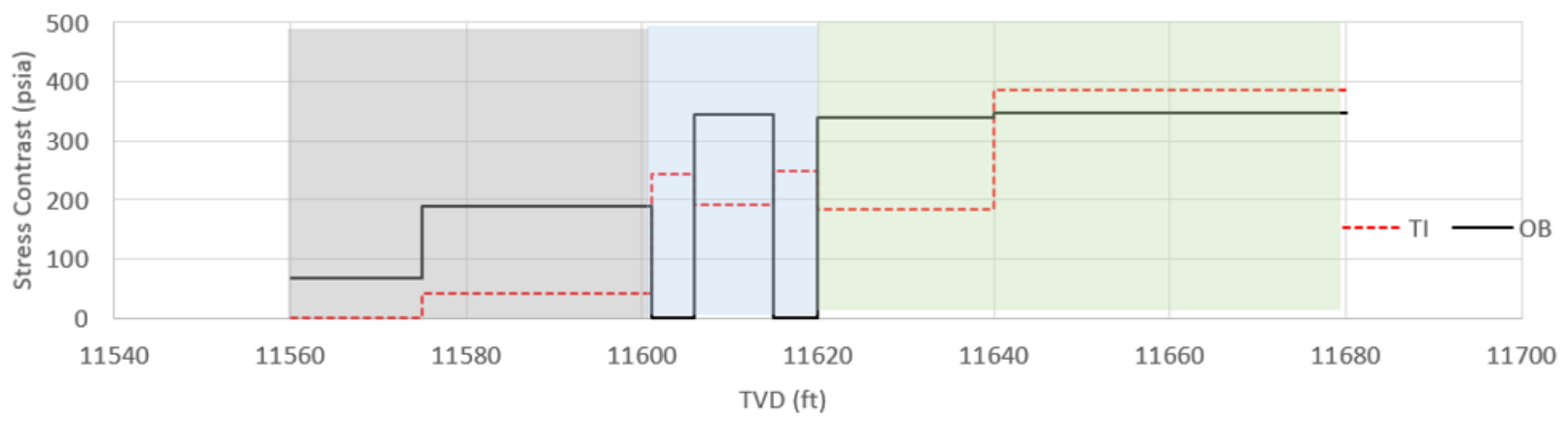

Figure 58: Stress contrasts of $O B$ and TI within the Niobrara Shale versus TVD while the SWS is 4.16 percent 


\subsubsection{Young's Modulus approach for NFs impact on the Niobrara Shale}

Figure 59 shows how young's modulus change was examined within the shale rock. For a better understanding, horizontal young's modulus and the SWS in percent were studied in three sections for Niobrara Shale, namely, lower zone, middle zone, and upper zone. The figure also shows the OB model, which is true value of the estimation with solid line, and TI models were drawn with the dashed lines for three sections. TI estimations show the shale rock model without natural fractures within the rock body.

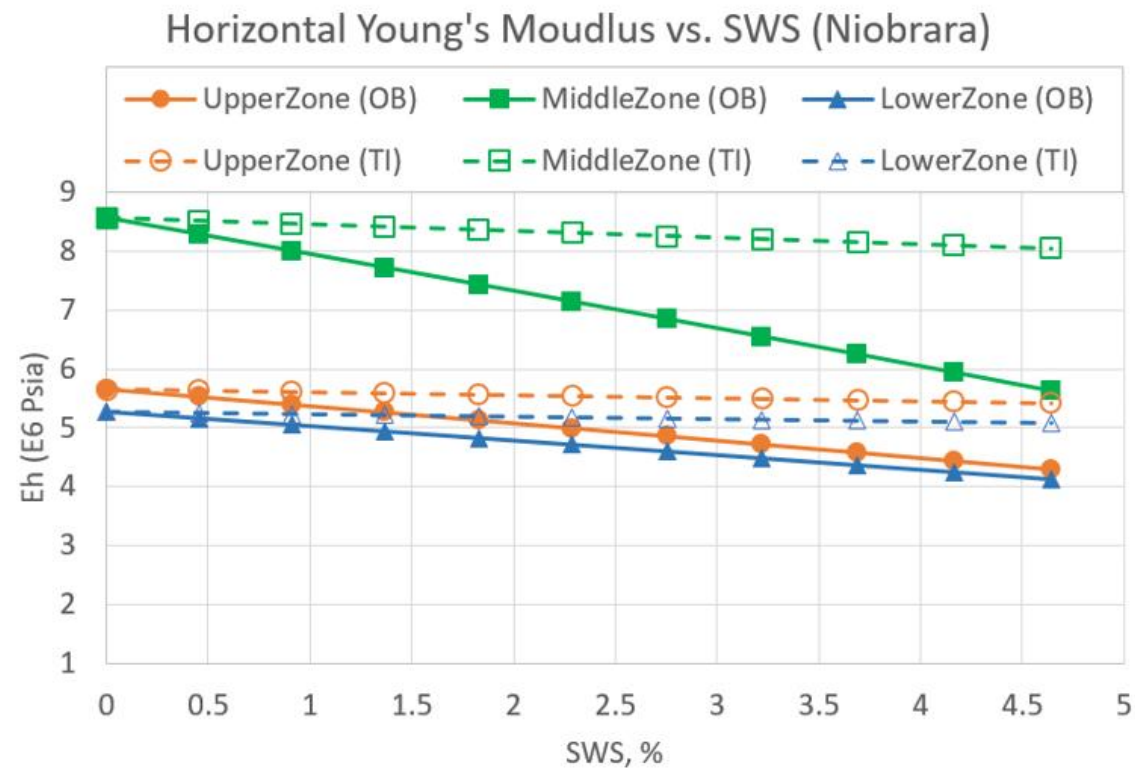

Figure 59: Young's Modulus approach for NFs impact on the Niobrara Shale

Figure 59 shows how TI misestimated the young modulus for the Niobrara Shale. The middle zone is the most deviated and most misestimated one, and the upper and lower zones deviate slightly, with almost the same rate of deviation. As SWS increases from $0.453 \%$ to $4.639 \%$, the upper, middle and lower zones' TI estimations are overestimated respectively as follows: 1.94\%-26.20\%, 2.76\%-43.03\%, and $1.75 \%-22.98 \%$. In the Niobrara result, the effect of neglecting the natural fractures in the shale rock body are significant like the Eagle Ford Shale example. 


\subsection{Discussion}

\subsubsection{Natural Fracture Induced Anisotropy Impact on Stress Contrast and Young's Modulus}

\subsubsection{Natural Fracture Induced Anisotropy Impact on Stress Contrast}

To take a close look on the fluctuation of upper and lower stress contrasts of $\mathrm{TI}$ and OB models, stress contrasts and SWS data were plotted for all the five shales in one table with different SWS percentages in Figure 60 and Figure 61.

In the Figure 60 and 61, how the upper and lower stress contrasts change with treading them $\mathrm{TI}$ instead of $\mathrm{OB}$ are shown by the misinterpreted values which are deviated from the red dashed base line. In another terms, more the deviated values from the red dashed line shows how much neglection the natural fracture induced anisotropy is wrong, so the TI is wrong.

Moreover, the underestimations and overestimations were summarized on the graphs in the Figure 60 and Figure 61. In Figure 60, Bakken and Marcellus shales' Upper Stress Contrasts are overestimated, and Haynesville, Eagle Ford and Niobrara Shales' Upper Stress Contrasts are underestimated. The most deviated ones respectively are the Bakken Shale, Niobrara Shale, Marcellus Shale and then the Eagle Ford Shale.

However, in the lower stress barriers graph, Eagle Ford Shale's result is the nearest to the base line, so lowest error in stress contrasts' graphs belongs to Eagle Ford with respect to lower stress contrast in Figure 61. With this respect, the errors of the upper and lower contrast of the shales respectively are: Bakken Shale's error is $679.9 \%$ and $-307.8 \%$. Eagle Ford Shale's error is $-30.5 \%$ and $8.36 \%$. The Haynesville Shale's error is $-12.6 \%$ and $135.5 \%$. Marcellus's error is $258.3 \%$ and $50 \%$. Niobrara Shale's error is $-44 \%$ and $-31 \%$. 


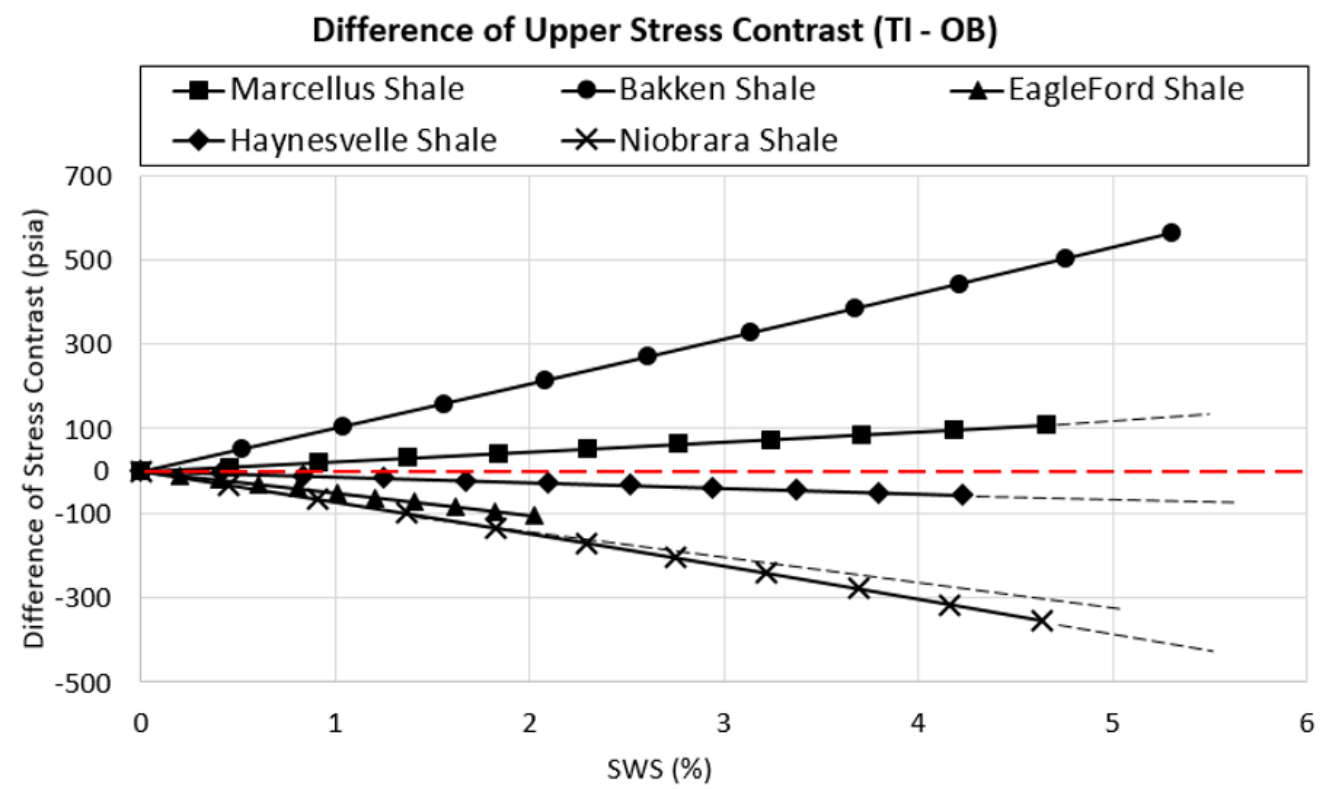

Figure 60: Difference of Upper Stress Contrasts of the Shales.

In Figure 61, similar estimations are observed in the deviation comparisons of the shales' graphs. However, only the Haynesville Shale shows a difference trend in the estimation's area, and while it is underestimated in the Figure 60 as its upper stress contrast, it rises over the red dashed line in the Figure 61 for its lower stress contrasts. However, only the Haynesville Shale shows such a difference in the estimation's area, and while it is underestimated in the Figure 60 as its upper stress contrast, it rises over the red dashed line in the Figure 61 for its lower stress contrasts, which shows the lower stress contrast of it is overestimated.

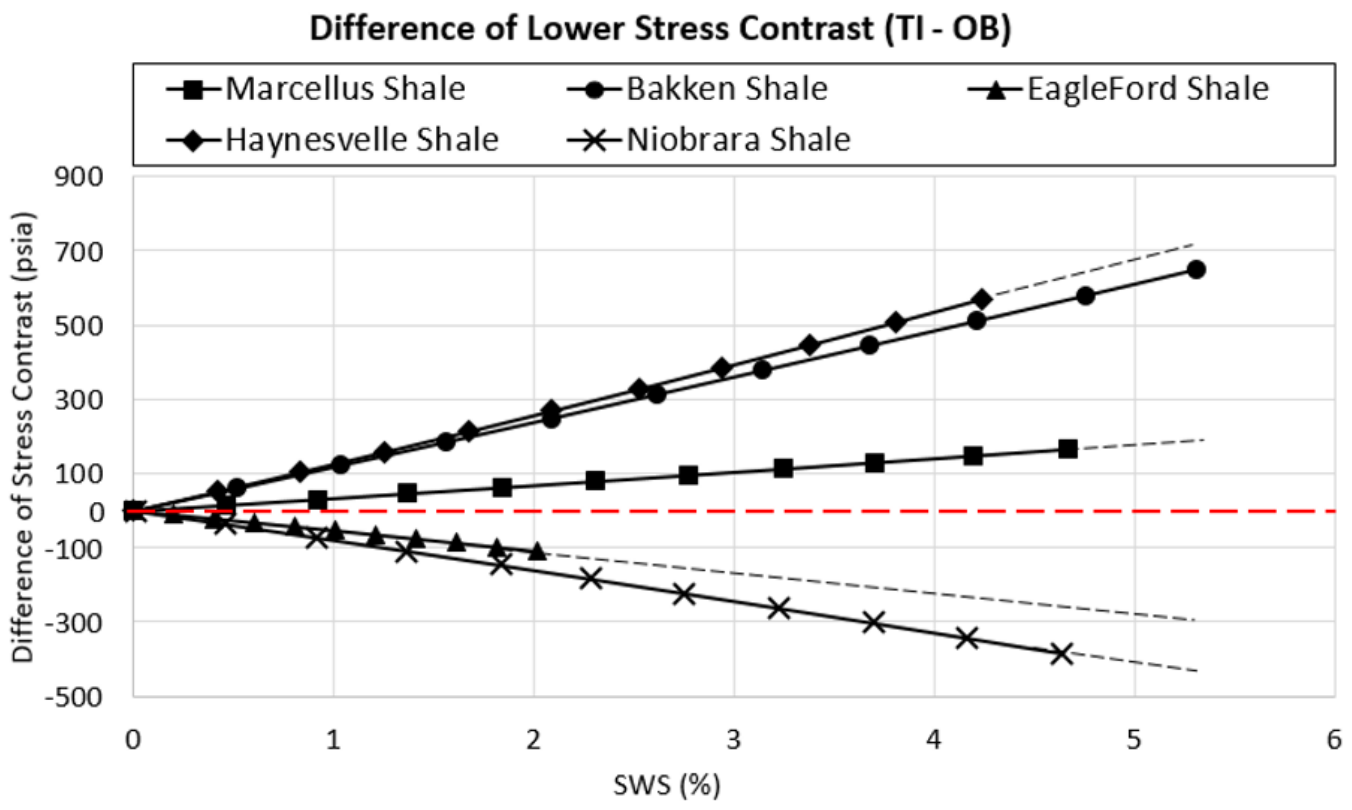

Figure 61: Deviation of TI treated shales from OB treated correction line -red dashed line- 
The reason of this change is thought as the result of the mineralogical change with the depth within the formation. In other words, the upper stress contrast of Haynesville Shale, which is between $10,530 \mathrm{ft}-10560 \mathrm{ft}$ has a thicker quartz layer, and the formation changes from thick quartz rich layer to a thick calcite rich layer at around $10,610 \mathrm{ft}-10,620 \mathrm{ft}$ as it was shown in the Figure 62 . In other words, the upper stress contrast of Haynesville Shale, which is between $10,530 \mathrm{ft}-10560 \mathrm{ft}$ has a thicker quartz layer, the formation changes from thick quartz rich layer to a thick calcite rich layer at around 10,610 ft $10,620 \mathrm{ft}$ as it was shown in the Figure 62. Even though at the both upper and lower stress barriers' depths there are calcite layers, the lower stress barrier has a thicker calcite layer than the upper stress barrier as Figure 62. In this graph, since the both graphs are TI graph, mineralogical change is thought as the only reason of this drastic change in the minimum horizontal stress estimation.

To clarify the reason of such big misestimation in the Haynesville Shale, rocks characteristics must be scrutinized as well, for instance, layers like quartz, which is faster in emitting the sonic waves than calcite layers give a lower measured slowness value since each of the layers have different toughness values. According the Table 8, calcite has a lesser toughness than quartz, so it emits the sonic waves slower than quartz within its body. This causes a higher value in the measured slowness of this part of the formation. Thus, the results this time are highly overestimated by the TI model, regarding the results of $\mathrm{OB}$ model. As a result, the upper stress contrast is underestimated, on the contrary the lower stress contrast is overestimated for the Haynesville Shale.

Table 8: Mohs Harness Scale

\begin{tabular}{|c|c|}
\hline \multicolumn{2}{|c|}{ Mohs Scale of Hardness } \\
\hline Hardness in Mohs Units & Sample Minerals \\
\hline 10 & Diamond \\
\hline 9 & Corundum \\
\hline 8 & Topaz \\
\hline 7 & Quartz \\
\hline 6 & Orthoclase Feldspar \\
\hline 5 & Apatite \\
\hline 4 & Fluorite \\
\hline 3 & Calcite \\
\hline 2 & Gypsum \\
\hline 1 & Talc \\
\hline
\end{tabular}




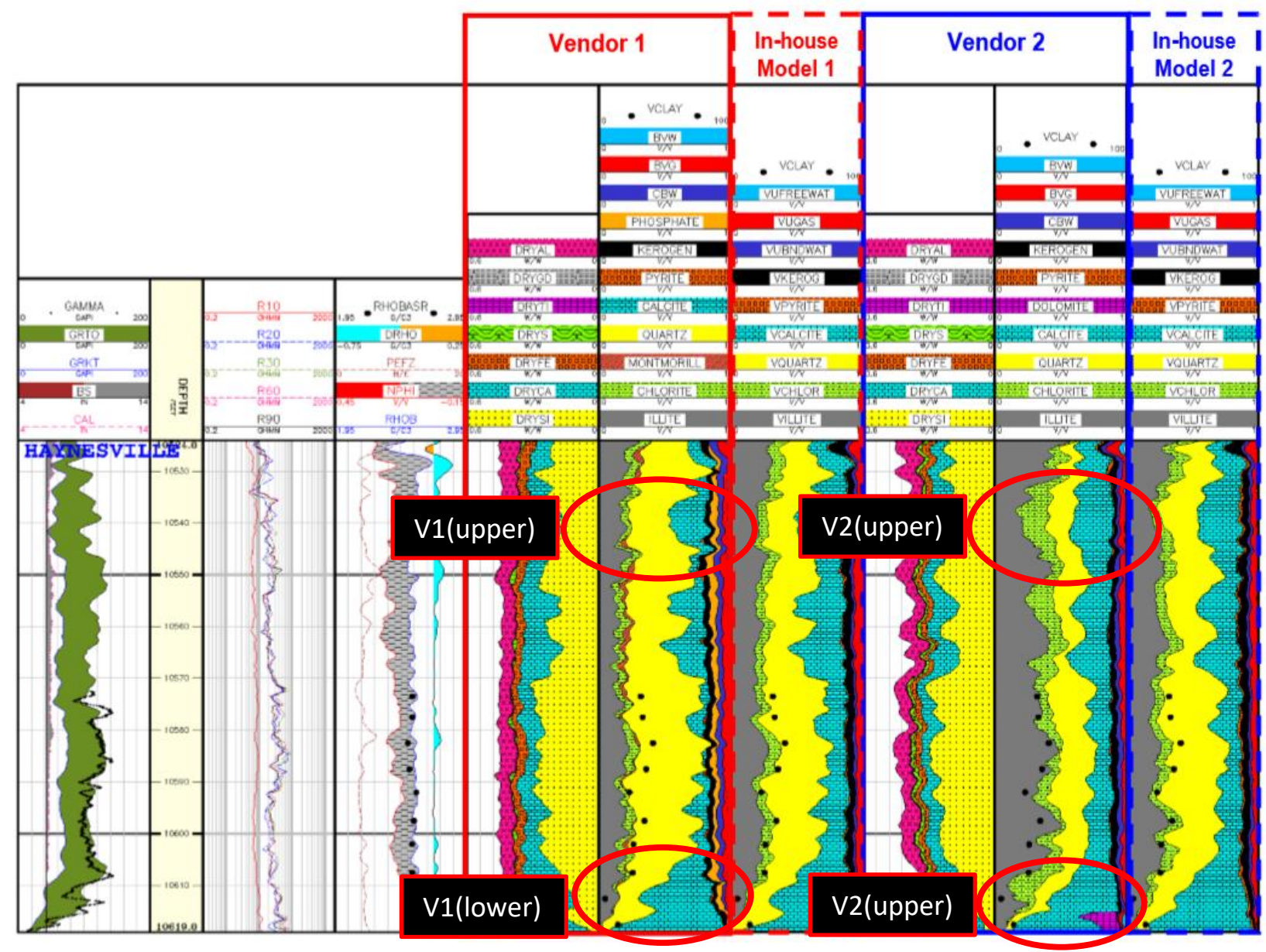

Figure 62: Mineral-based model results of the Haynesville Shale, provided by two different companies. (Ramirez et al., 2011)

In Figure 62, there are 2 different mineral-based logging model from two different vendors for Haynesville Shale. Besides the first vendor which was already discussed, the second vendor's lower stress barrier -V2 (lower)- has a thick dolomite layer which is seeable as a bulge at the end of the log. The hardness of dolomite is also very close to calcite's hardness value, which is around 3.5 to 4 according to Mohs harness scale. In addition to dolomite, calcite has a hardness as 3 , and quartz has a hardness value as 7 . Thus, dolomite existence still increases the rock's wave slowness value for the lower stress barriers of the rock. Therefore, with the increase of the rock wave slowness, the horizontal minimum stress value increases, so the estimation of the upper stress barrier of Haynesville is underestimated in treading rock with TI rock model instead of OB rock model, and the estimation of the lower stress barrier of Haynesville is overestimated in treading rock with $\mathrm{TI}$ instead of OB. 


\subsubsection{Natural Fracture Induced Anisotropy Impact on the horizontal Young's modulus}

Young's modulus is one of the most essential rock mechanic features which has a vital impact on the completion and hydraulic fracturing applications with minimum horizontal stress. As the results are summarized in perspective of the horizontal stress in the last chapter; in this chapter, canceling the natural fracture induced anisotropy effects on the Young's modulus were scrutinized with graphs and the results were evaluated regarding completion and hydraulic fracturing design.

According to (Chertov et al., 2013), young modulus has a reverse relationship with the fracture width. In another terms, increase in the young's modulus results with a decrease in the frac width. Thus, more TI model overestimates the Young's modulus, the fracture width is underestimated.

Underestimated fracture width results in insufficient proppant size or pumping amount design which both finalize with suboptimal low fracture conductivity design.

In Figure 63, 64, and 65, all five shales were examined in three parts as upper, middle and lower zones in terms of the horizontal young's modulus differences changes with SWS in percent. While SWS\% shows the muchness of the natural fractures within the rock body. The relative difference of horizontal young's modulus shows the horizontal young's modulus differences for all three zones.

In Figure 63, how upper zone's horizontal young's modulus relative differences increase with the increment of SWS in terms of the OB model percent were shown. With this graph for upper zone, TI model's mistake in calculation of young's modulus was clearly summarized. The amount of the relative differences of three shales, namely, Haynesville, Marcellus and Niobrara are very close to each other. This relative difference study has an importance in terms of the upper zone's completion design and hydraulic fracturing design aspects calculations.

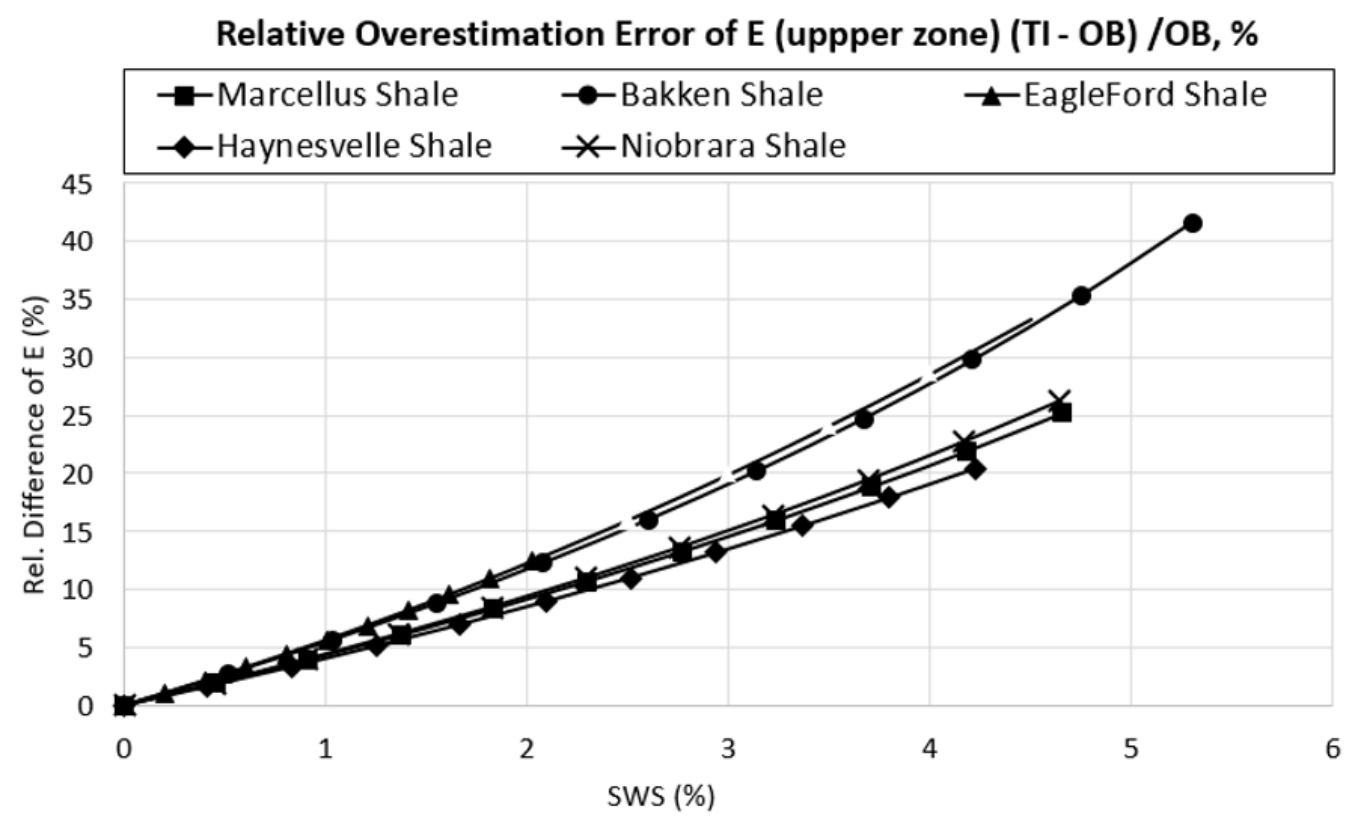

Figure 63: Horizontal Young Modulus differences vs. SWS\% for the upper zones of the five shales 
Figure 64 shows that as only in terms of the relative difference, only Haynesville's upper and lower zones are very close to each other. Bakken is the most deviated one. On the other hand, Bakken in the middle zone, has the lowest relative difference. This also show how the OB and TI models are closely estimate the horizontal Young's modulus value of the Bakken's middle zone. Thus, a conclusion can be drawn for the middle zone of the Bakken like that there is only a very limited amount of the natural fracture inducted anisotropy effect exists.

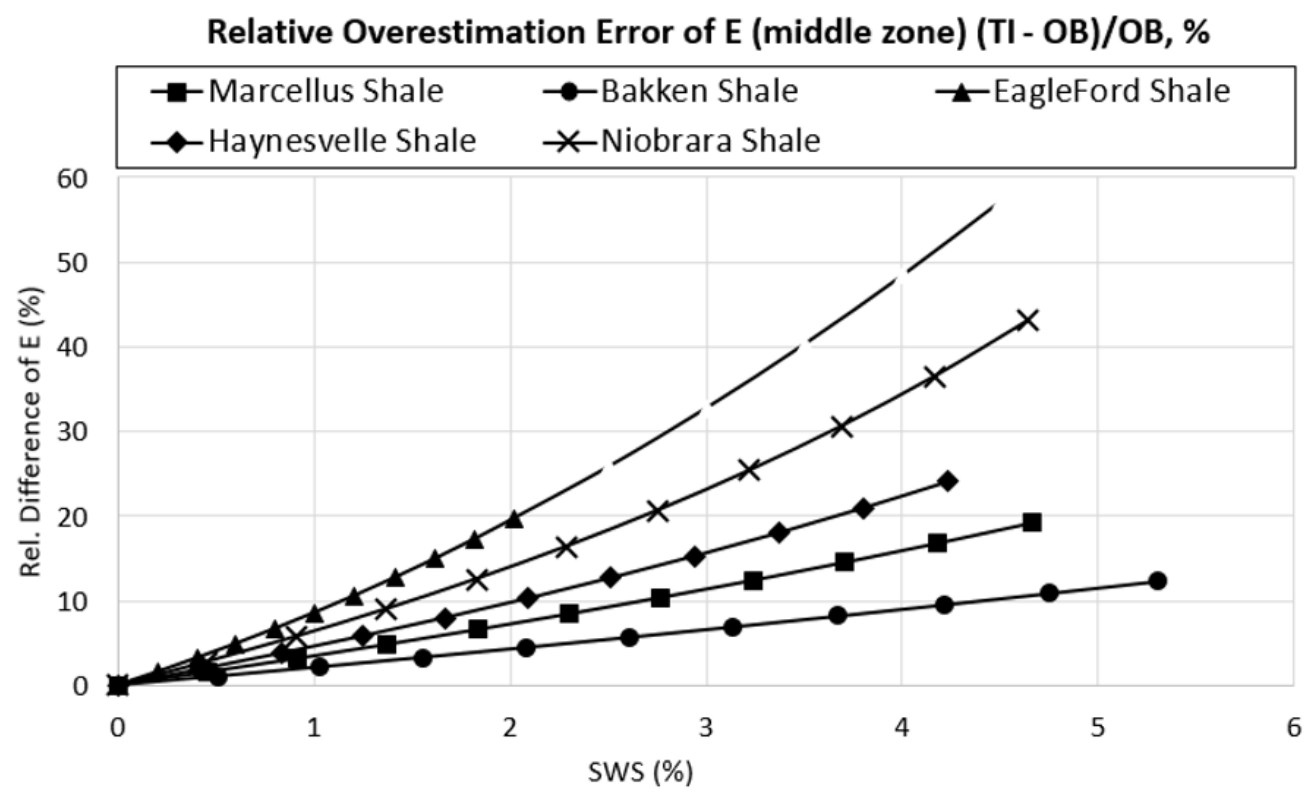

Figure 64: Horizontal Young's modulus vs. SWS\% for the middle zones of the five shales

Figure 65 depicts the lower zone horizontal Young's modulus values for the five shales. For Haynesville Shale the relative differences value points are higher than upper and middle zones. This shows how TI model calculates the Young's modulus more erroneous. Bakken is also very higher than middle and slightly higher than its upper zone Young's modulus differences, which is related with the natural fracture intensity and anisotropy effect. Figure 65 also shows that Marcellus, at lower zone, has higher natural fracture induced anisotropy effect in lower zone. On the other hand, Eagle Ford and Niobrara has lower natural fracture anisotropy effect in the lower zone than their upper and middle zones, as Figure 65 shows. 


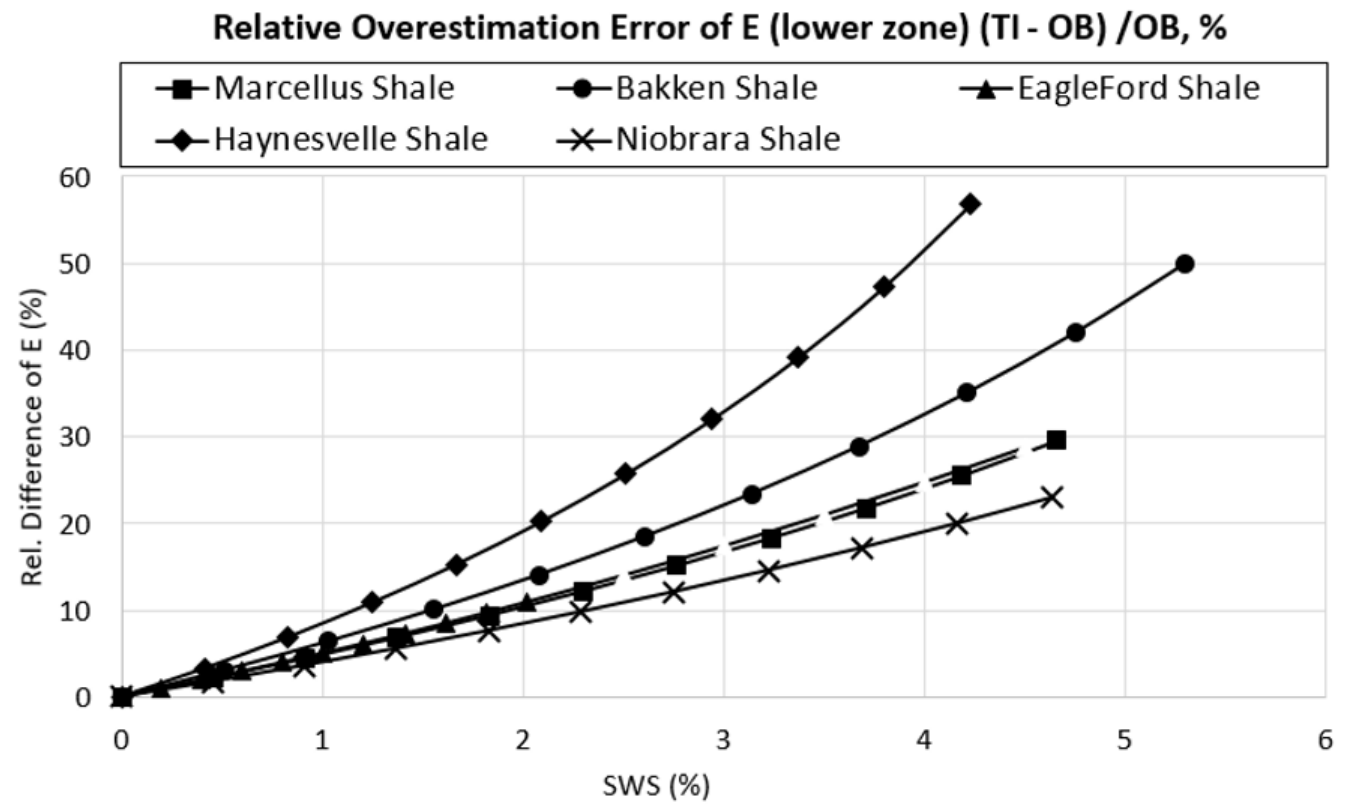

Figure 65: Horizontal Young's modulus vs. SWS\% for upper zone of the five shales

As a Conclusion, horizontal Young's modulus for OB model, $E_{1}$ and for TI model, $E_{h}$ were compared in the graphs. Since the Young's modulus is an extremely important mechanic property, the completion and hydraulic fracturing designs should consider the fluctuation in the horizontal young's modulus values differences in $\mathrm{TI}$ and $\mathrm{OB}$ models. The young modulus is an extremely important completion and frac design parameter which also has an essential impact on fracturing process and has an almost direct relationship with the net treating pressure, fracture geometry, fracture width, and interpretation fluid loss from pressure decline data (NSL Laboratory Service., 2002).

Specifically, for the upper zones of all shales, the overestimations of Young's modulus are similar for Bakken and Eagle Ford, which increases from 0 to $28 \%$ as SWS increases from $0-4 \%$. The overestimation error is lower for Niobrara, Marcellus, and Haynesville, which are around $0-21 \%$, respectively, when SWS increases from 0-4\%.

For the middle zone (specified pay zone), the overestimation error is very different for different shale reservoirs. The largest overestimation occurs in Eagle Ford, whereas the second largest overestimation occurs in Niobrara, followed by Haynesville, Marcellus, and Bakken.

Same as the middle zone, the overestimation error is very different for different shale reservoirs in the lower zone. Unlike the upper and middles zones, the largest overestimation error occurs in Haynesville, while the second largest overestimation occurs in Bakken, followed by Eagle Ford, Marcellus, and Niobrara.

As a result of neglecting the natural fracture anisotropy might result with the vital problems such as economical misestimations, unsuccessful frac treatment, fluid loss, proppant injection problems like proppant screen out problems due to wrong estimated fracture geometry and insufficient fracturing treatment. 


\subsubsection{Investigation of Inherent relationship between NF induced anisotropy impact and mineralogy/lithology sequence}

Table 66 concludes the prediction errors of stress contrast and Young's modulus caused by ignoring natural fracture induced anisotropy in log interpretation for different shale formations. In the same table, the last column concludes the mineralogy/lithology features of each shale observed from the mineralogy/lithology logs (Fig.66). By comparing the prediction error results and the mineralogy/lithology features of all shales, the inherent relationship between NF induced anisotropy impact and shale mineralogy/lithology is investigated.

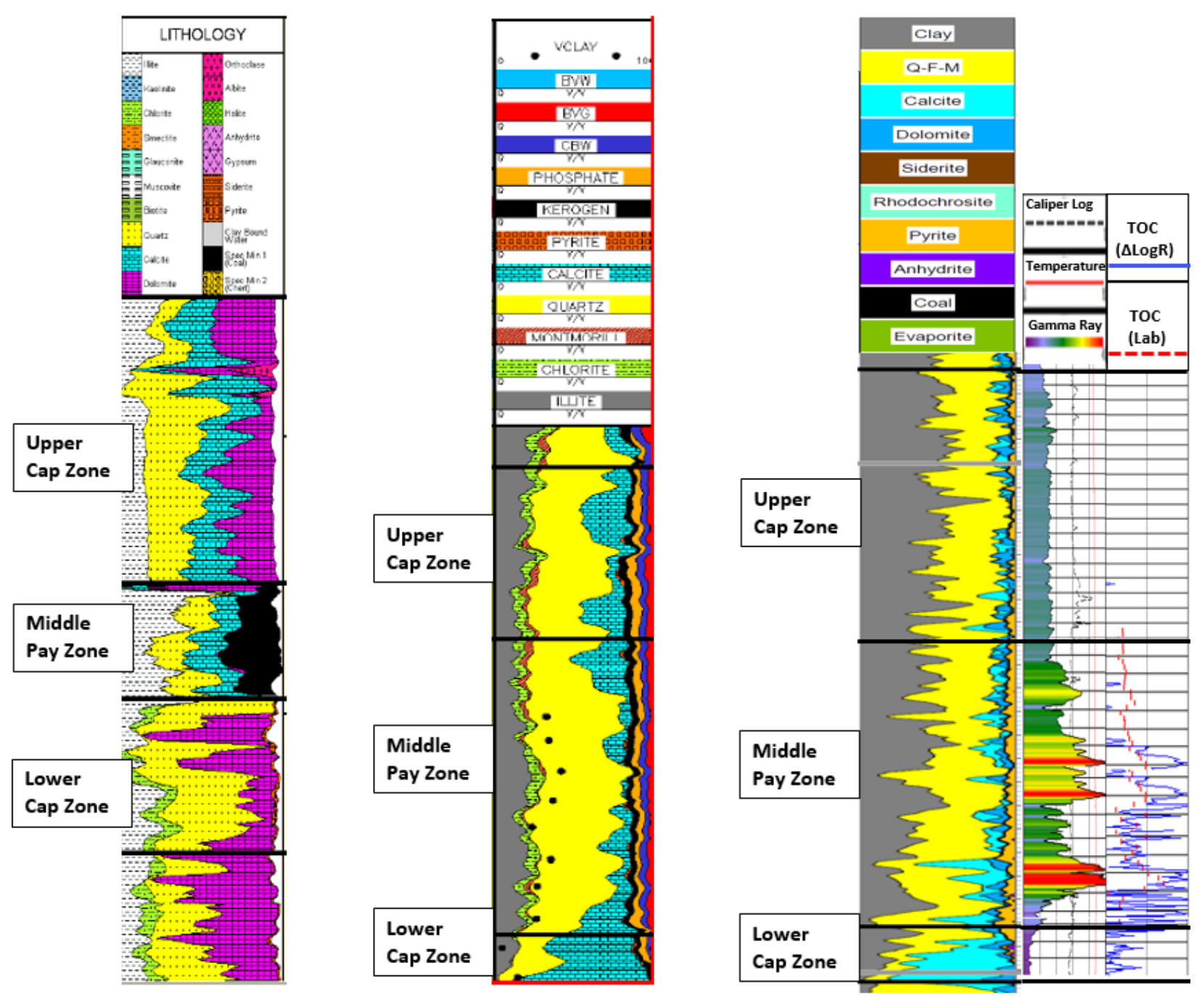

Figure 66: The mineralogy/lithology logs for Bakken (modified from Ramakrishna et al., 2010), Haynesville (modified from Ramirez et al., 2011), and Marcellus Shale 
According to the Bakken shale results, the natural fracture induced anisotropy has higher impact in the "stiffer" zones with higher quartz and calcite/dolomite content and lower amount of clay and organic matter. Regarding to the prediction of minimum horizontal stress, ignoring natural fracture induced anisotropy leads to larger overestimation in the stress magnitude of the "stiffer" zones (upper and lower zones) than that of the "softer" zone (middle zone). Regarding to the prediction of Young's modulus, ignoring natural fracture induced anisotropy leads to larger overestimation errors in upper and lower "stiffer" zones. The possible explanation is that natural fractures, which are usually more porous with higher fluid content than the TI background rock, have an elastic behavior closer to the "softer" zone than the upper and lower "stiffer" zones. Thus, introducing natural fractures into the rock body will lead to a relatively low natural fracture impact for the middle payzone with higher clay and hydrocarbon contents than the upper and lower cap rocks.

Haynesville Shale yields the similar conclusion as the Bakken Shale, which is that the natural fracture induced anisotropy has higher impact in the "stiffer" rock zones. Because the middle zone contains a total of quartz and calcite a little higher than the upper zone, the middle pay zone exhibits stiffer than the upper cap rock. Thus, ignoring natural fracture induced anisotropy leads to a slightly higher overestimation error in stress magnitude and Young's modulus of the middle zone than those of the upper zone. That is why the upper stress contrast is underestimated slightly. In contrast to that, the sudden increase of calcite in the lower zone makes the lower cap rock to be stiffer than the middle and upper rocks. Thus, ignoring natural fracture induced anisotropy leads to a much higher overestimation error in stress magnitude and Young's modulus of the lower zone, which results in a large overestimation of lower stress contrast and up to $20 \%$ relative overestimation error in lower zone's Young's modulus.

For Marcellus Shale, similar phenomena is observed. Comparing with upper and lower cap zones, the middle zone has much higher TOC content. In addition to that, the lower zone has a sudden increase of calcite and decrease of clay as compared with the upper and middle zones. Thus, the natural fracture induced anisotropy has the highest overestimation impact on stress and Young's modulus predictions for the lower cap zone, followed by the upper cap zone and then middle pay zone. As a result, both the upper and lower zones' Young's modulus are overestimated.

Overall, the natural fracture induced anisotropy is less significant in the "softer zone" with higher clay content, less quartz and calcite content, and higher organic matter content. For most of shale formations, the pay zone (zone to frac) has higher clay amount and organic matter amount than the upper and lower cap zones. Thus, ignoring natural fracture induced anisotropy will lead to lower overestimation error in the predictions of minimum horizontal stress and Young's modulus of the middle pay zone as compared with the upper and lower cap zones. As a result, the upper and lower stress contrasts (stress barrier), which is $\sigma h_{\text {mid }}-\sigma h_{u p / l o}$, are overestimated. The larger difference of clay/quartz/calcite/HC content between the cap zones and pay zone, the larger the overestimation error caused by ignoring the natural fracture induced anisotropy from treating the $\mathrm{OB}$ rock as a TI medium in log interpretation. 
Table 9: Conclusion of prediction errors of stress contrast and Young's modulus, and mineralogy/lithology features of five Shales

\begin{tabular}{|c|c|c|c|}
\hline $\begin{array}{c}\text { Shale } \\
\text { Formation }\end{array}$ & $\begin{array}{l}\text { Prediction Error of Stress Contrast When } \\
\text { Treating the OB Rock with a TI model }\end{array}$ & $\begin{array}{l}\text { Prediction Error of Young's modulus When } \\
\text { Treating the OB Rock with a TI model }\end{array}$ & Mineralogy/Lithology Feature \\
\hline Bakken & $\begin{array}{l}\text { 1. Both upper and lower stress contrasts are } \\
\text { overestimated. } \\
\text { 2. At around } 2 \% \text { SWS, the upper stress contrast is } \\
\text { overestimated from } 105 \text { psi to } 357 \mathrm{psi} \text {, and the } \\
\text { lower stress contrast is overestimated from }-55 \\
\text { psi to } 228 \text { psi. }\end{array}$ & $\begin{array}{l}\text { 1. The upper, middle, and lower zones' } \\
\text { Young's modulus are all overestimated. } \\
\text { 2. At around } 2 \% \text { SWS, the relative } \\
\text { overestimation errors are } 12.21 \%, 4.35 \% \text {, } \\
\text { and } 13.84 \% \text { for the upper, middle, and } \\
\text { lower zones respectively. }\end{array}$ & $\begin{array}{l}\text { 1. As moving from the upper to the middle zone, the volume } \\
\text { percentage of Illite content increases, quartz decreases, dolomite } \\
\text { decreases, calcite slightly decreases, and coal increases (Fig. 66). } \\
\text { 2. As moving from the middle to the lower zone, Illite decreases, } \\
\text { quartz increases, coal disappears, calcite disappears, and dolomite } \\
\text { increases (Fig. 66). }\end{array}$ \\
\hline Eagle Ford & $\begin{array}{l}\text { 1. Both upper and lower stress contrasts are } \\
\text { underestimated. } \\
\text { 2. At around } 2 \% \text { SWS, the upper stress contrast is } \\
\text { underestimated by } 50 \% \text { (from } 235 \text { psi to } 118 \text { psi), } \\
\text { and the lower stress contrast is underestimated } \\
\text { by } 16 \% \text { (from } 759 \text { psi to } 638 \text { psi). }\end{array}$ & $\begin{array}{l}\text { 1. The upper, middle, and lower zones' } \\
\text { Young's modulus are all overestimated. } \\
\text { 2. At around } 2 \% \text { SWS, the relative } \\
\text { overestimation errors are } 12.9 \%, 20 \% \text {, and } \\
11.36 \% \text { for the upper, middle, and lower } \\
\text { zones respectively. }\end{array}$ & N/A \\
\hline Haynesville & $\begin{array}{l}\text { 1. The upper stress contrast is slightly } \\
\text { underestimated, while the lower stress contrast } \\
\text { is highly overestimated. } \\
\text { 2. At around } 2 \% \text { SWS, the upper stress contrast is } \\
\text { underestimated by } 12.5 \% \text { (from } 200 \text { psi to } 175 \\
\text { psi), and the lower stress contrast is } \\
\text { overestimated by } 130 \% \text { (from } 247 \text { psi to } 569 \text { psi). }\end{array}$ & $\begin{array}{l}\text { 1. The upper, middle, and lower zones' } \\
\text { Young's modulus are all overestimated. } \\
\text { 2. At around } 2 \% \text { SWS, the relative } \\
\text { overestimation errors are } 8.75 \%, 9.92 \% \text {, } \\
\text { and } 20.1 \% \text { for the upper, middle, and lower } \\
\text { zones respectively. }\end{array}$ & $\begin{array}{l}\text { 1. As moving from the upper to the middle zone, quartz increases, } \\
\text { calcite decreases, while other mineralogy contents change slightly. } \\
\text { The total of quartz and calcite slightly increases from the upper to } \\
\text { the middle zone (Fig. } 66 \text { ). } \\
\text { 2. As moving from the middle to the lower zone, there is a large } \\
\text { increase of calcite with decrease of all other mineralogy contents. } \\
\text { The total of quartz and calcite of the lower zone is higher than the } \\
\text { middle and upper zones (Fig. } 66 \text { ). }\end{array}$ \\
\hline Marcellus & $\begin{array}{l}\text { 1. Both upper and lower stress contrasts are } \\
\text { overestimated; } \\
\text { 2. At around } 2 \% \text { SWS, the upper stress contrast is } \\
\text { overestimated by } 68 \% \text { (from } 86 \text { psi to } 144.2 \text { psi), } \\
\text { and the lower stress contrast is overestimated by } \\
42 \% \text { (from } 206 \text { psi to } 293 \text { psi). }\end{array}$ & $\begin{array}{l}\text { 1. The upper, middle, and lower zones' } \\
\text { Young's modulus are all overestimated. } \\
\text { 2. At around } 2 \% \text { SWS, the relative } \\
\text { overestimation errors are } 9.36 \%, 7.27 \% \text {, } \\
\text { and } 10.66 \% \text { for the upper, middle, and } \\
\text { lower zones respectively. }\end{array}$ & $\begin{array}{l}\text { 1. As moving from the upper to the middle zone, the contents of } \\
\text { clay, quartz, and calcite change slightly. However, according to the } \\
\text { delta-LogR analysis and the rock pyrolysis analysis, the middle } \\
\text { zone has much higher hydrocarbon contents (TOC), which makes } \\
\text { the middle zone "softer" than the upper and lower zones (Fig. 66). } \\
\text { 2. As moving from the middle to the lower zone, there is a large } \\
\text { increase of calcite with a decrease of clay and hydrocarbon } \\
\text { contents (Fig. 66). }\end{array}$ \\
\hline Niobrara & $\begin{array}{l}\text { 1. Both upper and lower stress contrasts are } \\
\text { underestimated. } \\
\text { 2. At around } 2 \% \text { SWS, the upper stress contrast is } \\
\text { underestimated by } 41 \% \text { (from } 412 \text { psi to } 245 \text { psi), } \\
\text { and the lower stress contrast is underestimated } \\
\text { by } 28 \% \text { (from } 637 \text { psi to } 457 \text { psi). }\end{array}$ & $\begin{array}{l}\text { 1. The upper, middle, and lower zones' } \\
\text { Young's modulus are all overestimated. } \\
\text { 2. At around } 2 \% \text { SWS, the relative } \\
\text { overestimation errors are } 9.84 \%, 14.47 \% \text {, } \\
\text { and } 8.84 \% \text { for the upper, middle, and lower } \\
\text { zones respectively. }\end{array}$ & N/A \\
\hline
\end{tabular}




\subsubsection{Investigation of NF induced anisotropy impact on operational designs}

Table 9 concludes the prediction errors of stress contrast and Young's modulus caused by ignoring natural fracture induced anisotropy in log interpretation for different shale formations. In the same table, the last column concludes the how the prediction errors result in improper or suboptimal operational designs.

Overall, when ignoring the natural fracture induced anisotropy in log interpretation for $O B$ rocks, the upper and lower stress contrasts (stress barrier) are overestimated for some shale formations (Bakken, Haynesville, and Marcellus), while they are underestimated for rest of shales (Eagle Ford and Niobrara). If the upper and lower stress contrasts (stress barrier) are overestimated, it leads to an underestimation of hydraulic fracture growth along the vertical direction and overestimation of hydraulic fracture growth along the lateral direction. If the upper and lower stress contrasts (stress barrier) are underestimated, it leads to an overestimation of hydraulic fracture growth along the vertical direction and underestimation of hydraulic fracture growth along the lateral direction. Such misinterpretation of fracture propagation geometries will finally result in problematic hydraulic fracturing pumping design. For example, if the vertical growth of hydraulic fracture is too large, less viscous pumping fluid and lower pumping rate are preferred to help control the vertical growth and improve the fracture confinement within the pay zone. Thus, the overestimation of fracture vertical growth will result in problematic hydraulic fracturing designs with too low proppant laden fluid viscosity and too low pumping rate. In the other case, if the vertical growth of hydraulic fracture is limited, higher viscous pumping fluid and higher pumping rate are preferred to maximize the fracture length and stimulated reservoir volume (SRV) within the pay zone. Thus, the underestimation of fracture vertical growth will result in problematic hydraulic fracturing designs with too high proppant laden fluid viscosity and too high pumping rate.

Regarding to Young's modulus, it is overestimated for all zones of all five shale formations by different levels. Thus, overestimation of Young's modulus leads to underestimation of fracture width, which further results in insufficient proppant pumping amount, proppant size, and hence suboptimal low fracture conductivity.

Regarding to stress gradient variation within the payzone, it can be non-affected, overestimated, or underestimated when ignoring the natural fracture induced anisotropy in log interpretation of an $\mathrm{OB}$ rock. If it is non-affected, applying $\mathrm{TI}$ assumption to a naturally fractured shale rock will not affect the perforation cluster placement design from the stress gradient perspective. If it is overestimated, it results in too short fracture stage length design, while it is underestimated, it results in too large fracture stage length design 
Table 10: Conclusion of prediction errors of stress contrast and Young's modulus, and resulted problematic operational designs of five Shales

\begin{tabular}{|c|c|c|c|}
\hline $\begin{array}{c}\text { Shale } \\
\text { Formation }\end{array}$ & $\begin{array}{l}\text { Prediction Error of Stress Contrast When Treating } \\
\text { the OB Rock with a TI model }\end{array}$ & $\begin{array}{c}\text { Prediction Error of Young's modulus } \\
\text { When Treating the OB Rock with a } \\
\text { TI model }\end{array}$ & Impact on the operational design \\
\hline Bakken & $\begin{array}{l}\text { 1. Both upper and lower stress contrasts are } \\
\text { overestimated. } \\
\text { 2. At around } 2 \% \text { SWS, the upper stress contrast is } \\
\text { overestimated from } 105 \text { psi to } 357 \text { psi, and the } \\
\text { lower stress contrast is overestimated from }-55 \text { psi } \\
\text { to } 228 \text { psi. } \\
\text { 3. Within the middle pay zone, the stress gradient } \\
\text { variation (stress contrast) does not change when } \\
\text { treating the OB rock with a Tl medium. }\end{array}$ & $\begin{array}{l}\text { 1. The upper, middle, and lower } \\
\text { zones' Young's modulus are all } \\
\text { overestimated. } \\
\text { 2. At around } 2 \% \text { SWS, the relative } \\
\text { overestimation errors are } 12.21 \% \text {, } \\
4.35 \% \text {, and } 13.84 \% \text { for the upper, } \\
\text { middle, and lower zones } \\
\text { respectively. }\end{array}$ & $\begin{array}{l}\text { 1. Overestimation of upper and lower stress contrasts (stress barrier) leads to } \\
\text { underestimation of hydraulic fracture growth along the vertical direction and } \\
\text { overestimation of hydraulic fracture growth along the lateral direction. } \\
\text { 2. Overestimation of Young's modulus leads to underestimation of fracture width, } \\
\text { which further results in insufficient proppant pumping amount, proppant size, } \\
\text { and hence suboptimal low fracture conductivity. } \\
\text { 3. The stress gradient variation does not change much, so applying Tl assumption } \\
\text { to a naturally fractured Bakken shale rock will not affect the perforation cluster } \\
\text { placement design from the stress gradient perspective. }\end{array}$ \\
\hline Eagle Ford & $\begin{array}{l}\text { 1. Both upper and lower stress contrasts are } \\
\text { underestimated. } \\
2 \text {. At around } 2 \% \text { SWS, the upper stress contrast is } \\
\text { underestimated by } 50 \% \text { (from } 235 \text { psi to } 118 \text { psi), } \\
\text { and the lower stress contrast is underestimated by } \\
16 \% \text { (from } 759 \text { psi to } 638 \text { psi). } \\
3 \text {. Within the middle pay zone, the stress gradient } \\
\text { variation does not change from } 6280-6480 \mathrm{ft} \text {, } \\
\text { while it is overestimated from } 6480-6600 \mathrm{ft} \text {. }\end{array}$ & $\begin{array}{l}\text { 1. The upper, middle, and lower } \\
\text { zones' Young's modulus are all } \\
\text { overestimated. } \\
\text { 2. At around } 2 \% \text { SWS, the relative } \\
\text { overestimation errors are } 12.9 \% \text {, } \\
20 \% \text {, and } 11.36 \% \text { for the upper, } \\
\text { middle, and lower zones } \\
\text { respectively. }\end{array}$ & $\begin{array}{l}\text { 1. Underestimation of upper and lower stress contrasts (stress barrier) leads to } \\
\text { overestimation of hydraulic fracture growth along the vertical direction and } \\
\text { underestimation of hydraulic fracture growth along the lateral direction. } \\
2 \text {. Overestimation of Young's modulus leads to underestimation of fracture width, } \\
\text { which further results in insufficient proppant pumping amount, proppant size, and } \\
\text { hence suboptimal low fracture conductivity. } \\
\text { 3. Overestimation of stress gradient variation in the lower pay (6480-6600 ft) will } \\
\text { result in too short fracture stage length design. }\end{array}$ \\
\hline Haynesville & $\begin{array}{l}\text { 1. The upper stress contrast is slightly } \\
\text { underestimated, while the lower stress contrast is } \\
\text { highly overestimated. } \\
\text { 2. At around } 2 \% \text { SWS, the upper stress contrast is } \\
\text { underestimated by } 12.5 \% \text { (from } 200 \text { psi to } 175 \\
\text { psi), and the lower stress contrast is overestimated } \\
\text { by } 130 \% \text { (from } 247 \text { psi to } 569 \text { psi). } \\
\text { 3. Within the middle pay zone, the stress gradient } \\
\text { variation is generally overestimated. }\end{array}$ & $\begin{array}{l}\text { 1. The upper, middle, and lower } \\
\text { zones' Young's modulus are all } \\
\text { overestimated. } \\
2 \text {. At around } 2 \% \text { SWS, the relative } \\
\text { overestimation errors are } 8.75 \% \text {, } \\
9.92 \% \text {, and } 20.1 \% \text { for the upper, } \\
\text { middle, and lower zones } \\
\text { respectively. }\end{array}$ & $\begin{array}{l}\text { 1. High overestimation of the lower stress barrier leads to large underestimation } \\
\text { of downward growth of the hydraulic fracture and overestimation of hydraulic } \\
\text { fracture growth along the lateral direction. } \\
\text { 2. Overestimation of Young's modulus leads to underestimation of fracture width, } \\
\text { which further results in insufficient proppant pumping amount, proppant size, } \\
\text { and hence suboptimal low fracture conductivity. } \\
\text { 3. Overestimation of stress gradient variation in the pay zone will result in too } \\
\text { short fracture stage length design. }\end{array}$ \\
\hline Marcellus & $\begin{array}{l}\text { 1. Both upper and lower stress contrasts are } \\
\text { overestimated; } \\
2 \text {. At around } 2 \% \text { SWS, the upper stress contrast is } \\
\text { overestimated by } 68 \% \text { (from } 86 \text { psi to } 144.2 \text { psi), } \\
\text { and the lower stress contrast is overestimated by } \\
42 \% \text { (from } 206 \text { psi to } 293 \text { psi). } \\
3 \text {. Within the middle pay zone, the stress gradient } \\
\text { variation is overestimated for } 7454-7480 \mathrm{ft} \text { and } \\
7516-7540 \mathrm{ft} \text {. }\end{array}$ & $\begin{array}{l}\text { 1. The upper, middle, and lower } \\
\text { zones' Young's modulus are all } \\
\text { overestimated. } \\
2 \text {. At around } 2 \% \text { SWS, the relative } \\
\text { overestimation errors are } 9.36 \% \text {, } \\
7.27 \% \text {, and } 10.66 \% \text { for the upper, } \\
\text { middle, and lower zones } \\
\text { respectively. }\end{array}$ & $\begin{array}{l}\text { 1. Overestimation of upper and lower stress contrasts (stress barrier) leads to } \\
\text { underestimation of hydraulic fracture growth along the vertical direction and } \\
\text { overestimation of hydraulic fracture growth along the lateral direction. } \\
\text { 2. Overestimation of Young's modulus leads to underestimation of fracture width, } \\
\text { which further results in insufficient proppant pumping amount, proppant size, } \\
\text { and hence suboptimal low fracture conductivity. } \\
\text { 3. Overestimation of stress gradient variation in the sub-payzones of 7454-7480 ft } \\
\text { and } 7516-7540 \mathrm{ft} \text { will result in too short fracture stage length design for those two } \\
\text { zones. }\end{array}$ \\
\hline Niobrara & $\begin{array}{l}\text { 1. Both upper and lower stress contrasts are } \\
\text { underestimated. } \\
\text { 2. At around } 2 \% \text { SWS, the upper stress contrast is } \\
\text { underestimated by } 41 \% \text { (from } 412 \text { psi to } 245 \text { psi), } \\
\text { and the lower stress contrast is underestimated by } \\
28 \% \text { (from } 637 \text { psi to } 457 \text { psi). } \\
\text { 3. Within the middle pay zone, the stress gradient } \\
\text { variation is underestimated for the upper } \\
\text { subpayzone ( } 11560-11620 \mathrm{ft} \text { ), and overestimated } \\
\text { for the lower subpayzone ( } 11620-11680 \mathrm{ft} \text { ). }\end{array}$ & $\begin{array}{l}\text { 1. The upper, middle, and lower } \\
\text { zones' Young's modulus are all } \\
\text { overestimated. } \\
2 \text {. At around } 2 \% \text { SWS, the relative } \\
\text { overestimation errors are } 9.84 \% \text {, } \\
14.47 \% \text {, and } 8.84 \% \text { for the upper, } \\
\text { middle, and lower zones } \\
\text { respectively. }\end{array}$ & $\begin{array}{l}\text { 1. Underestimation of upper and lower stress contrasts (stress barrier) leads to } \\
\text { overestimation of hydraulic fracture growth along the vertical direction and } \\
\text { underestimation of hydraulic fracture growth along the lateral direction. } \\
\text { 2. Overestimation of Young's modulus leads to underestimation of fracture width, } \\
\text { which further results in insufficient proppant pumping amount, proppant size, } \\
\text { and hence suboptimal low fracture conductivity. } \\
\text { 3. Underestimation of stress gradient variation in the upper subpayzone (11560- } \\
11620 \mathrm{ft} \text { ) will result in too large fracture stage length design, while overestimation } \\
\text { of stress gradient variation in the lower subpayzone (11620-11680ft) will result in } \\
\text { too short fracture stage length design. }\end{array}$ \\
\hline
\end{tabular}




\section{Conclusion}

In this study, natural fracture induced anisotropy effect has been investigated for five selected shale formations in U.S. To do that, shale anisotropies are calculated with the published sonic log data along with the $\mathrm{TI}$ and $\mathrm{OB}$ rock acoustic interpretation models. To understand the essentialness of the natural fracture induced anisotropy within the shale rock, the interpretation results of the two models are compared in terms of minimum horizontal stress, stress contrast, and Young's modulus. Thus, the importance of accounting for natural fracture induced anisotropy in geomechanical log interpretation as well as completion/fracturing designs is examined for the five selected shales.

The published sonic log data is utilized to build the stiffness tensor for the TI background rock body for the five Shales. The natural fractures are then introduced into the TI rock by adding the excessive effective compliances introduced by natural fractures to the reverse of the TI background rock stiffness tensor to build the $O B$ rock stiffness tensor. By adjusting the natural fracture intensity, different levels of natural fracture induced anisotropy can be achieved, which can be measured with a shear wave splitting parameter (SWS). Finally, multiple OB rock stiffness tensors have been built for different shale formations with different levels of natural fracture induced anisotropy. These OB rock stiffness tensors are used to generate the acoustic log data based on the inversion calculation. The acoustic log data is used to derive the geomechanical properties and in-situ stress based on a TI rock assumption, which are compared with the "true" values obtained from the OB rock stiffness tensor. In the current study, of particular interests are the key parameters close associated with completion/fracturing design, such as the minimum horizontal stress magnitude, stress contrast (variation along the vertical depth), and Young's modulus. Through the comparison, some important observations are concluded below,

- In terms of the magnitude of minimum horizontals stress and Young's modulus, introducing the natural fractures into the TI background shale rock will lead to a decrease of stress and Young's modulus values. For the same background TI rock, the magnitude of stress and Young's modulus increases with an inreasing of SWS. As a result, ignoring the natural fracture induced anisotropy in acoustic log interpratation will result in an overestimation of stress and Young's modulus. The overestimation is more sigfinicant for the shale zones with larger split of fast and slow shear wave slowness (SWS).

- In terms of the sress contrast (vairation along the vertical direction), the impact of natural fracture induced anisotropy is diffrent for different shale formations. In this study, the stress contrast is defined as the stress cotnrast between the cap rock and pay rock, $\sigma_{\text {up } / l o}-\sigma_{\text {pay }}$. Ignoring the natural fracture induced anisotropy leads to a overestimation of the upper and lower stress contrasts for Bakken and Marcellus Shales, whereas it leads to a underestimation of the stress contrasts for EagleFord and Niobrara Shales. For Haynesvelle Shales, the upper stress contrast is slightly underestiamted, while the lower stress contrast is higly overestimated.

- Such complicated stress contrast impact can be linked inherently with the mineralgoy/lithology squance of the shale. It is found that the natural fracture induced anisotropy is less significant in the "softer zone" with higher clay content, less quartz/calcite content, and higher organic matter content. If the pay zone (zone to frac) has higher clay amount and organic matter amount than the upper and lower cap zones, which is usually the case, ignoring natural fracture 
induced anisotropy can lead to lower overestimation error in the predictions of minimum horizontal stress and Young's modulus of the middle pay zone as compared with the upper and lower cap zones. Thus, the upper and lower stress contrasts (stress barrier) can be overestimated. In the other case, if the pay zone is "harder" than the cap zones, the stress barrier can be underestimated due to the ignorance of the natural fracture induced anistropy in geomechanical log interpration.

- Regarding to the imapact of natural fracture induced anisotropy on operational design, the overstimation of upper and lower stress contrasts (stress barriers) can lead to the underestimation of hydraulic fracture growth along the vertical direction and overestimation of hydraulic fracture growth along the lateral direction. Such mis-interpretation of fracture propagation geometries will finally result in problematic hydraulic fracturing pumping design, such as too high pumping fluid viscosity desgin and too high pumping rate design.

- Overestimation of Young's modulus leads to underestimation of fracture width, which further results in insufficient proppant pumping amount, proppant size, and hence suboptimal low fracture conductivity.

- In addition to the stress contrast crossing different zones, the stress contrast within the payzone is also examined. Igonring the natural fracture induced anisotropy can lead to a overestimation of stress gradient vairation for Eagle Ford, Haynesville, Marcellus, and part of Niobrara, which will furhter lead to a too short design of fracture stage legnth. For Bakken Shale, the stress graident is uniform within the payzone, so applying $\mathrm{TI}$ assupmption to a naturally fractured Bakken shale rock will not affect the designs of stage legnth and perforation cluster placement much from the stress gradient perspective.

In the end, some future works have been suggested to furhter improve the understanding of the impact of the natura fracture induced anisotropy.

- As a a supplement to the current study, adding natural fractures into the shale rock with a different orientation as well as slanted natural fractures or two sets of orthogonal natural fractures adding can be the next work following this study.

- In the current study, the natural fracture compliance ratio (BN/BT) is fixed. It is necessary to examine how the conclusion of current study is affected by the fracture compliance ratio.

- Firstly, the study may be validated with applying the similar workflow into more sonic log data from some actual hydrocarbon production fields. More field measurement such as mini frac test or DFIT test can be applied in the natural fractued areas to validate our current conclusions.

- Based on the current study, new interpretation algorithm is developed to interpret the current log data or correct the current log interpretation by taking into account of natural fracture impact for those rocks with large SWS, which illustrates high intensity of natural fractures intersected with bedding layers. 


\section{Reference}

Azizov, A., Lemesany, L., Augustine, N., \& Loesel, C. (2014, March 4). The Latest Generation of Steerable Motor Overcomes Drilling Challenges in the Niobrara Shale Unconventional Play. Society of Petroleum Engineers. doi:10.2118/167982-MS

Breit, V. S., Stright, D. H., \& Dozzo, J. A. (1992, January 1). Reservoir Characterization of the Bakken Shale From Modeling of Horizontal Well Production Interference Data. Society of Petroleum Engineers. doi:10.2118/24320-MS

Breyer, J. A. (2013). Stratigraphy and Sedimentary Facies of the Eagle Ford Shale (Cretaceous) between the Maverick Basin and the San Marcos Arch, Texas, USA.

Brooks, S., Willms, T., Albrecht, T., Reischman, R., Walsh, J., \& Bammi, S. (2015, July 20). Acoustic Log Measurements in the Lower Eagle Ford Formation in Brazos and Robertson Counties, Texas and Their Implications on Completion Design. Unconventional Resources Technology Conference. doi:10.15530/URTEC-2015-2152866

Chertov, M. (2013, January 1). On the Limitations of Effective Medium Approaches for Estimating Fracture Width in Anisotropic Rocks. American Rock Mechanics Association.

Ellefsen, K.J., Toksoz, M.N., Tubman, K.M., and Cheng, C.H., 1992, Estimating a Shear Modulus of a Transversely Isotropic Formation, Geophysics, 57(11), 1428-1434. DOI: http://dx.doi.org/10.1190/1.1443210

Finn, T. M., \& Johnson, R. C. (2005). Niobrara Total Petroleum System in the Southwestern Wyoming Province. Petroleum Systems and Geologic Assessment of Oil and Gas in the Southwestern Wyoming Province, Wyoming, Colorado, and Utah.

Geology. (2017). Retrieved 2019, from https://bakkenshale.com/geology/ 
Gu, M., Quirein, J., Murphy, E., Barraza, S. R., \& Ou, L. (2016, April 1). Method for Acoustic Anisotropy Interpretation in Shales When the Stoneley-Wave Velocity is Missing. Society of Petrophysicists and Well-Log Analysts.

Gu, M., 2018, Impact of Anisotropy Induced By Shale Lamination And Natural Fractures On Reservoir Development and Operational Designs, SPE-191131, SPE Reservoir Evaluatoin \& Engineering, 21(04): 850-862.

Gupta, I., Rai, C., Sondergeld, C. H., \& Devegowda, D. (2018, August 1). Rock Typing in Eagle Ford, Barnett, and Woodford Formations. Society of Petroleum Engineers. doi:10.2118/189968-PA

Hammes, U., \& Gale, J. (Eds.). (2013). Geology of the Haynesville gas shale in East Texas and West Louisiana (AAPG memoir, 105). Tulsa, OK: American Association of Petroleum Geologists.

Kocoglu, S., \& University of Houston. Dept. of Earth Atmospheric Sciences. (2013). Description of the BAKKEN Formation's Rock Properties of the Williston Basin, North Dakota.

McClave, G. A. (2014, August 25). Correlation of Rebound-Hammer Rock Strength with Core and Sonic-Log-Derived Mechanical Rock Properties in Cretaceous Niobrara and Frontier Formation Cores, Piceance Basin, Colorado Unconventional Resources Technology Conference. doi:10.15530/URTEC-2014-1921941

Niobrara Shale. (n.d.). Retrieved 2019, from https://www.halliburton.com/en US/ps/solutions/unconventional-resources/shale-gas-oil/shale-plays/niobrara-shaleformation-an-emerging-oil-and-gas-play.html

Norris, A., and Sinha, B., 1993, Weak Elastic Anisotropy and the Tube Wave, Geophysics, 58(8), 1091- 1098. DOI: http://dx.doi.org/10.1190/1.1443493 
Parker, M. A., Buller, D., Petre, J. E., \& Dreher, D. T. (2009, January 1). Haynesville ShalePetrophysical Evaluation. Society of Petroleum Engineers. doi:10.2118/122937-MS

Pitman, J., L. Price, and J, Lefever., 2001, Diagenesis and Fracture Development in the Bakken Formation, Williston Basin, Implications on Reservoir Quality in the Middle Member. Denver: U.S. Geological Survey Professional Paper 1653, 1-19

Polzin, P. (2017, January 9). The Economic Impact of the Bakken. Retrieved February 20, 2019, from http://www.montanabusinessquarterly.com/economic-impact-bakken/

Popova, O. (2017). Marcellus Shale Play. Retrieved 2019, from https://www.eia.gov/maps/pdf/MarcellusPlayUpdate_Jan2017.pdf

Ramakrishna, S., Balliet, R., Miller, D., Sarvotham, S., \& Merkel, D. (2010, June 19). Formation Evaluation In the Bakken Complex Using Laboratory Core Data And Advanced LoggingTechnologies. Society of Petrophysicists and Well-Log Analysts.

Ramirez, T. R., Klein, J. D., Bonnie, R., \& Howard, J. J. (2011, January 1). Comparative Study of Formation Evaluation Methods for Unconventional Shale Gas Reservoirs: Application to the Haynesville Shale (Texas). Society of Petroleum Engineers. doi:10.2118/144062-MS

Ran, B., \& Kelkar, M. (2015, July 20). Fracture Stages Optimization in Bakken Shale Formation. Unconventional Resources Technology Conference. doi:10.15530/URTEC-2015-2154796

Review of Emerging Resources: U.S. Shale Gas and Shale Oil Plays. (2011). Retrieved 2019. INTEK, 2011

Saidian, M., Godinez, L. J., \& Prasad, M. (2015, August 10). Effect of Clay and Organic Matter on Nitrogen Adsorption Specific Surface Area and Cation Exchange Capacity in Shales (Mudrocks). Society of Petrophysicists and Well-Log Analysts. 
Smith, T., Smith, T., Jenkins, D., Smith, T., \& C\&C Reservoirs. (2014, January 21). From Trickle to Gusher: The Bakken Oil Story. Retrieved from https://www.geoexpro.com/articles/2012/05/from-trickle-to-gusher-the-bakken-oil-story

Suarez-Rivera, R., and Bratton, T.R., 2012, Estimating Horizontal Stress from Three-Dimensional Anisotropy, US Patent No. 8,175,807 B2, granted May 8, 2012.

Tran, T., Sinurat, P. D., \& Wattenbarger, B. A. (2011, January 1). Production Characteristics of the Bakken Shale Oil. Society of Petroleum Engineers. doi:10.2118/145684-MS

Tuttle, S, 2010. Oil Resource Plays-Examples and Technology. Geological Review, Internal Report, Petrohawk Energy Corporation, Huston, Texas. 